MATUS, Jean Pierre; RAMIREZ, María Cecilia; CASTILLO, Marcelo.

"Acerca de la necesidad de una reforma urgente de los delitos de contaminación en Chile,

a la luz de la evolución legislativa del siglo XXI".

Polít. crim. Vol. 13, No 26 (Diciembre 2018) Art. 4, pp. 771-835.

[http://www.politicacriminal.cl/Vol_13/n_26/Vol13N26A4.pdf]

\title{
Acerca de la necesidad de una reforma urgente de los delitos de contaminación en Chile, a la luz de la evolución legislativa del siglo XXI*
}

\section{On the need for an urgent reform of pollution offenses in Chile, in the light of the legislative evolution of the 21 st century}

\author{
Por Jean Pierre Matus Acuña** \\ Profesor Titular de Derecho Penal de la Universidad de Chile \\ jpmatus@derecho.uchile.cl \\ Mª Cecilia Ramírez Guzmán*** \\ Abogada Integrante de la I. Corte de Apelaciones de Santiago \\ mcramirez@vicent.cl \\ Marcelo Castillo Sánchez ${ }^{* * * *}$ \\ Abogado \\ mcastillo@vicent.cl
}

\section{Resumen}

El artículo describe y sistematiza las modificaciones a las normas que protegen el medio ambiente y los objetos que lo componen en la última década en Chile. Este análisis permite concluir que, mientras han existido importantes avances en la protección penal de la biodiversidad y en algunos otros aspectos puntuales, ello no se observa en lo referido a la regulación penal del fenómeno de la grave contaminación ambiental, la burla del sistema administrativo de protección del medio ambiente y la sanción de las personas jurídicas responsables de los delitos ambientales. Se sostiene que el origen de estas diferencias parece encontrarse en el desacuerdo respecto de la necesidad y forma de regular los delitos de contaminación. Atendidas esta diferencias, el texto propone avanzar en la protección del medio ambiente perfeccionando las figuras penales ya existentes en nuestro ordenamiento, como vía para llenar el vacío legislativo detectado.

\footnotetext{
* Este artículo se realiza en el marco del Proyecto FONDECYT N 1160343, dirigido por JP Matus. Para la realización del texto, se contó con la colaboración de la abogada Srta. Camila Hernando Martel.

** Abogado P.U.C. de Chile, Mg. y Dr. en Derecho por la Universidad Autónoma de Barcelona. Profesor Titular de Derecho Penal de la Universidad de Chile.

*** Abogado P.U.C. de Chile, Mg. en Derecho Penal por la Universidad de Barcelona.

***** Abogado P.U.C. de Chile.
} 
Polít. crim. Vol. 13, No 26 (Diciembre 2018) Art. 4, pp. 771-835.

[http://www.politicacriminal.cl/Vol_13/n_26/Vol13N26A4.pdf]

\title{
Palabras clave
}

Derecho Ambiental; Derecho Penal; Derecho Internacional; Chile; Propuesta Legislativa

\begin{abstract}
The article describes and systematizes the modifications to the norms that protect the environment and the objects that compose it in the last decade in Chile. This analysis allows to conclude that, while there have been important advances in the criminal protection of biodiversity and in some other specific aspects, this is not observed regarding the penal regulation of the phenomenon of serious environmental pollution, the mockery of the administrative system of protection of the environment and punishment of legal persons responsible for environmental crime. It is argued that the origin of these differences seems to be in the disagreement regarding the legitimacy, necessity and form of regulating the crimes of contamination. Given this differences, the text proposes to advance in the protection of the environment by perfecting the criminal figures already existing in our system, as a way to fill the legislative vacuum detected.
\end{abstract}

\section{Key words}

Environmental law; Criminal law; International law; Chile; Legislative Proposal

\section{Introducción}

El presente trabajo consiste en una puesta al día de los principales resultados del Proyecto FONDECYT 1010206-2001 ${ }^{1}$, enfocada en poner de manifiesto las importantes modificaciones de nuestra legislación penal con relación al medio ambiente en esta última década, las deficiencias aún subsistentes, y la necesidad de introducir algunas modificaciones legales que permitan su perfeccionamiento.

En cuanto a los avances, en la primera parte de este trabajo se da cuenta del perfeccionamiento de nuestra legislación respecto a la protección de la biodiversidad y el establecimiento del delito de tráfico ilícito de residuos, como producto - principalmentede la implementación de las obligaciones contraídas en la materia en convenciones internacionales y de ciertas modificaciones relacionadas con fenómenos locales de intensificación del Derecho penal. La segunda sección constata que, a pesar de los avances, sigue ausente entre nosotros la regulación de verdaderos delitos de contaminación, destacando las dificultades de aplicación de los existentes con anterioridad al establecimiento

\footnotetext{
${ }^{1}$ MATUS, Jean Pierre; RAMÍREZ, Ma Cecilia; CASTILLO, Marcelo; y ORELLANA, Marcos, “Análisis dogmático del Derecho Penal Ambiental chileno, a la luz del Derecho Comparado y las obligaciones contraídas por Chile en el ámbito del Derecho Internacional. Conclusiones y propuesta legislativa fundada para una nueva protección penal del medio ambiente en Chile”, Ius et Praxis, Año 9, No 2 (2003), pp. 11-57. Lamentablemente, en esta ocasión no pudimos contar con la colaboración de Marcos Orellana, por encontrarse fuera del país en actividades profesionales.
} 
MATUS, Jean Pierre; RAMIREZ, María Cecilia; CASTILLO, Marcelo.

"Acerca de la necesidad de una reforma urgente de los delitos de contaminación en Chile, a la luz de la evolución legislativa del siglo XXI”.

del actual sistema administrativo de gestión ambiental. En la tercera, atendida la situación descrita, se cuestiona la legitimidad y necesidad de la introducción de delitos de contaminación propiamente tales, a luz de las disposiciones constitucionales vigentes y la completa reformulación del sistema de protección administrativa del medio ambiente, que creó la Superintendencia del ramo como órgano fiscalizador y sancionador de carácter administrativo. En la cuarta, se profundiza en el análisis de los proyectos existentes en orden a establecer verdaderos delitos de contaminación, destacando sus fortalezas y debilidades. Finalmente, tras las conclusiones, se agrega un anexo con una propuesta acotada de reformas que permitan superar los vacíos legislativos en aquello que se estima, por el momento, indispensable y justificado.

\section{Los avances en la protección penal del medio ambiente en la última década}

\subsection{Avances derivados directamente del proceso de internacionalización del Derecho Penal}

Como se ha señalado en otro lugar, la legislación penal chilena en el siglo XXI se caracteriza, entre otras particularidades, por su acelerada internacionalización, entendiendo por tal el fenómeno de adecuar la legislación local a las exigencias de la comunidad internacional "mediante la implementación de reglas cada vez más detalladas de diversos tratados internacionales multilaterales"2.

La particularidad de este fenómeno estriba en que la implementación de los tratados internacionales se entiende ahora como un proceso de detallada adecuación de la legislación nacional a las disposiciones de dichos tratados, como la mejor forma de cumplir los propósitos de los Estados Parte de los mismos.

En materia ambiental, Fuentes y Arístegui afirman al respecto que "si los compromisos ambientales internacionales se implementaran mediante la correcta dictación de normativa interna, sin duda que ello colaboraría con una mejor gestión sustentable de nuestros recursos naturales". Dichos autores agregan que, no obstante, "el problema, es que no existe una tradición de implementación de tratados, colaborando de esa forma con el déficit regulatorio en materia ambiental" 3 .

2 MATUS, Jean Pierre, "Evolución del Derecho Penal chileno en el siglo XXI: Democratización, diversificación, intensificación e internacionalización de la respuesta penal", en Nova Criminis, No 7 (2014), pp. 149-174., p. 163s. Allí se señala que el origen sociológico de este fonómeno puede deberse a "la integración creciente de los Estados, la ocurrencia de hechos de carácter transnacional, y la necesidad de establecer reglas comunes para la seguridad de las personas, el comercio y el tráfico jurídico".

${ }^{3}$ FUENTES, Ximena y ARÍSTEGUI, Juan Pablo, “ ¿Nos basta con los convenios internacionales existentes para una adecuada regulación del uso sustentable de los recursos naturales?", en CENTRO DE ESTUDIOS DE DERECHO AMBIENTAL, FACULTAD DE DERECHO DE LA UNIVERSIDAD DE CHILE, Actas de las VII Jornadas de Derecho ambiental. Recursos naturales: ¿sustentatibildad o sobreexplotación?”, Santiago: Thomson Reuters, 2014, pp. 65-105, p. 102. Sobre la necesidad de "implementar" legislativamente las obligaciones de establecer delitos contempladas en los tratados internacionales, y particularmente los relativos al Derecho Internacional, junto con una descripción de los mecanismos para hacerlo, puede verse los textos de 
Sin embargo, esta afirmación no puede compartirse en este lugar, al menos no en lo que respecta al Derecho Penal del medio ambiente, pues como se demostrará enseguida, en los casos que los tratados y convenciones multilaterales obligan específicamente a establecer delitos, estas obligaciones se han ido implementando en Chile de manera bastante rigurosa.

A este proceso de implementación ha contribuido significativamente la existencia en las convenciones multilaterales de mecanismos especiales de enforcement que, por su forma de ejecución, Cassese denomina monitoreo ${ }^{4}$. Este monitoreo consiste en la permanente fiscalización mediante la presentación y evaluación periódica de informes de implementación solicitados a los Estados Parte para ser presentados a las Asambleas o Conferencias de los Estados Partes, Secretarías y los organismos que ejecutan presupuestos orientados a la implementación de las políticas que expresan dichos tratados y convenciones ${ }^{5}$.

A continuación, demostraremos cómo tales mecanismos de monitoreo han operado en estos últimos diez años, acelerando cambios legales que han conducido a aumentar la protección penal del medio ambiente, en el entendido que con dichas normas se cumplen las exigencias impuestas por los organismos encargados de la implementación de ciertos tratados internacionales.

\subsubsection{El fortalecimiento de la protección penal de la biodiversidad}

En esta materia, dos son los avances sustanciales producidos y que se encuentran causalmente vinculados a los mecanismos de monitoreo antes descritos: la prohibición de la caza de las ballenas y del contrabando de especies protegidas en peligro de extinción ${ }^{6}$.

CÁRDENAS, Claudia, "Los crímenes del Estatuto de la Corte Penal Internacional en el derecho chileno, necesidad de una implementación", en Política Criminal, N 2 (2006), A1, pp. 1-17, en: http://www.politicacriminal.cl/n_02/a_1_2.pdf [visitado el 20.10.2017] ; y "La implementación de los crímenes de competencia de la Corte Penal Internacional en la Ley № 20.357”, en Revista de Derecho (Valdivia), Vol. XXIII, No 2 (2010), pp. 23-44.

4 CASSESE, Antonio, "Fostering Increased Conformity with International Standards: Monitoring and Institutional Fact-Finding", en CASSESE, Antonio (Ed.), Realizing Utopia: The Future of International Law, Oxford: Oxford U. Press, 2012, pp. 295-303, p. 300.

5 Atendidos los efectos de estos mecanismos, Loibl los denomina también mecanismos de evitación de conflictos, por cuanto están destinados a lograr la progresiva implementación de las obligaciones de los tratados sin necesidad de adoptar los mecanismos de represalia o denuncia propios del Derecho Internacional Público anterior al término de la Segunda Guerra Mundial (LOIBL, Gerhard, "Dispute avoidance and dispute settlement in International Environmental Law. Some reflections on recent developments”, en SECRETARÍA GENERAL OEA, XXIV Curso de Derecho Internacional del Comité Jurídico Interamericano (1997), Washington: OEA, 1998, pp. 101-126, pp. 105 s.).

${ }^{6}$ En este siglo, además, se han añadido al sistema internacional de protección de la biodiversidad otras convenciones y tratados cuya implementación no ha supuesto modificaciones a la ley penal, pues no establecen obligaciones específicas en orden a tipificar delitos. Así, podemos citar, en primer lugar, el Acuerdo para promover el cumplimiento de las medidas internacionales de conservación y ordenación por los buques pesqueros que pescan en alta mar (D.S. No 78, de 2004 [Relaciones Exteriores]); la Convención sobre la conservación y ordenamiento de los recursos pesqueros en alta mar en el Océano Pacífico Sur (D.S. N 89 , de 2012 [Relaciones Exteriores]); y la Convención Interamericana para la protección y conservación de las 
MATUS, Jean Pierre; RAMIREZ, María Cecilia; CASTILLO, Marcelo.

"Acerca de la necesidad de una reforma urgente de los delitos de contaminación en Chile, a la luz de la evolución legislativa del siglo XXI".

Así, con respecto a la caza de las ballenas, la Convención Internacional para la Regulación de la Caza de Ballenas y su Anexo, de 1946, fue promulgada como Ley de la República el año 2004 (D.S. 78 [RR.EE.], 10.06.2004), y su definitiva implementación en materia penal tuvo lugar apenas cuatro años después, mediante la introducción, el año 2008, de un nuevo Art. 135 bis en la Ley General de Pesca y Acuicultura, que castiga al "que dé muerte o realice actividades de caza o captura de un ejemplar de cualquier especie de cetáceos"; y al "que tenga, posea, transporte, desembarque, elabore o efectúe cualquier proceso de transformación, así como comercialice o almacene estas especies vivas o muertas o parte de éstas".

En el primer párrafo del Mensaje con que se dio inicio a la tramitación del Proyecto que se convertiría en esta ley, se explicita que su presentación tiene "el objeto de cumplir las obligaciones internacionales y profundizar la posición de uso no letal de los cetáceos", agregándose más adelante la referencia al mecanismo de monitoreo de la Convención respectiva, con la siguiente frase: "El presente año 2008, en su calidad de país sede de la $60^{\circ}$ Reunión de la Comisión Ballenera Internacional, Chile debe dar una señal clara y contundente de su voluntad de proteger a los cetáceos en aguas bajo su jurisdicción, con el objeto de efectuar un uso no consuntivo de ellos". La rápida tramitación del proyecto y las fundamentaciones que se dieron por las distintas Comisiones y en Sala para su aprobación

tortugas marinas (D.S. No 78, de 2004 [Relaciones Exteriores]). Sin embargo, ninguno de estos instrumentos contempla precisas directas de establecer delitos en la materia. En efecto, el primero de los tratados citados faculta a los Estados Parte para, "si fuera apropiado", a considerar "como infracción en la legislación nacional" la pesca en alta mar sin permiso o ilegal por parte de buques de su pabellón, estipulando que, en ese caso, "las sanciones aplicables a tales contravenciones serán lo bastante severas como para garantizar el cumplimiento efectivo de las disposiciones de este acuerdo y privar a los infractores de los beneficios derivados de sus actividades ilegales" (Art. V.8). En un sentido todavía un poco más imperativo, la Convención sobre la conservación y ordenamiento de los recursos pesqueros en alta mar en el Océano Pacífico Sur, establece que "deberá garantizarse el efectivo cumplimiento de las medidas de conservación y ordenamiento, y las sanciones por las violaciones de las mismas deberán ser lo suficientemente severas para evitar que se incurra en ellas, cualquiera sea el lugar en que ocurran y, en particular, deberán privar a los infractores de los beneficios derivados de sus actividades ilegales" (Art. 3.1.a).ix)). Sin embargo, no sólo el establecimiento de estas sanciones no es obligatorio, sino que, además, el propio Tratado da a entender que podrían tratarse de sanciones administrativas, al vincularlas a las naves antes que las personas responsables de las infracciones que se traten (Art. 25.3.e)). Específicamente, respecto a la tortugas marinas, la Convención Interamericana establece que los Estados Parte tomarán como "medida apropiada y necesaria" para su conservación, "la prohibición de la captura, retención o muerte intencionales de las tortugas marinas, así como del comercio doméstico de las mismas, de sus huevos, partes o productos" (Art. IV.2.a), prohibición que no califica de penal aunque se entiende - implícitamente - que debe ser sancionada de alguna manera, al exigirle a los Estados información anual de "las acciones realizadas para asegurar el cumplimiento de sus leyes y reglamentos, incluyendo las sanciones impuestas en el caso de infracciones" (Anexo IV, letra d)).

A los tratados citados se suma el Acuerdo sobre medidas del Estado rector del puerto destinadas a prevenir, desalentar y eliminar la pesca ilegal, no declarada y no reglamentada (D.S. N ${ }^{\circ}$ 105, de 2006 [Relaciones Exteriores]). Sin embargo, aquí no se hace ninguna mención a las sanciones a imponer a los transgresores. 
Polít. crim. Vol. 13, No 26 (Diciembre 2018) Art. 4, pp. 771-835.

[http://www.politicacriminal.cl/Vol_13/n_26/Vol13N26A4.pdf]

sin modificaciones, permiten afirmar que el Congreso Nacional compartió esta necesidad de implementación en el momento de celebrarse dicha reunión internacional ${ }^{7}$.

En cuanto a la Convención sobre el Comercio Internacional de Especies Amenazadas de Fauna y Flora Silvestres (CITES), de $1973^{8}$, la eficacia de los mecanismos de monitoreo también se refleja en la historia y contenido de la Ley $\mathrm{N}^{\mathrm{o}} 20.962$, de 16.11.2016, que tuvo por objeto preciso su adecuada implementación.

En efecto, CITES dispone en su Art. VIII que "las partes adoptarán las medidas apropiadas para velar por el cumplimiento de sus disposiciones y para prohibir el comercio de especímenes en violación de las mismas", señalando que tales medidas “incluirán” “a) sancionar el comercio o la posesión de tales especímenes o ambos", lo que ha sido interpretado por la Conferencia de las Partes del año 2000 como la necesidad de "penalizar tales violaciones" (Resolución 11.3, 11ª Conferencia de las Partes, Kenia, 2000).

Antes de esta resolución, la Conferencia de las Partes del año 1992 había encargado a la Secretaría el establecimiento de un mecanismo de monitoreo (el Proyecto de Legislación Nacional) que permitía categorizar los Estados Parte cuyas legislaciones se había adaptado o no a las exigencias de la Convención, y proponer sanciones (prohibición de comercio, básicamente) a quienes fueran contumaces en no adaptar sus legislaciones ni informar los avances al respecto. Este es el mecanismo que se utilizaría para monitorear la antedicha obligación de sancionar penalmente ciertas infracciones al Tratado 9 .

Así, al celebrarse la $16^{\text {a }}$ Conferencia de las Partes, en Bangkok, el año 2013, la Secretaría de las Partes informó que Chile se encontraría en la Categoría 2 ("legislación que se considera que en general no cumple todos los requisitos para la aplicación de la CITES”), de manera que le resultarían aplicables las Resoluciones 16.33 y 16.34, que obligaban a informar, antes de la siguiente Conferencia, "las medidas apropiadas que han adoptado para la aplicación

7 BIBLIOTECA DEL CONGRESO NACIONAL, Historia de la Ley $N^{o}$ 20.293, en: http://www.bcn.cl/historiadelaley/nc/historia-de-la-ley/5161/ [visitado el 20.10.2017] El proyecto comenzó a tramitarse el 18 de junio de 2010 y se aprobó por ambas cámaras con en septiembre de ese año.

${ }^{8} \mathrm{La}$ Convención fue promulgada como Ley en Chile por D.L. No 873, de 28.01.1975. Además, Chile retiró su reserva a la Enmienda adoptada por la VI Conferencia de las Partes, de 1987 (D.S. N 340, de 2005 [Relaciones Exteriores]), que trasladaba al Apéndice I al Alerce Costero. En consecuencia, Chile considera ahora también que dicha especie está "en peligro de extinción", por lo que su comercio se encuentra restringido a circunstancias excepcionales y no, como en la situación anterior, solo "controlado".

${ }^{9} \mathrm{El}$ mecanismo establecido en la Res. 8.4, adoptada en la Conferencia de 1992, fue revisado en las $14^{\mathrm{a}}$ y $15^{\mathrm{a}}$ Conferencia de los Estados Parte y reforzado posteriormente al adoptarse la llamada Visión Estratégica de la CITES 2008-2020 (Conf.16.3, Rev. CoP17, en https://cites.org/sites/default/files/document/S-Res-16-03-

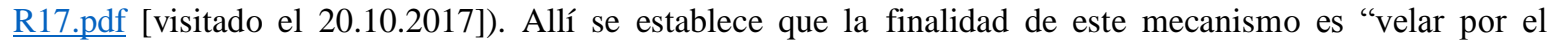
cumplimiento, la aplicación y observancia de la Convención", y su primer objetivo es que las partes cumplan "sus obligaciones en el marco de la Convención mediante políticas, legislación y procedimientos adecuados", lo que posibilitó una detallada revisión de la implementación que cada Estado hacía de tales disposiciones, sugiriendo la Secretaria a través de las Conferencias de las Parte cambios legislativos precisos para la homologación de las tipificaciones y sanciones disponibles (Véase los detalles de este mecanismo y formalidades de los informes en https://cites.org/esp/resources/reports.php [visitado el 20.10.2017]). 
MATUS, Jean Pierre; RAMIREZ, María Cecilia; CASTILLO, Marcelo.

"Acerca de la necesidad de una reforma urgente de los delitos de contaminación en Chile, a la luz de la evolución legislativa del siglo XXI".

efectiva de la Convención"10. Como Chile no dio cumplimiento a esa obligación dentro del plazo fijado, al celebrarse la $66^{\text {a }}$ Reunión del Comité Permanente, en agosto de 2015, se estimó que los informes de Chile eran insuficientes para tener por cumplidas sus obligaciones de implementación y la Secretaría notificó una advertencia de que se encontraba clasificado entre los países de Categoría 2, con más de 20 años de suscripción del tratado que no habrían dado debido cumplimiento a sus obligaciones de implementación, de modo que sería "objeto de una recomendación de suspender el comercio", si al 23 de septiembre de ese año (antes de celebrarse la $17^{\mathrm{a}}$ Conferencia de las Partes), no informaba de sus esfuerzos por poner en vigor la legislación adecuada para implementar las obligaciones CITES ${ }^{11}$.

En este marco, bajo la advertencia real de ser suspendido como país habilitado para el comercio de especies protegidas, se tramitó la última etapa de la que sería nuestra Ley $\mathrm{N}^{\circ}$ 20.962, de 16.11.2016, con la celeridad propia para evitar las sanciones señaladas. En efecto, aunque dicha ley había comenzado a tramitarse el año 2010 (Mensaje No 1923-357), con el objetivo declarado de aplicar la Convención sobre el Comercio Internacional de Especies Amenazadas de Flora y Fauna Silvestre (CITES), llevaba - al 2015 - cinco años de escaso progreso en los trámites legislativos. Y ello, a pesar de que en el texto del Mensaje se indicaba que el Proyecto perseguía lograr que Chile mejorase su calificación en el contexto de la Conferencia de Estados Parte CITES, pasando de la Categoría 2 a la Categoría 1 (legislación que se considera que en general cumple los requisitos para la aplicación de la CITES), mediante la adecuación de la legislación tanto a los requerimientos explícitos de la Convención cuanto a las recomendaciones que para su implementación había dado a nuestro país su Secretaría ya en esa fecha. Mediante esta adecuación se esperaba mejorar "la aplicación de la Convención CITES en nuestro país, permitiendo, por una parte, disminuir los factores que amenazan a nuestra biodiversidad, pero también subsanando una serie de vacíos a la fecha existentes, por otra", particularmente en lo que se refería a la penalización del comercio en la forma descrita por el Art. I, letra c) de CITES ("exportación, reexportación, importación o introducción procedente del mar”) y de la posesión, o ambos, de los especímenes CITES en contravención con las prohibiciones que, según su naturaleza (grado de peligro de extinción) se establecen.

Al finalizar su tramitación, la mencionada Ley $N^{\circ}$ 20.962, estableció los nuevos delitos de contrabando, tráfico y posesión con fines comerciales de especies protegidas,

\footnotetext{
10 “Res. 16.33. Antes de la 66 a reunión del Comité Permanente (SC66), las Partes cuya legislación está en la Categoría 2 ó 3 en el marco del proyecto de legislación nacional y que han sido Partes en la Convención durante más de cinco años en marzo de 2013 deberían someter a la Secretaría, en uno de los idiomas de trabajo de la Convención, las medidas apropiadas que han adoptado para la aplicación efectiva de la Convención.

Res. 16.34. En el caso de que una Parte concernida por la Decisión 16.33, que ha sido Parte durante menos de 20 años, no haya adoptado las medidas apropiadas para la aplicación efectiva de la Convención debido a circunstancias excepcionales, esa Parte debería comunicar por escrito a la Secretaría esas circunstancias excepcionales antes de la $66^{\mathrm{a}}$ reunión del Comité Permanente." CITES, Decisiones de la Conferencia de las Partes en la CITES en vigor después de su 16 ${ }^{a}$ reunión, Bongkok: s/e, 2013, en https://cites.org/sites/default/files/esp/dec/valid16/S16-Dec.pdf [visitado el 20.10.2017], p. 8.

${ }^{11}$ CITES, Notificación No. 2016/025, de 21.03.2016, en https://cites.org/sites/default/files/notif/S-Notif-2016025.pdf [visitado el 20.10.2017].
} 
haciendo expresa remisión a los listados de los Anexos CITES (Art. 11). Además, prevé que la asociación ilícita para cometer este delito será sancionada de conformidad con las reglas generales del Código Penal (Arts. 292 y siguientes), y un aumento de pena en un grado para quienes sean reincidentes o intervengan formando parte de una agrupación o reunión de personas que no constituya asociación ilícita (Art. 12). Así, la Ley en definitiva aprobada contempló más casos relacionados con los tres apéndices de la Convención CITES que el Proyecto original y un concepto de "contrabando" equivalente al del comercio internacional de las especies protegidas, en el sentido CITES. Sin embargo, por una parte, la posesión no justificada de especímenes CITES se castiga solo como infracción administrativa en procedimientos ante los Juzgados de Policía Local; y, por otra, es difícil afirmar que las sanciones previstas en uno y otro caso sean disuasivas, en los términos de la Convención, sobre todo porque la mayor parte de ellas no permiten la extradición, al ser menores a un año de prisión, salvo las referidas a la asociación ilícita y al contrabando de especímenes del Anexo I ${ }^{12}$.

La información oportuna de la reactivación de la tramitación de este proyecto y su contenido a la Secretaría, permitió que, a pesar de no encontrarse afinada en septiembre de 2016, fecha de la realización de la $17^{\mathrm{a}}$ Conferencia de las Partes CITES de Johannesburgo, en los documentos oficiales de dicha Conferencia Chile ya no aparece en el grupo de países mencionados como problemas críticos ni bajo la amenaza de ser sancionados con la suspensión del comercio, quedando pendiente, sin embargo, la revisión del contenido de la nueva ley por la Secretaría, a efectos de determinar su efectiva adecuación a las exigencias de la Convención ${ }^{13}$.

1.1.2. La implementación de la obligación de establecer como delito el tráfico ilícito de residuos peligrosos

La Convención de Basilea sobre el Control de los Movimientos Transfronterizos de Desechos Peligrosos y su Eliminación, de 1989, establece en su Art. 4 que "(3) las Partes considerarán que el tráfico ilícito de desechos peligrosos y otros desechos es delictivo", agregando, en consecuencia, como obligación específica en su Art. 9, que “(5) cada Parte promulgará las

\footnotetext{
${ }^{12}$ Como se informó por el profesor Jean Pierre Matus en el Congreso Nacional, al momento de discutirse la Ley N ${ }^{\circ} 20.962$, desde el punto de vista de las obligaciones CITES, era posible afirmar que el entonces proyecto "llena la laguna de punibilidad que deja la actual Ley de Caza en relación con el concepto de "comercio" de CITES, pero no parece ofrecer solución al problema de la falta de sanciones penales "disuasivas", sino al contrario, atendida la magnitud de las penas previstas y la reducción en cierta medida de la punibilidad respecto de la actual Ley de Caza, salvo para los casos de asociación ilícita y la agravación del Art. 12. Particularmente, llamó la atención respecto al hecho de que todavía se prevean penas cuya duración mínima es inferior a un año, lo que impide la extradición de quienes sean responsables de estos hechos, de evidente carácter transnacional” (Intervención de Jean Pierre Matus ante la Comisión de Agricultura del Senado, en BIBLIOTECA DEL CONGRESO NACIONAL, Historia de la Ley $N^{o}$ 20.962, Valparaíso: s/ed., en http://www.bcn.cl/historiadelaley/nc/historia-de-la-ley/5855/ [visitado el 20.10.2017], p. 162.).

13 Documento CITES CoP17 Doc. 22. Annex 3 (Rev. 1), en https://cites.org/sites/default/files/eng/cop/17/WorkingDocs/E-CoP17-22-A3-R1.pdf [visitado el 20.10.2017]; y Documento CITES SC67 Doc. 11, 23.09.2016, en https://cites.org/sites/default/files/eng/com/sc/67/E-SC6711.pdf [visitado el 20.10.2017].
} 
MATUS, Jean Pierre; RAMIREZ, María Cecilia; CASTILLO, Marcelo.

"Acerca de la necesidad de una reforma urgente de los delitos de contaminación en Chile, a la luz de la evolución legislativa del siglo XXI”.

disposiciones legislativas nacionales adecuadas para prevenir y castigar el tráfico ilícito" ${ }^{14}$. Allí se define como tráfico ilícito "todo movimiento de desechos realizado":

“a) sin notificación a todos los Estados interesados conforme a las disposiciones del presente Convenio; o

b) sin el consentimiento de un Estado interesado conforme a las disposiciones del presente

Convenio; o

c) con consentimiento obtenido de los Estados interesados mediante falsificación, falsas declaraciones o fraude; $o$

d) de manera que no corresponda a los documentos en un aspecto esencial; o

e) que entrañe la eliminación deliberada (por ejemplo, vertimiento) de los desechos peligrosos

o de otros desechos en contravención de este Convenio y de los principios generales del derecho internacional."

Posteriormente, la llamada Enmienda de la Prohibición, aprobada por la Tercera Reunión de la Conferencia de las Partes de 1995, determinó la prohibición de exportaciones de residuos peligrosos desde países desarrollados (en general, miembros de la OCDE), con cualquier finalidad (eliminación, reutilización, reciclado o recuperación), de modo que tales exportaciones podrían considerarse ilícitas per se.

Chile ratificó tempranamente esta Convención (D.S. 685 [RR.EE.], de 13.10.1992) y también la Enmienda de la Prohibición, aunque ésta un poco más de 15 años después de su adopción (D.S. 264 [RR. EE.], de 16.04. 2011).

Finalmente, la implementación de la sanción penal del tráfico ilícito de residuos se produjo por medio del Art. 44 de la Ley N N $^{\circ}$ 20.920, que establece el Marco para la Gestión de Residuos, la Responsabilidad Extendida del Productor y Fomento al Reciclaje, de 01.06.2016, y castiga con la pena de presidio menor en su grado mínimo a medio al que "exporte, importe o maneje residuos peligrosos, prohibidos o sin contar con las autorizaciones para ello", pena agravada "si además la actividad ha generado algún tipo de impacto ambiental".

En este caso, el proceso de internacionalización descrito en los apartados anteriores sufre una sutil variación, pues la presión por la implementación de las obligaciones comprendidas en la Convención de Basilea no provino directamente de los organismos creados por dicha Convención, sino de otro organismo de carácter internacional al que Chile recientemente se había incorporado: la OCDE. Así se expresa en el Mensaje $N^{o} 182-351$, de agosto de 2013, con que se dio inicio al Proyecto que se transformaría en la Ley $\mathrm{N}^{\circ} 20.920$, donde se menciona el Convenio de Basilea como antecedente del proyecto, junto a otras iniciativas parlamentarias anteriores y el Programa de Gobierno del entonces presidente Piñera. Así, se afirma que "el envío de este proyecto de ley no viene sólo a honrar un compromiso asumido por nuestro Gobierno, sino que también viene a hacerse cargo de una solicitud expresa

${ }^{14}$ La Convención tiene por objetivo la limitación y el control racional de los movimientos transfronterizos y el tráfico ilícito de desechos peligrosos, entendiendo por tales básicamente los clínicos, farmacéuticos y químicos, que sean explosivos, inflamables, corrosivos, tóxicos, etc. (Anexos I y III). 
Polít. crim. Vol. 13, No 26 (Diciembre 2018) Art. 4, pp. 771-835.

[http://www.politicacriminal.cl/Vol_13/n_26/Vol13N26A4.pdf]

manifestada por el Poder Legislativo en cuanto a la necesidad de introducir una regulación de esta naturaleza. Asimismo, el envío de este proyecto de ley significa cumplir con una de las recomendaciones hechas por la OCDE" ${ }^{15}$. El cumplimiento de estas recomendaciones y su vinculación con el Convenio de Basilea fue un aspecto recurrente en toda la tramitación del proyecto que pasó del Gobierno de Piñera al de Bachelet, sin que el cambio de coalición política alterase sustancialmente su contenido en el aspecto penal. En tal sentido se expresó el entonces ministro del Medio Ambiente de la presidenta Michelle Bachelet, Sr. Pablo Badenier en su intervención ante la Cámara de Diputados, en abril de 2015, cuando se reactivó la tramitación del Proyecto ${ }^{16}$. Y ello se refleja especialmente en la referencia que el Art. $8^{\circ}$ de la Ley $N^{\circ} 20.920$ hace al Convenio de Basilea, cuando dispone, en su inciso primero, que "los importadores y exportadores de residuos se regirán por lo dispuesto en el Convenio de Basilea sobre el control de los movimientos transfronterizos de desechos peligrosos y su eliminación, y por las demás normas legales y reglamentarias que regulen la materia".

\subsection{Avances de la protección penal del medio ambiente derivados del proceso de intensificación del Derecho Penal nacional}

Junto con el proceso de internacionalización del Derecho Penal, la llegada del Siglo XXI ha producido un marcado proceso de intensificación de la respuesta penal ante hechos que antes no se sancionaban penalmente o para los cuales se preveían penas menores ${ }^{17}$.

En materia ambiental, algunas veces estas modificaciones son coincidentes con la existencia de obligaciones de carácter internacional en la materia, pero su característica principal es que ellas no han sido gatilladas por algún mecanismo de monitoreo como los descritos en el apartado anterior, sino que parecen producto de la espontánea actividad de los órganos colegisladores, originada en acontecimientos o demandas de carácter local.

15 BIBLIOTECA DEL CONGRESO NACIONAL, Historia de la Ley $N^{o}$ 20.920, Valparaíso: s/ed., en http://www.bcn.cl/historiadelaley/nc/historia-de-la-ley/5030/ [visitado el 20.10.2017], p. 6. En el Mensaje se citan la Moción del Boletín N 8450, “presentada el 17 de julio de 2012 por los Diputados señores Eugenio Bauer, Romilio Gutiérrez, Gustavo Hasbún, Javier Hernández, Iván Moreira, Leopoldo Pérez, Manuel Rojas, David Sandoval, Ignacio Urrutia y Gastón Von Mühlenbrock, y en el cual se propone incorporar un nuevo Art. 47 bis en la ley 19.300 sobre Bases Generales del Medio Ambiente, estableciendo que los productores deberán evitar la propagación de los residuos que se generen con ocasión del desarrollo de su actividad económica debiendo adoptar todas las medidas necesarias para que se efectúe con el menor impacto medio ambiental posible"; la del Boletín N ${ }^{\circ} 8854$ "presentada el 20 de marzo de 2013 por las Senadoras señoras Isabel Allende y Soledad Alvear, y los Senadores señores Guido Girardi y Alejandro Navarro, y en la cual se establece que el generador de un residuo será siempre responsable subsidiariamente de los efectos y perjuicios que éste genere hasta su completa disposición o eliminación"; y el Acuerdo la Cámara de Diputados № 620, de 9 de mayo de 2012, "en virtud del cual se le solicita a S.E. el Presidente de la República que por su intermedio "solicite al Ministerio del Medio Ambiente que nos indique cuáles son las factibilidades técnicas, administrativas y presupuestarias para hacer el envío inmediato del proyecto de la Ley General de Residuos que contempla dentro de sus principios significativos la Responsabilidad Extendida del Productor".

${ }^{16}$ BIBLIOTECA DEL CONGRESO NACIONAL, Historia de la Ley $N^{o}$ 20.920, cit. nota anterior, p.174.

${ }^{17}$ MATUS, “Evolución”, cit. nota al pie No 2, p. 157. 
MATUS, Jean Pierre; RAMIREZ, María Cecilia; CASTILLO, Marcelo.

"Acerca de la necesidad de una reforma urgente de los delitos de contaminación en Chile, a la luz de la evolución legislativa del siglo XXI”.

Las modificaciones más relevantes de la última década en cuanto a la sanción penal de los atentados contra el medio ambiente y sus componentes, así como de la burla de los sistemas administrativos de protección, son las siguientes ${ }^{18}$ :

\subsubsection{Protección penal de la biodiversidad}

Respecto de la protección de las especies hidrobiológicas, las disposiciones de la Ley General de Pesca y Acuicultura se han adaptado a los requerimientos de conservación de las especies marinas, estableciendo requisitos más estrictos para la realización de actividades como la acuicultura, que podrían poner en mayor riesgo la ya deprimida población de especias locales ${ }^{19}$.

Así, por moción parlamentaria de los H. Senadores Horvath y Ruiz (Boletín 2753-03), se tramitó el proyecto que dio origen a la Ley $\mathrm{N}^{\circ}$ 20.116, de 24.08.2006, la que introdujo en la Ley General de Pesca y Acuicultura los delitos de introducción, investigación, cultivo o comercialización con organismos genéticamente modificados sin contar con la autorización respectiva (Art. 136 bis, inc. $1^{\circ}$ ), y de introducción o mandar a introducir organismos genéticamente modificados "con dolo o culpa" al mar, ríos, lagos o cualquier otro cuerpo de aguas, sin contar con la autorización respectiva (Art. 136 bis, inc. $\left.2^{\circ}\right)^{20}$. Es interesante destacar que, aunque en la Historia de la ley se vincula insistentemente la necesidad de introducir estas modificaciones con el llamado Protocolo de Cartagena (Protocolo de Cartagena sobre Seguridad de la Biotecnología del Convenio sobre la Diversidad Biológica,

\footnotetext{
18 Aparte de las disposiciones que mencionaremos arriba en el texto, pueden considerarse indirectamente protectoras del medio ambiente ciertas disposiciones vinculadas con las armas de destrucción masiva, como las contempladas en las leyes $\mathrm{N}^{\mathrm{o}} 17.798$ y $\mathrm{N}^{\mathrm{o}} 18.314$, cuyo análisis particular excede las pretensiones de este trabajo.

${ }^{19}$ Sobre el estado de conservación de estas especies, es necesario tener en cuenta lo señalado en GIGLIO V., Nicolo (Dir.), Informe País: Estado del medio ambiente en Chile. Comparación 1999-2015, Santiago: U. de Chile, 2015, p. 388: "La disminución de los distintos recursos pesqueros, ya sea por extracción humana o por factores ambientales, ha sido fuerte y sostenida, llegado a una situación dramática y preocupante en 2015 . La tasa de variación de las principales pesquerías pelágicas disminuyó en más del 70\%, respecto a 1999, mientras que la pesquería demersal de peces se redujo por sobre el $82 \%$. Los crustáceos considerados en el análisis y los erizos disminuyeron sus desembarques en torno a un $45 \%$ en el periodo comparado. Los moluscos están entre los recursos que menos variación han registrado en estos 16 años comparativos $(-21,5 \%)$, debido principalmente a que están manejados por las AMERB. Esta realidad de colapso y sobreexplotación de la mayoría de las pesquerías más importantes del país es altamente preocupante, y de no mediar cambios importantes en el actual proceder humano respecto a estos recursos, la mayor parte de los stocks comerciales pesqueros estarían colapsados dentro de pocos años más. Por otro lado, esta sobreexplotación está generando cambios sociales y económicos que amenazan no sólo a los ecosistemas marinos, sino también a la seguridad alimentaria mundial". ${ }^{20}$ Aparte de esta regulación, no existe en Chile otra protección penal frente a los peligros que se atribuyen a los organismos genéticamente modificados, salvo su prohibición administrativa respecto de su cultivo para el consumo humano, prohibición que no es aplicable a los que se emplean para la producción de alimentos de animales. Sobre las limitaciones de la legislación chilena en esta materia, véase ANWANDTER V., Sofía; SOLÍS S., Pía, ¿Debe intervenir el Derecho Penal respecto de la introducción y producción de Organismos Genéticamente Modificados, en Chile, para una adecuada tutela del medio ambiente? Análisis a la luz de los elementos que conforman el principio de precaución, Valparaíso: Tesis U de Valparaíso, 2017, especialmente, pp.69-83.
} 
Polít. crim. Vol. 13, No 26 (Diciembre 2018) Art. 4, pp. 771-835.

[http://www.politicacriminal.cl/Vol_13/n_26/Vol13N26A4.pdf]

Montreal, 2000), dicho Protocolo no está suscrito por Chile, por lo que no pueden considerarse las modificaciones realizadas como una implementación propiamente tal del mismo $^{21}$.

Por otra parte, en cuanto a la protección de la salud de los animales y, por tanto, de manera indirecta, a la conservación de la biodiversidad (al menos de las especies bajo el control humano), las presiones mediáticas que se encuentran en el origen de las disposiciones de la Ley $\mathrm{N}^{\mathrm{o}}$ 21.020, de 02.08.2017, al punto de que su denominación popular es Ley Cholito, por el nombre de un perro maltratado que fue tomado como ejemplo y motor del cambio legislativo $^{22}$, demuestran el carácter de intensificación local del proceso que llevó a una agravación de las penas prevista para el maltrato animal en el Art. 291 bis del Código Penal.

1.2.2. Intensificación de las sanciones penales frente a la destrucción de ambientes naturales por el fuego

Según el mensaje con que inició su tramitación la Ley № 20.653, de 02.12. 2013, "la magnitud del daño ocasionado por incendios forestales es preocupante, con cifras estimadas del orden de cincuenta millones de dólares en pérdidas económicas directas durante cada período de incendios forestales", a lo que debe añadirse "las pérdidas en valores ambientales y, lo más significativo, el daño social y la pérdida de vidas humanas"23.

Ello justificaría, en el contexto de una larga sequía ${ }^{24}$ y un incendio devastador en el Parque Nacional Torres ${ }^{25}$, la creación de los nuevos delitos que contiene y la agravación de los antes existentes en el Código Penal y en la Ley de Bosques. De allí que esta modificación pueda concebirse como parte del proceso general de intensificación de nuestro Derecho Penal.

21 BIBLIOTECA DEL CONGRESO NACIONAL, Historia de la Ley $N^{o}$ 20.116, Valparaíso, s/ed., en http://www.bcn.cl/historiadelaley/nc/lista-de-resultado-de-busqueda/20116/ [visitado el 20.10.2017].

22 BIBLIOTECA DEL CONGRESO NACIONAL, Historia de la Ley $N^{o}$ 21.020, Valparaíso, s/ed., en http://www.bcn.cl/historiadelaley/nc/lista-de-resultado-de-busqueda/21020/ [visitado el 20.10.2017], especialmente pp. 612 y 644, donde, en la transcripción de la discusión en la Sala del Senado y de la Cámara de diputados, aparece con claridad el impacto del caso del perro mencionado, como motor de la indicación que se transformación en la reforma Art. 291 bis del Código Penal. Vésae, además, el texto del discurso de promulagación de la ley, en cuyo encabezado la propia Presidente de la República se refiere a ella como Ley Cholito (https://prensa.presidencia.cl/discurso.aspx?id=57488 [visitado el 20.10.2017]). Una nota de prensa que hace referencia a la noticia que originó esta denominación y su impacto en la actividad política puede verse en http://www.emol.com/noticias/Tendencias/2017/01/10/839366/Justicia-para-Cholito-Cientos-se-movilizanen-redes-sociales-y-organizan-manifestacion-tras-muerte-de-perro-en-Patronato.html.

23 BIBLIOTECA DEL CONGRESO NACIONAL, Historia de la Ley $N^{o}$ 20.653, Valparaíso, s/ed., en http://www.bcn.cl/historiadelaley/nc/historia-de-la-ley/4449/ [visitado el 20.10.2017], p. 3.

${ }^{24}$ SANTIBÁÑEZ Q., Fernando, El cambio climático y los recursos hídricos de Chile, Santiago: Ministerio de Agricultura, 2016, en http://www.odepa.cl/wpcontent/files mf/1482956610RecursosHidricosCambioClimatico.pdf [visitado el 20.10.2017], pp.16ss.

${ }^{25}$ ABUMOHOR, José, Incendio Forestal Parque Nacional Torres del Paine, Santiago, 2012: ONEMI, en http://repositoriodigitalonemi.cl/web/bitstream/handle/2012/1613/ConsolidadoIncendioForestalTdelPaine20 11 2012.pdf?sequence=1, [visitado el 20.10.2017]. 
MATUS, Jean Pierre; RAMIREZ, María Cecilia; CASTILLO, Marcelo.

"Acerca de la necesidad de una reforma urgente de los delitos de contaminación en Chile, a la luz de la evolución legislativa del siglo XXI”.

En efecto, la Ley $\mathrm{N}^{\circ}$ 20.653, de 02.02.2013, por una parte, modificó el Código Penal para incluir entre los incendios graves de su Art. $476 \mathrm{~N}^{\circ} 3$ a los que afectaran a "formaciones xerofíticas"26; y agregar un nuevo $\mathrm{N}^{\mathrm{o}} 4$ que sanciona al que "provoque un incendio que afectare gravemente las condiciones de vida animal o vegetal de un Área Silvestre Protegida". Y, por otra, modificó completamente la sistemática de la Ley de Bosques, para incorporar el empleo del fuego contra la reglamentación como delito autónomo (Art. 22); encender fuego en lugares no autorizados en las Áreas Silvestres Protegidas (Art. 22 bis); y el causar un incendio por mera negligencia en el uso del fuego u otras fuentes de calor, situación que se ve agravada si el incendio se produjere en un Área Silvestre Protegida o se propagare a alguna de ellas (Art. 22 ter ${ }^{27}$.

\subsubsection{Penalización del tráfico de residuos peligrosos hacia vertederos clandestinos}

La Ley $N^{\circ}$ 20.879, de 25.11.2015, incorpora como inciso $3^{\circ}$ de un nuevo Art. 192 bis de la Ley General de Tránsito, el delito consistente en encargar o realizar "el transporte, traslado o depósito de desechos tóxicos, peligrosos o infecciosos, en cualquier tipo de vehículo". Según la Moción (Boletín 7908-15) de H. Senadores Girardi, Pizarro y Letelier, la introducción de este nuevo delito se justificaba por los "vacíos" de la legislación existente a esa época, la "insuficiencia" de las sanciones administrativas para "disuadir" tales comportamientos y "el riesgo" que la existencia de vertederos clandestinos representaba para "la salud de la población y el medio ambiente". Con este nuevo delito, se anticipa de manera limitada e inconsciente la verdadera implementación de la Convención de Basilea contra el tráfico de desechos peligrosos descrita en los apartados anteriores. Este carácter inconsciente queda en evidencia al revisar la historia de la tramitación legislativa del texto legal, donde no se menciona dicha convención ni una sola vez ${ }^{28}$.

1.2.4. Indirecta protección penal del medio ambiente mediante la intensificación de la sanción penal frente a la burla de los sistemas administrativos de protección del medio ambiente

Uno de los mecanismos más recurrentes en nuestra legislación para otorgar protección penal a la actividad de la administración en diversos ámbitos es el establecimiento de formas especiales de perjurio o falsificaciones realizadas para impedir o burlar la fiscalización ${ }^{29}$.

\footnotetext{
${ }^{26}$ Según el Art. $2^{\text {o }}$, No 14 de la Ley No 20.283, de 30.07.2008, Sobre Recuperación del Bosque Nativo y Fomento Foresta, una formacióin xerofítica es una "formación vegetal, constituida por especies autóctonas, preferentemente arbustivas o suculentas, de áreas de condiciones áridas o semiáridas ubicadas entre las Regiones I y VI, incluidas la Metropolitana y la XV y en las depresiones interiores de las Regiones VII y VIII".

${ }^{27}$ Este delito, no bien se encontraba recién "salido de la imprenta", hubo de tener lamentable e inmediata aplicación a raíz de uno de los últimos "mega-incendio" que han asolado a Valparaíso (SCA Valparaíso 07.09.2015, Rol No 1271-2015).

${ }^{28}$ De hecho, en ninguna parte de la discusión parlamentaria se menciona la Convención de Basilea ni la intención de cumplir con obligaciones internacionales (BIBLIOTECA DEL CONGRESO NACIONAL, Historia de la Ley $N^{o}$ 20.879, Valparaíso: s/ed, en http://www.bcn.cl/historiadelaley/nc/historia-de-la-ley/4659/ [visitado el 20.10.2017]. Lo citado entrecomillas de la Moción está en p. 3).

${ }^{29}$ Como casos de perjurio especialmente regulados para evitar la burla de la administración en la resolución de solicitudes de particulares en diferentes asuntos, pueden citarse las siguientes disposiciones penales vigentes:
} 
Polít. crim. Vol. 13, No 26 (Diciembre 2018) Art. 4, pp. 771-835.

[http://www.politicacriminal.cl/Vol_13/n_26/Vol13N26A4.pdf]

Así, en esta materia, la preocupación por la supervivencia de las especies que conforman el llamado bosque nativo ha llevado, en los Arts. 40, 49 y 50 de la Ley $\mathrm{N}^{\circ} 20.283$, de 30.07.2008, sobre Recuperación del Bosque Nativo y Fomento Forestal, a establecer algunas figuras especiales de falsificación en la confección y uso de certificaciones con relación a planes de manejo y solicitudes de subvenciones o bonificaciones.

Del mismo modo, pero con relación con los efectos del cierre de las faenas mineras, la Ley No 20.511, de 11.11.2011, estableció en su Art. 32 el delito de otorgamiento u obtención de certificaciones falsas de cierre parcial o final de faenas mineras, protegiendo indirectamente el cumplimiento de las obligaciones contraídas con la administración en orden a implementar "las medidas comprometidas en el plan de cierre".

\section{El gran ausente: la inexistencia de delitos de contaminación propiamente tales y la insuficiencia de la legislación vigente para enfrentar los fenómenos de grave contaminación}

De lo dicho en el apartado anterior es posible concluir que en la década pasada se han producido importantes avances en la protección penal de la biodiversidad y del ambiente como tal ante el tráfico ilícito de residuos peligrosos. Incluso se han llegado a establecer

Art. 29 del DL 1.305/1976 que reestructura y regionaliza el Ministerio de la Vivienda y Urbanismo; Art. 17 del DL 1.939/1977; Art. 1. ${ }^{\circ}$ de la Ley 18.270, que establece Normas para el otorgamiento de Títulos Gratuitos de Dominio sobre Tierras Fiscales Rurales en la XI Región; Art. 11 inc. $4 .^{\circ}$ y 18 inc. $3^{\circ}$ de la Ley 18.883, que Aprueba Estatuto Administrativo de los Funcionarios Municipales; Arts. 13 inc. $4^{\circ}$ y $20^{\circ}$ inc. último, del DFL 29/2005 (Hacienda) que fija el Texto Refundido, Coordinado y Sistematizado de la Ley N 18.834 sobre Estatuto Administrativo; Art. $6^{\circ}$ letra e) de la Ley 19.360; Art. 18 inciso $5^{\circ}$, de la Ley 18.603, Ley Orgánica Constitucional de Partidos Políticos; Art. 16 del DL 539/1974, que establece Normas sobre Reajustabilidad y Pago de Dividendos de Deudas Habitacionales; Art. $1^{\circ}$ de la Ley $\mathrm{N}^{\circ} 20.634$ que otorga Beneficios a los Deudores del Crédito con Garantía Estatal y modifica la Ley N²0.027, Art. 11 bis de la Ley N 20.027 que establece Normas para el Financiamiento de Educación Superior.

Como supuestos de falsificación y presentación de documentos falsos especiales, en la presentación de solicitudes o para burlar la fiscalización en diferentes materias, pueden citarse los siguientes tipos penales: Art. 70 de la Ley $\mathrm{N}^{\circ}$ 16.741, establece Normas para Saneamiento de los Títulos de Dominio y Urbanización de Poblaciones en Situación Irregular; Art. $1^{\circ}$, Ley $\mathrm{N}^{\circ}$ 19.083, establece Normas sobre Reprogramación de Deudas del Crédito Fiscal Universitario; Art. $6^{\circ}$ de la Ley $\mathrm{N}^{\circ} 19.287$, modifica la Ley $\mathrm{N}^{\circ} 18.591$ y establece Normas sobre Fondos Solidarios de Crédito Universitario; Art. 6, de la Ley $\mathrm{N}^{\circ}$ 19.162, establece Sistema Obligatorio de Clasificación de Ganado; Art. 37, inc. $2^{\circ}$ de la Ley N¹8.168, General de Telecomunicaciones; Art. 228 del DFL 1/2005 (Salud), fija Texto Refundido, Coordinado y Sistematizado del Decreto Ley $\mathrm{N}^{\circ} 2.763$, de 1979 y de las Leyes $\mathrm{N}^{\circ} 18.933$ y $\mathrm{N}^{\circ}$ 18.469; Art. 49 del DFL 251/1931, sobre Compañías de Seguros, Sociedades Anónimas y Bolsas de Comercio; Art. 59, letras a) y f) de la Ley N 18.045 , sobre Mercado de Valores; Art. 49 Ley $\mathrm{N}^{\circ}$ 18.876, establece el Marco Legal para la Constitución y Operación de Entidades Privadas de Depósito y Custodia de Valores; Art. 59 de la Ley N 18.840, Orgánica Constitucional del Banco Central de Chile; Art. 19 bis de la Ley N 18.902, crea la Superintendencia de Servicios Sanitarios; Art. 158 DFL 3/1997 (Hacienda), Ley General de Bancos; Art. 8 DFL 15/1991 (Hacienda), establece Normas sobre Deudores Habitacionales de la Ley $\mathrm{N}^{\circ}$ 19.003; Art. 30, Ley $\mathrm{N}^{\circ}$ 19.353, condona Deudas que indica derivadas del proceso de Reforma Agraria; Art. 30, Ley N 20.255 que establece la Reforma Previsional; Art. 27 de la Ley $N^{\circ} 19.728$ que establece un Seguro de Desempleo; Art. $1^{\circ}$ de la ley $N^{\circ} 20.634$ que otorga Beneficios a los Deudores del Crédito con Garantía Estatal y modifica la Ley $\mathrm{N}^{\circ} 20.027$, Art. 11 bis de la Ley $\mathrm{N}^{\circ} 20.027$ que establece Normas para el Financiamiento de Educación Superior. 
MATUS, Jean Pierre; RAMIREZ, María Cecilia; CASTILLO, Marcelo.

"Acerca de la necesidad de una reforma urgente de los delitos de contaminación en Chile, a la luz de la evolución legislativa del siglo XXI”.

algunos delitos que protegen el funcionamiento de algunas áreas particulares del sistema administrativo de gestión ambiental frente a la burla de este por medio de declaraciones o certificaciones falsas.

Sin embargo, también es cierto que nuestro ordenamiento jurídico no ha incorporado figuras penales que castiguen directamente la grave contaminación, entendida como emisión no autorizada —dolosa o culposa-, así como la burla del principal sistema de protección administrativa del medio ambiente creado a partir de las modificaciones a la Ley $\mathrm{N}^{\mathbf{0}} 19.300$, tal como se hace en buena parte de los ordenamientos occidentales ${ }^{30}$.

Ello, a pesar de los intentos del Ministerio Público en orden a hacer operativas, como delitos de contaminación, las disposiciones de los Arts. 291 del Código Penal y 136 de la Ley General de Pesca y Acuicultura, ante la presión pública por establecer responsabilidades penales en los graves hechos de contaminación de este siglo ${ }^{31}$.

Sin embargo, estos intentos de aplicación de estas dos disposiciones penales, anteriores al establecimiento del sistema de gestión ambiental administrativo hoy existente, se han enfrentado a serias dificultades técnicas ${ }^{32}$.

30 Véase al respecto MATUS A., Jean Pierre; RAMÍREZ G., M Cecilia y CASTILLO S., Marcelo, "Informe sobre el derecho penal ambiental en el Derecho comparado de tradición continental", en Gaceta Jurídica, $\mathrm{N}^{\circ}$ 260 (2002), pp. 7ss.

${ }^{31}$ Los casos más conocidos han tenido que ver con el intento de aplicación de los Arts. 291 del Código Penal y 136 de la Ley General de Pesca y Acuicultura, como sucedió con la causa sobre la contaminación del Río Cruces en Valdivia, el año 2004 (terminada con decisión de no perseverar el año 2010), y el reciente derrame petrolero en la Bahía de Quintero, del año 2014, cuya causa criminal fue sobreseída a principios de 2016. Según la página web del Ministerio Público, sección "Delitos contra los Recursos Naturales", el "área de persecución” especializada en "Medio Ambiente y Patrimonio Cultural" tiene entre su "competencia", los siguientes delitos: extracción ilegal de recurso en veda; tala ilegal; quema ilegal; usurpación de aguas (http://www.fiscaliadechile.cl/Fiscalia/areas/amb-delitos.jsp [visitado el 20.10.2017]). Por su parte, el Oficio del Fiscal Nacional № 60 / 2009, de 30.01.2009, Instrucción General que imparte criterios de actuación en delitos económicos (en http://www.fiscaliadechile.cl/Fiscalia/archivo?id=636\&pid=68\&tid=1\&d=1 [visitado el 20.10.2017], califica como "delito económico" el daño a Monumentos Nacionales, Arts. 38 y 38 bis de la Ley $\mathrm{N}^{\mathrm{o}}$ 17.288. Sin embargo, no se encuentra publicada en la página Web de la Fiscalía Nacional ninguna Instrucción General u oficio específicamente referido a los delitos ambientales.

${ }^{32}$ Por su nula apliación práctica, no consideraremos en este lugar el conjunto de faltas del Art. 494 del Código Penal que de antiguo regulaban la materia, No 20 (infracción de las reglas de policía en la elaboración de objetos fétidos o insalubres), № 22 (no entregar basuras o desperdicios a la policía de aseo) y № 29 (construcción en contravención de los reglamentos de fuentes de emisión fija -hornos, chimeneas o estufas-).

La misma razón vale para no profundizar en este lugar acerca de la infracción al Art. 138 de la Ley General de Urbanismo y Construcciones, que castiga la venta en verde de loteos que han de ser urbanizados, sin que previamente se cumplan los requisitos que dicha ley establece, su aplicación ha sido sorteada por los constructores mediante el artilugio de no celebrar promesas de compraventa, sino recibir ofertas de compra por parte de futuros compradores, ahora no "en verde" siquiera, sino también "en blanco" (al momento de instalar la faena, sin necesariamente iniciar las obras.

Tampoco ha tenido ninguna aplicación la disposición que Rafael Valenzuela entiende también aplicable a la protección de las aguas, contenida en el Art. $6^{\circ}$, letra e) de la Ley de Seguridad del Estado, No 12.927, que sanciona a los que "inciten, promuevan o de hecho envenenen alimentos, aguas o fluidos destinados al uso o 
Polít. crim. Vol. 13, No 26 (Diciembre 2018) Art. 4, pp. 771-835.

[http://www.politicacriminal.cl/Vol_13/n_26/Vol13N26A4.pdf]

Así, respecto del delito de propagación de contaminantes del Art. 291 del Código penal, como figura que sancionaría principalmente la contaminación del aire y del suelo, sigue siendo cierto que "la falta de una clara identificación de los deberes jurídicos que debieran infringirse para cometer el delito, hace de muy difícil aplicación práctica la fórmula utilizada por el legislador; ello, sin contar con la dificultad adicional de probar la propagación de tales sustancias y, sobre todo, su capacidad (una vez propagadas) para poner en peligro la salud animal o vegetal o el abastecimiento de la población" ${ }^{33}$. En efecto, esta predicción se ha visto confirmada en la práctica judicial, a pesar de los esfuerzos del Ministerio Público y de Muñoz y Fernández por otorgarle un sentido diverso al texto legal, que permitiese soslayar las limitaciones de su alcance normativo ${ }^{34}$.

Por otra parte, respecto a la contaminación de las aguas y, particularmente, de las marinas, la principal novedad que ha traído la actividad del Ministerio Público en esta materia ha sido la confirmación jurisprudencial del limitado alcance del Art. 136 de la Ley General de Pesca y Acuicultura que, lamentablemente no comprende en su literalidad los hechos culposos, origen mayoritario de los naufragios y accidentes causantes de derrames y emisiones en los

consumo públicos", ni su correspondiente agravación en caso de resultar lesiones o muertes del Art. $7^{\circ}$ de dicha ley (VALENZUELA, Rafael, El Derecho Ambiental. Presente y pasado. $2^{a}$ ed., Santiago: Editorial Jurídica de Chile, 2012, p. 182s.). La misma suerte ha corrido el Art. 315 del Código Penal, pues el envenenamiento de aguas interiores difícilmente puede castigarse por esa vía, al no estar en la actualidad destinados al consumo humano los cursos de los ríos y esteros.

${ }^{33}$ MATUS, Jean Pierre (Ed.), Derecho Penal del Medio Ambiente. Estudios y propuesta para un nuevo Derecho Penal Ambiental chileno, Santiago: Ed. Jurídica de Chile, 2004, p. 208s. Con detalle, hemos estudiado esta figura en MATUS, Jean Pierre, "Sobre el sentido y alcance del artículo 291 del Código Penal", en Revista de Derecho (Valdivia), Vol. XXVI, No 2 (2013), pp. 137-167, a donde remitimos al lector. Véase, además, QUIROGA, S.; TRONCOSO, R., Análisis de delitos de carácter ambiental contenidos en el código penal y las leyes especiales chilenas, Talca: Tesis UTAL, 2002; y BULLEMORE, V., Curso de Derecho Penal, Vol. 3, Santiago: Legal Publishing, 2007, p. 256.

${ }^{34}$ La propuesta de interpretación que amplía el alcance de estas figuras, pero que no ha tenido acogida en la práctica, puede verse en MUÑOZ LORENTE, José y FERNANDEZ CRUZ, José Ángel. "Estudio dogmático penal de los artículos 291 del Código penal y 136 de la Ley General de Pesca y Acuicultura: A propósito del caso del Santuario de la Naturaleza Carlos Anwandter", en Política criminal, Vol. 5, No 10 (2010), en http://www.politicacriminal.cl/Vol_05/n_10/Vol5N10A4.pdf [visitado el 20.10.2017], pp. 410-454. Los alcances de esta propuesta son discutidos MATUS, “Art. 291”, cit. nota anterior, p. 139. Sin embargo, lo más significativo que puede decirse acerca de sus verdaderas limitaciones es la constatación de que sigue siendo cierto hoy como en 2013, que, "revisadas las bases de datos de jurisprudencia que son públicas (Microjuris y Legal Publishing), no existen antecedentes de formalizaciones, condenas o sobreseimientos que permitan tener una idea de los límites que jurisprudencialmente se hayan establecido para esta figura típica". La única causa seguida por este delito que aparece en la base de datos Vlex, correspondiente al año 2015, se encuentra actualmente suspendida en su tramitación al haberse interpuesto una cuestión prejudicial (SCA Concepción14.08.2015, Rol No 575-2015). 
MATUS, Jean Pierre; RAMIREZ, María Cecilia; CASTILLO, Marcelo.

"Acerca de la necesidad de una reforma urgente de los delitos de contaminación en Chile, a la luz de la evolución legislativa del siglo XXI”.

mares $^{35}$. Esta limitación se encuentra también reconocida por una parte significativa de la doctrina que, en estos últimos años, se ha ocupado del tema ${ }^{36}$.

En consecuencia, podemos afirmar que las actuales disposiciones que podrían aplicarse a los más graves hechos de contaminación del aire, el suelo y las aguas, son insuficientes para dar una respuesta penal adecuada a la fenomenología de estos sucesos por lo que, a pesar de los esfuerzos del Ministerio Público por lograr su aplicación, lo cierto es que la calificación de la situación normativa no puede ser diferente de la que existía a principios del siglo. Por tanto, sigue siendo cierto que nuestro sistema penal en la materia puede calificarse como uno de prescindencia, donde no existen normas penales que castiguen directamente la contaminación dolosa del medio ambiente, sino un cúmulo de disposiciones aisladas sobre determinados aspectos, medios y elementos del ambiente ${ }^{37}$.

Luego, parece pertinente discutir la afirmación que se hiciera hace una década acerca del hecho de que, aparentemente, no existiría una discusión acerca del si de la protección del medio ambiente a través de delitos de contaminación propiamente tales, sino únicamente acerca del cómo establecerlos ${ }^{38}$.

\section{La disputa acerca del sí o no deben establecerse delitos de contaminación en Chile}

\subsection{Las razones para afirmar la necesidad de establecer delitos de contaminación en el ordenamiento nacional}

3.1.1. El derecho a vivir en un ambiente libre de contaminación como finalidad legítima de protección por la vía penal, constitucionalmente reconocida

Si aceptamos la premisa de que, en un Estado de Derecho constitucionalmente ordenado, la legitimidad de una disposición penal ha de fundamentarse de alguna manera con el Texto Fundamental, en el sentido que ella proteja intereses o bienes jurídicos "cuya vinculación con los preceptos constitucionales a que se refieren permiten afirmar el reconocimiento del principio de proporcionalidad, en un sentido débil, enfatizando la legitimidad subyacente de

\footnotetext{
${ }^{35}$ SCA Valparaíso 16.11.2015, Rol 1822-2015, donde se sobreseyó una causa de derrame accidental de petróleo en la bahía de Quintero por no ser punible la comisión culposa del delito del Art. 136 de la Ley General de Pesca y Acuicultura.

${ }^{36}$ Véase, por todos, SILVA, Hernán, El Delito ambiental en el Derecho Chileno y Comparado, Santiago: Ed. Thomson Reuters, 2010, p. 400; y TOMASELLO, Leslie, Régimen jurídico de la contaminación marina, $2^{a}$ ed., Santiago: Librotecnia, 2011, p. 150s, quien cita a un informe del Profesor Juan Carlos Osorio en el caso del B/T “José Fuchs", para sostener la afirmación de que la multa prevista para el caso de falta dolo en la contaminación de las aguas, sólo debería entenderse como una sanción aplicable al caso de actuación con dolo eventual.

${ }^{37}$ Este modelo, no es, con todo, absolutamente excepcional, pues en idéntico caso se encuentra la regulación Argentina (VALLS, Mario F., Derecho Ambiental, $2^{a}$ Ed., Buenos Aires: Abeledo Perrot, 2012, p. 80s.).

${ }^{38}$ MATUS / RAMÍREZ / CASTILLO / ORELLANA, “Análisis digmático”, cit., nota al pie No 1, p. 44.
} 
Polít. crim. Vol. 13, No 26 (Diciembre 2018) Art. 4, pp. 771-835.

[http://www.politicacriminal.cl/Vol_13/n_26/Vol13N26A4.pdf]

una regulación que tenga una finalidad legítima y constitucionalmente reconocida" 39 , entonces la eventual existencia de delitos de contaminación estaría, en Chile, constitucionalmente justificada.

En efecto, el Art. $19 \mathrm{~N}^{\circ} 8$ de la Constitución asegura a todas las personas "el derecho a vivir en un medio ambiente libre de contaminación", consagrando como un deber del Estado "velar para que este derecho no sea afectado y tutelar la preservación de la naturaleza"40. Y agrega: "La ley podrá establecer restricciones específicas al ejercicio de determinados derechos o libertades para proteger el medio ambiente", con lo cual se autoriza, ya a nivel constitucional, la imposición de sanciones penales (privativas del derecho a la libertad personal del Art. 19 $\mathrm{N}^{\mathrm{o}}$ 7) y pecuniarias (que afectan el derecho de propiedad del Art. $\left.19 \mathrm{~N}^{\mathrm{o}} 24\right)^{41}$.

En consecuencia, esta cobertura constitucional de la protección del medio ambiente — no considerada en las Constituciones de 1833 y 1925 - permite afirmar no sólo la legitimidad de las disposiciones penales que analizamos en el primer apartado de este trabajo y las subsistentes de la legislación anterior, sino también el establecimiento de delitos de contaminación propiamente tales e, indirectamente, la protección penal del sistema administrativo de gestión ambiental, ya que es precisamente este sistema el que pretende materializar la garantía en juego ${ }^{42}$.

${ }^{39}$ MATUS, Jean Pierre y RAMÍREZ, María Cecilia, Manual de Derecho Penal chileno, Parte Especial, Valencia: Editorial Tirant lo Blanch, 2017, p. 29.

${ }^{40}$ Sobre el contenido preciso del derecho y las dificultades de intepretación del texto, desde el punto de vista constitucional, véasa, entre otros, AGUILAR, Gonzalo, "Las deficiencias de la fórmula "derecho a vivir en un medio ambiente libre de contaminación en la Constitución chilena y algunas propuestas para su revisión", en Estudios Constitucionales, Vol. 14, № 2 (2016), pp. 365-416.

${ }^{41}$ No obstante la importancia del alcance de esta disposición para el Derecho Penal, lo cierto es que la discusión acerca de su interpretación se ha concentrado en las limitaciones que el reconocimiento de este Derecho autorizaría (o no) a la forma de hacer efectivos los derechos regulados en la denominada "Constitución Económica", esto es, a la manera en que la ley, desarrollando el derecho a vivir en un ambiente libre de contaminación podría (o no) limitar el ejercico de los derechos de libertad económica y propiedad garantizados en el texto fundamental (véase, por todos, GUILOFF, Matías, "El dilema del artículo 19 N 8 inciso 2", en Revista de Derecho (Coquimbo), Vol. 18, № 1 (2011), pp. 147-169.

${ }^{42}$ Desde otra perspectiva, que aquí no se comparte porque la argumentación de fondo no está basada en el Derecho positivo vigente, sino en asunciones de política criminal previas del autor, Bascuñán estima legítima la sanción penal de los hechos de grave contaminación, basado en la siguientes circunstancias: (i) el carácter de fin estatal legítimo que, en sí mismo considerado, tendría la protección del medio ambiente, y su carácter de interés polivalente en relación con la calidad de vida y el aseguramiento de la disponibilidad de recursos para el futuro; (ii) la determinación normativa del margen en que cabe reconocer el objeto de ataque como un objeto merecedor de protección, habiendo una medida de afectación que ha de encontrarse necesariamente permitida en relación al bien jurídico "medio ambiente"; y, (iii) la consideracion de las emisiones contaminantes como acciones dañinas, donde "dañino" sólo puede significar que la contribución al daño total es superior al nivel permitido en razón de su valor social, lo que supone un esquema de distribución de prioridades institucionalmente operativo (BASCUÑÁN R., Antonio, "Comentario crítico a la regulación de los delitos contra el medio ambiente en el Anteproyecto de Código Penal de 2005", Revista de Estudios Públicos, № 110 (2008), pp. 241-322). En términos similares, desde el punto de vista del derecho alemán, justifica la existencia de un Derecho Penal Ambiental HEFENDEHL, Ronald, "Derecho Penal Medio Ambiental: ¿por qué o cómo?", Revista de Estudios Públicos, No 110 (2008), pp. 165-192. 
MATUS, Jean Pierre; RAMIREZ, María Cecilia; CASTILLO, Marcelo.

"Acerca de la necesidad de una reforma urgente de los delitos de contaminación en Chile, a la luz de la evolución legislativa del siglo XXI”.

Sin embargo, una cosa es que el derecho a vivir en un ambiente libre de contaminación pueda considerarse un interés constitucionalmente protegido que permita la restricción de otros derechos mediante el establecimiento de delitos, y otra bien diferente es que ello comporte un mandato explícito de sancionar los atentados contra el medio ambiente, como más claramente parece ser el caso de las constituciones de España ${ }^{43}$ y Brasil ${ }^{44}$.

En efecto, como lo ha declarado recientemente nuestro Tribunal Constitucional, el reconocimiento de intereses constitucionalmente protegidos, particularmente en lo referido a derechos y garantías constitucionales, habilita la protección penal, pero no supone un mandato absoluto de penalización y ésta, de existir, puede verse a su vez limitada por el principio de proporcionalidad en sentido $\operatorname{amplio}^{45}$ y la necesidad de reconocer el valor de otros derechos fundamentales ${ }^{46}$. Debido a ello, se hace necesario preguntarse si existirían otras razones que justificarían el establecimiento de delitos de contaminación, respetando los límites indicados.

3.1.2. El reconocimiento a nivel internacional del derecho a vivir en un ambiente libre de contaminación como interés de protección legítimo

Una de las razones adicionales que pueden invocarse para justificar la legitimidad de la protección penal del medio ambiente a través de delitos de contaminación, está dada por el reconocimiento del derecho a vivir en un ambiente libre de contaminación en el orden internacional, aunque no existan mandatos precisos de penalización como en los casos analizados en el primer apartado de este texto.

${ }^{43}$ BUJÁN, Fernando, Delitos ambientales y accesoriedad administrativa, aspectos problemáticos, Buenos Aires: Lajouane, 2009, p. 17. En el mismo sentido, ESTEVE, José, Derecho del medio ambiente, Madrid: Marcial Pons, 2014, p. 108. Una extensa discusión acerca del sentido de la disposición del Art. 45 de la Constitución española, en la que se concluye que "las normas penales destinadas a garantizar el uso racional de los recursos naturales y, con ello, proteger el medio ambiente encuentran fundamento directo en la Constitución, pero es tarea del legislador determinar en qué caso es adecuada una respuesta penal y cuáles imponen otras reacciones por parte del ordenamiento jurídico", puede verse en QUINTERO OLIVARES, Gonzalo, Derecho Penal Ambiental, Valencia: Tirant Lo Blanch, 2013, pp. 15-46, p. 45. En el mismo sentido, SILVA SÁNCHEZ, Jesus María; MONTANER, Raquel, Los delitos contra el medio ambiente. Reforma legal y aplicación judicial, Barcelona: Atelier, 2012, p. 29, hacen suya una referencia a Manzanares Samaniego, diciendo que el precepto constitucional español "puede entenderse en el sentido de la imperatividad de las sanciones en determinados supuestos, pero dejando al legislador ordinario la opción entre acudir a las penas penales, a las administrativas o a ambas clases".

${ }^{44}$ Sobre la imperatividad del mandot constitucional brasileño en orden a cirminalizar los atentados al medio ambiente y, acdicionalmente, establecer sanciones penales para las personas jurídicas, véase QUEIROZ, Cláudia C.; GURGEL, Yaira P.; COSTA, Rafaela C., "A responsabilidade penal das pessoas jurídicas de direito público nos crimes ambientais: necessidade de adequação das sanções penais da lei de n. 9.605/98", en Veredas do Direito, Belo Horizonte, Vol. 10, № 19 (2013), pp. 301-324, especialmente p. 103s.

${ }^{45}$ STC 26.11.2013, Rol No 2402-13.

46 STC 28.08.2017, Rol 3729-2017, Cons. 31 y 32. En el caso se discutía la constitucionalidad de establecer supuestos de interrupción lícita del embarazo frente al texto constitucional que declara la protección de "la vida del que está por nacer". 
Polít. crim. Vol. 13, № 26 (Diciembre 2018) Art. 4, pp. 771-835.

[http://www.politicacriminal.cl/Vol_13/n_26/Vol13N26A4.pdf]

En efecto, no es despreciable el número e importancia de instrumentos internacionales que dan cuenta de la preocupación de la comunidad internacional -y del Estado de Chile como parte de ella-, respecto a los efectos de la degradación del medio ambiente estos últimos $a_{n ̃ o s}{ }^{47}$. Entre ellos podemos mencionar el Protocolo de Kioto de la Convención Marco de las Naciones Unidas sobre el Cambio Climático (D.S. 349 [RR.EE.], 16.02.2005) ${ }^{48}$; el Plan de Aplicación de las Decisiones de la Cumbre Mundial sobre el Desarrollo Sostenible, realizada

${ }^{47}$ Antes del año 2005 se habían suscrito otros instrumentos que hacían referencia a la protección del ambiente frente a la contaminación, particularmente en lo que se refiere al ambiente marino. Así, desde fines del siglo pasado, el Art. 192 de la Convención de las Naciones Unidas Sobre el Derecho del Mar de 1988 establece que "los Estados tienen la obligación de proteger y preservar el medio marino". Sin embargo, allí no se indican las medidas que deben adoptarse en cumplimiento de esta obligación, que quedan entregadas a la implementación de buena fe de cada Estado Parte. Esta obligación de protección es coincidente con la regla general del Convenio Internacional Para Prevenir la Contaminación por los Buques (MARPOL 1973/1978) y sus convenios y protocolos relacionados: allí tampoco se imponen obligaciones de establecer delitos, sino solo se faculta la opción legislativa al respecto. En efecto, la regla general en MARPOL, según su Edición refundida de 2011, es que "toda transgresión" a las disposiciones del Convenio, "done quiera que ocurra", "estará prohibida y será sancionada por la legislación de la administración del buque interesado" (Art. 4.1), sanciones que "serán suficientemente severas para disuadir toda transgresión" (Art. 4.4.). Como expresa la literalidad del texto citado, criterio básico de interpretación según el Art. 31.1. de la Convención de Viena, no existe realmente una obligación de sancionar por la vía penal las transgresiones al Tratado, pero tampoco se prohíbe a los Estados Parte adoptar esta vía. Lo único que se pide es que las sanciones (penales o de otra clase) sean "suficientemente severas para disuadir de toda transgresión" (Art. 4.4.) y que sean informadas a la Organización Marítima Internacional, anualmente (Art. 11.1, f)). No obstante, la Organización Marítima Internacional —organismo encargado de implementar las regulaciones MARPOL — y sus Conferencias Diplomáticas anuales han producido varios instrumentos que apuntan a la adopción de medidas técnicas de seguridad para prevenir la contaminación.

En el mismo sentido, esto es, como medidas técnicas para prevenir la contaminación producto de los accidentes en la navegación, en general, y en el transporte de combustible nuclear, en particular, pueden considerarse el Código Internacional de Gestión de la Seguridad operacional del buque y la prevención de la contaminación (Código IGS) (D.S. 12 [RR.EE.], de .11.2011) y el Código Internacional para la seguridad del transporte de combustible nuclear irradiado, plutonio y desechos de alta actividad en bultos a bordo de los buques (Código CNI) (D.S. 12 [RR.EE.], de 23.11.2011), respectivamente; así como toda la regulación de seguridad de las personas en el mar, para evitar naufragios y sus consecuencias, del sistema del Convenio SOLAS (cuya primera versión, de 1914, tuvo como antecedente el hundimiento del Titanic), que, indirectamente, protegen el medio ambiente al procurar evitar tales hechos que, inevitablemente, lo contaminan. Un tratamiento de conjunto de la regulación de la seguridad en el tráfico marítimo puede verse en el texto de FERRÉ M., Ferran, Análisis, recopilación y comentario de la normativa aplicable al transporte marítimo, Barcelona: Tesis UPC, 2010.

En lo que respecta a la protección del medio antártico, el Comité para la Protección del Medio Ambiente creado por el Protocolo al Tratado Antártico Sobre Protección del Medio Ambiente, de 1991-, que sesiona anualmente junto con la Reunión Consultiva del Tratado Antártico, ha propuesto diversas medidas de gestión, conservación y protección del medio ambiente Antártico y de zonas determinadas dentro del mismo (La última de estas sesiones se realizó en Chile entre el 23 de mayo al 1 de junio de 2016. Las medidas y resoluciones adoptadas por la Reunión Consultiva del Tratado Antártico pueden verse en el sitio web de la Secretaría del Tratado Antártico (http://www.ats.aq/index s.htm [visitado el 20.10.2017]).

48 Sin embargo, este protocolo no impone ninguna obligación de reforma legal que implique algún procedimiento sancionatorio ni mucho menos obligaciones de establecer como delitos ciertos hechos que impidan, dificulten o atenten contra el logro de sus metas de reducción de emisiones. Antes, se había promulgado nuestra adhesión a las Rectificaciones al texto de la Convención Marco de las Naciones Unidas sobre el Cambio Climático (D.S. 378 [RR.EE.], de 12.06.2001), que tampoco contempla obligaciones y ni siquiera invitaciones o sugerencias en orden a sancionar determinadas conductas. 
MATUS, Jean Pierre; RAMIREZ, María Cecilia; CASTILLO, Marcelo.

"Acerca de la necesidad de una reforma urgente de los delitos de contaminación en Chile, a la luz de la evolución legislativa del siglo XXI".

en Johannesburgo (Sudáfrica), entre el 26 de agosto al 4 de septiembre de 2002 ${ }^{49}$; la Convención Conjunta sobre Seguridad en la Gestión del Combustible Gastado y sobre Seguridad en la Gestión de Desechos Radiactivos (D.S. 148 [RR.EE.], de 28.02.2012); y la Agenda para el Desarrollo 2030, adoptada por la Asamblea General de las Naciones Unidas en la Conferencia citada al efecto en Nueva York, entre el 25 y el 27 de septiembre de $2015^{50}$.

Sin embargo, a pesar de la amplitud de las declaraciones a favor del ambiente como objeto de protección, el lenguaje impreciso que se emplea en ellos, llamando a la preocupación por la materia y a la adopción de medidas adecuadas de protección, pero sin determinar su naturaleza y contenido, así como las formas que adoptan la mayoría de tales instrumentos que, en general, no son tratados o convenciones multilaterales propiamente tales, sino lo que se denomina Soft Law, no permiten concluir que allí se impongan obligaciones internacionales cuya implementación exija el establecimiento de delitos de contaminación en los ordenamientos nacionales ${ }^{51}$.

Tampoco los instrumentos que sí son tratados o convenciones propiamente tales, como el Protocolo de Kioto y la Convención Conjunta sobre Seguridad en la Gestión del Combustible Gastado y sobre Seguridad en la Gestión de Desechos Radiactivos, imponen obligaciones de esa naturaleza ${ }^{52}$.

${ }^{49}$ El Plan se encuentra como Anexo del Informe de la Cumbre, documento A.CONF/199.20, en http://www.undocuments.net/jburgdec.htm [visitado el 20.10.2017].

${ }^{50}$ La Agenda 2030 fue aprobada el primer día de la Cumbre y se encuentra en el documento A/RES/70/1, en http://unctad.org/meetings/es/SessionalDocuments/ares70d1_es.pdf [visitado el 20.10.2017]. La precupación por el medio ambiente y la necesidad de su regulación desde el punto de vista internacional ha llegado, incluso, a la Iglesia Católica, cuyo actual Pontífice ha manifestado que: "Urgen acuerdos internacionales que se cumplan, dada la fragilidad de las instancias locales para intervenir de modo eficaz. Las relaciones entre Estados deben resguardar la soberanía de cada uno, pero también establecer caminos consensuados para evitar catástrofes locales que terminarían afectando a todos. Hacen falta marcos regulatorios globales que impongan obligaciones y que impidan acciones intolerables, como el hecho de que países poderosos expulsen a otros países residuos e industrias altamente contaminantes" (FRANCISCO, Carta Encíclica Laudato si' del Santo Padre Francsico sobre el cuidado de la Casa Común, Ciudad del Vaticano: e/ed., 2015, en http://w2.vatican.va/content/francesco/es/encyclicals/documents/papa-francesco_20150524_enciclicalaudato-si.html [visitado el 20.10.2017], $\mathrm{N}^{\circ} 173$ ).

${ }^{51}$ Las limitaciones de esta forma de "regular" o establecer "principios" en el Derecho Internacional del Medio Ambiente son objeto de serias críticas entre los especialistas, véase, por ejemplo: SUSSKIND, Lawrence E.; H. ALI, Saleem, Environmental Diplomacy: Negotiating More Effective Global Agreements, $2^{a}$ Ed., Oxford: Oxford Univ. Press, 2014, especialmente pp. 10-38; y HUMPHREYS, Stephen; OTOMO, Yoriko, "Theorizing International Environmental Law", en OXFORD, Anne and HOFFMAN, Florian, The Oxford Handbook of the Theory of International Law, Oxford: Oxford Univ. Press, 2016, pp. 797-825. Antes, ya habíamos advertido de estas dificultades en MATUS, Jean Pierre; ORELLANA, Marcos, "Acerca de la existencia de obligaciones internacionales de establecer delitos medioambientales, contempladas en los tratados suscritos por la República de Chile", en Revista de Derecho y Jurisprudencia, Vol. XCVIII, No 4 (2001), pp. 93-113, p. 97.

${ }^{52}$ Sin embargo, un efecto que sí es palpable del conjunto de estas Declaraciones y Tratados y Convenciones, es el establecimiento de programas de apoyo técnico-financiero a proyectos en áreas específicas. Sólo a vía ejemplar, pueden citarse los establecidos en estos años últimos para el desarrollo de los siguientes proyectos: "Fortalecimiento de los marcos nacionales para la gobernabilidad de las especies exóticas invasoras: proyecto piloto en el archipiélago de Juan Fernández" (D.S. 186 [RR.EE.], de 22.02.2017); "Actividades de apoyo para 
Polít. crim. Vol. 13, No 26 (Diciembre 2018) Art. 4, pp. 771-835.

[http://www.politicacriminal.cl/Vol_13/n_26/Vol13N26A4.pdf]

No obstante, parece ser cierto que la comunidad internacional mediante esta profusión de instrumentos reconoce la existencia del derecho a vivir en un medio ambiente libre de contaminación como un derecho fundamental de tercera generación ${ }^{53}$, lo que más allá de la habilitación constitucional, permitiría justificar su protección por la vía penal ${ }^{54}$.

\subsection{Las razones del no a la pretensión de contar con delitos de contaminación}

3.2.1. La crítica a los delitos de contaminación como parte de un fenómeno ilegítimo de expansión del Derecho Penal

A pesar del reconocimiento constitucional e internacional del medio ambiente como objeto legítimo de protección jurídica, a partir de la obra de Silva Sánchez sobre la Expansión del Derecho Penal se afirma que la sanción penal de hechos como la grave contaminación no es tarea propia del derecho penal clásico o nuclear, sino únicamente un producto de procesos sociológicos que conduce a ello, sin que pueda afirmarse la legitimidad de tales sanciones, atendiendo al principio de ultima ratio, por cuanto en esta clase de hechos nos encontraríamos ante la existencia de un completo sistema administrativo que bien podría hacerse cargo de su control y sanción.

preparar la tercera comunicación nacional (TCN) de Chile ante la Convención Marco de las Naciones Unidas sobre el Cambio Climático" (D.S. 191 [RR.EE.], de 08.03.2016); "Apoyo en el diseño de un Fondo Forestal Ambiental (FFA) como herramienta de la arquitectura financiera de la estrategia nacional de cambio climático y recursos vegetales (ENCCRV) de Chile" (D.S. 173 [RR.EE.], de 03.02.2016); "Apoyo a la implementación del plan de acción: turismo sustentable en Áreas Protegidas del Estado” (D.S. 149 [RR.EE.], de 09.12.2015); "Programa de lucha y apoyo a políticas públicas contra la desertificación" (D.S. 149 [RR.EE.], de 09.12.2015); "Programa de fomento de capacidades en desarrollo bajo en emisiones en Chile" (D.S. 5 [RR.EE.], de 06.06.2015); "Planificación nacional de la biodiversidad para apoyar la implementación del plan estratégico de la Convención de Diversidad Biológica (CDB)” (D.S. 260 [RR.EE.], de 23.04.2015). Otros acuerdos bilaterales apuntan en la misma dirección. Por ejemplo, el suscrito con la Unión Europea para el "Apoyo a la evaluación ambiental estratégica en Chile" (D.S. 206 [RR.EE.], de 28.10.2008); y los suscritos con Alemania sobre "Fomento de la energía solar en Chile" (D.S. 78 [RR.EE.], 19.06.2014), "Manejo sustentable del bosque nativo" (D.S. 441 [RR.EE.], de 31.10.2001), y "Gestión de residuos peligrosos en Chile" (D.S. 45 [RR.EE.], de 30.04.2004).

53 ABOSO, Gustavo, Derecho Penal Ambiental. Estudio sobre los principales problemas en la regulación de los delitos contra el ambiente en la sociedad del riesgo, Montevideo: BdeF, 2015, pp. 269-278, con mayores referencias a casos concretos.

${ }^{54}$ Sin emabargo, no parece ser cierto que, como propone Cassola, "debemos ser realistas en admitir que la contaminación en gran escala, puede definirse como un delito contra la humanidad, de igual rango que el genocidio o el terrorismo" (CASSOLA, Gustavo, Medio Ambiente y Derecho Penal. Un acercamiento, Montevideo: BdeF, 2005, p. 47). El argumento de que así lo reconocería indirectamente el Estatuto de Roma en su Art. 8.2.b) iv), al calificar como un crimen de guerra, "lanzar un ataque intencionalmente, a sabiendas de que causará pérdidas de vidas, lesiones a civiles o daños a bienes de carácter civil o daños extensos, duraderos y graves al medio ambiente natural que serían manifiestamente excesivos con la ventaja militar concreta y directa de conjunto que se prevea..." no parece suficiente, en la medida que la literalidad del texto citado no hace más que ratificar lo dicho: que no existe en el derecho internacional una exigencia clara y directa de sancionar como delito en el orden interno la grave contaminación, dolosa o culposa, como tal y sin consideración a otros hechos acompañantes. 
MATUS, Jean Pierre; RAMIREZ, María Cecilia; CASTILLO, Marcelo.

"Acerca de la necesidad de una reforma urgente de los delitos de contaminación en Chile, a la luz de la evolución legislativa del siglo XXI".

En efecto, según Silva Sánchez, la introducción de los delitos ambientales en el Derecho Penal moderno puede verse como parte de un fenómeno que se caracterizaría por "una tendencia claramente dominante en la legislación de todos los países hacia una introducción de nuevos tipos penales así como a una agravación de los ya existentes, que cabe enclavar en el marco general de la restricción, o la "reinterpretación" de las garantías clásicas del Derecho Penal sustantivo y del Derecho procesal penal". Atribuye este fenómeno a la intervención local de defensores más o menos explícitos de los intereses económicos en el origen de nuevas reglas penales, burocracias internacionales dependientes (p. ej., la UNODC), múltiples ONG de protección de "víctimas" de diversa naturaleza y otros "emprendedores morales atípicos" interesados que, mediante técnicas de lobby y comunicación estratégica en medios masivos, intervienen para promover los cambios legislativos que buscan la expansión del Derecho Penal. Respecto de la técnica legislativa, el profesor Silva Sánchez ha sostenido, en primer lugar, que los bienes jurídicos de carácter universal o colectivo propios de los tipos delictivos modernos, tal como sería el caso de los delitos medioambientales, sólo se podrían formular de un modo vago e impreciso, lo cual daría lugar a la disolución del concepto mismo de bien jurídico, tipicidades iguales de vagas e imprecisas y una preferencia por los delitos de peligro abstracto, que no sería conforme a los principios de lesividad y de protección subsidiaria de bienes jurídicos, adoptándose el modo de razonar propio del derecho administrativo sancionador, en el sentido de criminalizar hechos individuales que carecen de lesividad e incluso de peligrosidad general, sustentando su penalización en los efectos que la acumulación, fenómeno que ha denominado administrativización del Derecho Penal ${ }^{55}$.

Entre nosotros, estas ideas ha sido recogidas por Aboso, quien afirma que la "expansión" del Derecho Penal a este ámbito ha alcanzado "resultados magros", lo que obedecería "al intento de construir una imagen de eficacia del Derecho Penal frente a los peligros y amenazas de las modernas sociedades del riesgo, que le ha restado legitimación a la intervención punitiva al renunciar a su carácter subsidiario"56; y por Ma Magdalena Ossandón, quien agrega que la legislación que pretende castigar los hechos de grave contaminación se ha mostrado ineficaz allí donde existe y que "la ineficiencia de aquellos tipos penales que no tienen capacidad para ir más allá del papel y que no cumplen un rol significativo de prevención, puede también tener un efecto contraproducente en la protección del bien jurídico", de modo que "en la práctica, el Derecho penal del medio ambiente ha llegado a ser visto más como un regalo funesto que como una oportunidad para mejorar el medio ambiente" 57 .

Sin embargo, estas críticas parecen desconocer que en los Estados constitucionalmente ordenados los intereses dignos de protección están fijados, en primer lugar, en las propias Constituciones y que la discusión política acerca de si esa protección merece ser penal o no parece exceder el ámbito de la academia, cuyos miembros no representan la voluntad

\footnotetext{
${ }^{55}$ SILVA SÁNCHEZ, Jesús María, La expansión del Derecho Penal, aspectos de la Política criminal en las sociedades postindustriales, $3^{a}$ ed., Montevideo: BdeF, 2008, pp. 4, 64 a 110 y 131 y ss.

${ }^{56}$ ABOSO, cit. nota al pie $\mathrm{N}^{\circ}$ 53, p. 546.

57 OSSANDÓN, María Magdalena, "Eficiencia del Derecho Penal. El caso de los Delitos contra el Medio Ambiente", en Revista de Derecho de la Pontificia Universidad Católica de Valparaíso, Vol. N XXIV (2003), pp. $379-394$, p. 393.
} 
soberana. Como se ha sostenido, muchas veces estos los cambios legales, denunciados como expansivos, no son mas que una simple modernización del Derecho Penal, de conformidad con las valoraciones de la sociedad de estos tiempos, pues "a pesar de las eventuales deficiencias técnicas en la formulación legal", "a través de ellas se recoge la idea de profundizar en la protección de la democracia, los derechos ciudadanos, las libertades públicas y de lograr una igualitaria aplicación del Derecho Penal"58.

Otro asunto es, por tanto, si una regulación particular de los delitos de contaminación resulta necesaria o funcional en un contexto normativo y social determinado y si, en su concreta manifestación legal, respeta o no el resto de los límites constitucionales que para el establecimiento de los delitos y sus penas contempla un ordenamiento nacional determinado. Pero, en este caso, habría que admitir que dicha crítica sólo estaría justificada, a lo sumo, respecto del "cómo" de la regulación particular, "pero no a si los hechos en ellas comprendidas son merecedores de una sanción penal más o menos uniforme en el concierto de naciones" 59 , en general, y en cada Estado que, en particular, reconoce el medio ambiente como un interés digno de protección penal.

Ello explicaría el hecho de que, a pesar de su crítica inicialmente devastadora, el propio Silva Sánchez haya terminado por enfrentar el estudio dogmático de estos delitos en España ${ }^{60}$; Abaso admita en Uruguay que al menos sería legítimo sancionar penalmente "un núcleo de conductas dolosas o imprudentes que produzcan resultados contaminantes significativos" 61 ; y en Chile, Carnevali — un discípulo directo de Silva Sánchez-, haya terminado por afirmar que "no me parece que puedan rechazarse per se ciertas manifestaciones de expansión, lo que no impide, claro está, que deban tenerse en consideración y valorarse cuán eficiente puede ser el Derecho Penal en ciertas áreas", precisando que, "a diferencia de lo que sostuve en el pasado, creo difícil admitir que, atentados contra el medio ambiente u otros delitos de peligro común puedan quedar al margen del Derecho Penal por no responder a criterios del llamado Derecho Penal clásico" ${ }^{2}$. Incluso la propia Ossandón afirma, con cierta resignación, que con sus críticas a las concretas regulaciones medioambientales "no h[a] querido negar la importancia del medio ambiente ni rechazar absolutamente la posibilidad de que se configure

\footnotetext{
${ }^{58}$ MATUS, Jean Pierre y RÁMIREZ, María Cecilia, Fundamentos y Límites Constitucionales del Derecho Penal positivo, Santiago: Thomson Reuters, 2015, p. 95.

59 Para un mayor desarrollo de estos argumentos, véase: MATUS, Jean Pierre, "La Política Criminal de los Tratados Internacionales", en Ius et Praxis, Vol. 13, N¹ (2007), pp. 267 - 289. Para un detallado resumen de las críticas que es posible hacer a la pretensión de deslegitimación de nuevas figuras penales a través de su calificación como “expansión del Derecho Penal”, véase GRACIA MARTÍN, Luis, Modernización del Derecho Penal y Derecho Penal del enemigo, Lima: Idemsa, 2007, pp. 83 a 101.

${ }^{60}$ SILVA SÁNCHEZ / MONTANER, Los delitos, cit. nota al pie No 43, p. 29.

${ }^{61}$ ABOSO, cit. nota al pie $\mathrm{N}^{\circ} 53$, p. 546, quien agrega que, en todo caso, el resto de los hechos vinculados a los atentados ambientales hab'ria que dejarlos “a otras áreas del Derecho, por ejemplo, la contravencional, la administrativa sancionadora, o directamente construir el llamado "Derecho de intervención” de Hassemer, para intentar escapar de este dilema que actualmente ofrece un Derecho Penal meramente simbólico y caracterizado por su déficit de ejecución en la persecución de delitos ambientales".

${ }^{62}$ CARNEVALI, Raúl, Problemas de política criminal y otros estudios, Santiago: Legal Publishing, 2009, p. VI.
} 
MATUS, Jean Pierre; RAMIREZ, María Cecilia; CASTILLO, Marcelo.

"Acerca de la necesidad de una reforma urgente de los delitos de contaminación en Chile, a la luz de la evolución legislativa del siglo XXI”.

como objeto de protección del Derecho penal, pues éste podría cumplir un papel importante en la sanción de los más graves atentados contra este bien jurídico" 63 .

3.2.2. El principio de ultima ratio y la eventual falta de necesidad de establecer delitos de contaminción frente a la construcción y fortalecimiento de una nueva institucionalidad ambiental con facultades sancionatorias

Como hemos venido sosteniendo, la sola existencia de un interés constitucional legítimo podría no ser suficiente para afirmar la necesidad de un Derecho Penal del Medio Ambiente si ésta no supera también la barrera del principio de ultima ratio, entendido en el sentido de que "no deberían imponerse penas allí donde existan alternativas que permitan lograr el mismo fin constitucionalmente admitido con un menor sacrificio para los derechos y garantías constitucionales afectados”, por lo que, antes de la utilización del Derecho Penal,

“debiera preceder el ensayo de otros recursos estatales o sociales, para evitar tanto llegar por la vía de la extrema penalización a lo que podría considerarse un Estado Policial con la forma democrática o a una 'inflación penal' que desprestigie el ejercicio del poder democrático al conducir a la paradoja de terminar por no ser obedecido, por la incapacidad del sistema de perseguir todo lo que prohíbe" 64 .

De allí que podría considerarse innecesario plantear una regulación moderna de los delitos de contaminación frente a la reciente introducción de un completo y nuevo sistema administrativo y judicial de protección del medio ambiente, mediante las Leyes $\mathrm{N}^{\mathrm{o}} 20.417$, de 26.01.2010, y $\mathrm{N}^{\circ}$ 20.600, de 28.06.2012, que transformaron la institucionalidad ambiental, creándose el Ministerio del Medio Ambiente, el Servicio de Evaluación Ambiental, los Tribunales Ambientales y la Superintendencia del Medio Ambiente, pero no crearon delitos de contaminación ${ }^{65}$.

${ }^{63}$ OSSANDÓN, cit. nota al pie No 57, p. 394.

${ }^{64}$ MATUS Y RAMÍREZ, Fundamentos, cit. nota al pie No 58, p. 248 y ss. En España, los autores que se ocupan del problema de la legitimidad material del Derecho Penal Ambiental, afirman que su sistema administrativo no es eficaz o es insuficiente para garantizar la adecuada protección preventiva o represiva de los hechos de grave contaminación, tanto por el carácter meramente económico de sus sanciones (costeables por los infractores), cuanto por la importancia que tiene la preservación del ambiente, más allá de la "presión adicional" que ejercería la sanción penal, siempre que no se reduzca a un mero Derecho Penal simbólico (MUÑOZ CONDE, Francisco; LÓPEZ PEREGRÍN, Carmen; GARCÍA ÁLVAREZ, Pastora, Manual de Derecho Penal Medioambiental, Valencia: Tirat Lo Blanch, 2013, pp. 70-73).

${ }^{65}$ Sobre el detalle de estas modificaciones, véase, por todos, FERNÁNDEZ, Pedro, Manual de Derecho Ambiental Chileno, $3^{\circ}$ ed., Santiago: Thomson Reuters, 2013, p. 113. Además, queda pendiente todavía la aprobación del Proyecto de Ley que "Crea el Servicio de Biodiversidad y Áreas Protegidas y el Sistema Nacional de Áreas Protegidas", institución cuya creación anticipa el Art. $8^{\circ}$ transitorio de la Ley $\mathrm{N}^{\circ} 20.417$, Proyecto que se encuentra en actual tramitación en Primer Trámite Constitucional en el Senado, en el Boletín $\mathrm{N}^{\circ}$ 9404-12, según infrmación contenida en la página web de Senado, $<$ http://www.senado.cl/appsenado/templates/tramitacion/index.php?boletin_ini=9404-12> [visitado el 20.10.2017].

En materia de delitos, estas leyes solo contemplan el delito funcionario de violación de secretos del inciso $2 .^{\circ}$ del Art. 30 del Artículo Segundo de la Ley No 20.417 que sanciona a "quienes realicen las acciones de 
Esta transformación supuso el reemplazo del anterior modelo de "coordinación" 66 por uno de dirección y control funcionalmente centralizado, que otorga amplias facultades a la Superintendencia del Medio Ambiente para fiscalizar e imponer sanciones por diversas infracciones, incluyendo algunas que pueden describirse como hechos de contaminación y de burla del sistema de gestión administrativo.

En efecto, en cuanto a los hechos de contaminación propiamente tales, sancionables administrativamente, el Art. 35 de la Ley Orgánica de la Superintendencia del Medio Ambiente contempla en sus letras $g$ ) y $h$ ) los siguientes: el incumplimiento de las Normas de Emisión, cuando corresponda $(g)$; y el incumplimiento de las leyes, reglamentos y demás normas relacionadas con las descargas de residuos líquidos industriales $(h)$.

En cuanto a la burla del sistema de gestión del medio ambiente, los hechos susceptibles de sanción, según las letras $b$ ), $d$ ), e), f), $i$ ) y $m$ ) de dicho Art. 35, son los siguientes: la ejecución de proyectos y el desarrollo de actividades, para los que la ley exige Resolución de Calificación Ambiental, sin contar con ella y el incumplimiento del requerimiento para someterse a dicho sistema $(b)$; el incumplimiento por parte de entidades técnicas acreditadas por la Superintendencia, de los términos y condiciones bajo las cuales se les haya otorgado la autorización, o de las obligaciones que esta ley les imponga $(d)$; el incumplimiento de las normas e instrucciones generales que la Superintendencia imparta en ejercicio de las atribuciones que le confiere esta ley (e); el incumplimiento de la suspensión transitoria de las autorizaciones de funcionamiento contenidas en las Resoluciones de Calificación Ambiental o de otras medidas urgentes adoptadas para el resguardo del medio ambiente $(f)$; y el incumplimiento de los requerimientos de información que la Superintendencia dirija a los sujetos fiscalizados, de carácter general $(j)$ y específico, respecto de los responsables de fuentes emisoras $(m)$.

Estas infracciones pueden llegar a sancionarse con multas de hasta diez mil unidades tributarias mensuales, en caso de ser calificadas como gravísimas, lo que ocurre, según el $\mathrm{N}^{\circ}$ 1 del Art. 36 de la Ley Orgánica de la Superintendencia de Medio Ambiente, entre otros

fiscalización deberán guardar la debida confidencialidad de la información obtenida relativa a procesos y sistemas productivos o cualquier otro sujeto a propiedad industrial o de carácter reservado".

Del régimen anteror, subsiste, con todo, el sistema sancionatorio civil, derivado de las acciones de reparación del daño ambiental que provienen de la primitiva redacción de la Ley N 19.300, con la única modificación de extenderse el valor de la excepción de cumplimiento (compliance) a los casos en que ésta se invoca frente a la acción de reparación por daño ambiental y el demandado, con posterioridad al daño, "ejecutó satisfactoriamente un plan de reparación aprobado por la Superintendencia del Medio Ambiente", excepción que la doctrina administrativa denomina "preclusión de la acción ambiental" (BERMÚDEZ, Jorge, Fundamentos de Derecho Ambiental, Valparaíso: Ediciones Universitarias de Valparaíso, 2016, p. 427ss).

${ }^{66}$ En el modelo de coordinación de la versión anterior de la Ley $\mathrm{N}^{\circ} 19.300$ "se estructura a la autoridad ambiental con facultades de coordinación horizontal o transversal,no como un ente centralizado, sino como coordinador de los diferente sectores que afectan el medio ambiente; generalmente de carácter interministerial, apoyada en comités técnicos, esta autoridad tiene por función proponer políticas y normas de ejecución diversificada en los diversos organismos que tienen competencia en las diferentes áreas que afectan la problemática ambiental" (BOETTIGER, Camila, "Nueva Institucionalidad Ambiental”, en Actualidad Jurídica, $\mathrm{N}^{\mathrm{o}} 22$ (2010), pp. 429-454, p. 433). 
MATUS, Jean Pierre; RAMIREZ, María Cecilia; CASTILLO, Marcelo.

"Acerca de la necesidad de una reforma urgente de los delitos de contaminación en Chile, a la luz de la evolución legislativa del siglo XXI”.

casos, cuando se causa un daño ambiental no susceptible de reparación (a) o se afecte gravemente la salud de la población (b), esto es, en supuestos que podríamos calificar como de grave contaminación ${ }^{67}$.

Esta somera descripción del sistema administrativo sancionador ahora existente y del que carecíamos a principios de siglo, obliga a reconcer la expresa voluntad del legislador en orden a someter al mismo los hechos de grave contaminación y burla del sistema administrativo de gestión y protección del medio ambiente y, ante ello, a plantear como cuestión debatible la necesidad de sancionar tales hechos a través de disposiciones penales, limitadas por el principio de ultima ratio.

Al respecto, contra la necesidad de un derecho penal que refuerce las facultades sancionatorias de la Superintendencia del Medio Ambiente, no sólo puede señalarse la inequívoca voluntad del legislador en orden a entregar tales hechos a la propia potestad sancionatoria administrativa, sino otros dos argumentos de texto: primero, que dichas facultades no pueden ser reforzadas por la vía penal, ya que las multas que contempla (hasta mil unidades tributarias) exceden con mucho el máximo generalmente previsto para los crímenes en el Art. 25 del Código Penal (solo treinta unidades tributarias mensuales); y en segundo lugar, que las sanciones aplicables por la Superintendencia del Medio Ambiente se pueden hacer efectivas directamente sobre las personas jurídicas titulares de los proyectos, sin necesidad de pruebas relativas a la subjetividad de los responsables, mientras el Derecho Penal se aplica, en primer lugar, a personas naturales cuyo actuar doloso o al menos culposo debe ser probado en un juicio contradictorio.

A ellos pueden agregarse ahora otros dos argumentos empíricos. El primero es la existencia de una efectiva fiscalización por parte de la Superintendencia, junto con el control jurisdiccional de las multas y sanciones aplicadas por la Superintendencia de Medio Ambiente, ante los Tribunales Ambientales, que ha dado lugar a una abundante e interesante jurisprudencia ambiental ${ }^{68}$, que ha ido configurando los límites de dicha actividad

\footnotetext{
${ }^{67}$ Además, se consideran infracciones gravísimas la reiteración o reincidencia en infracciones graves y las que consistan en impider u obstaculzar deliberadamente el cumplimiento de metas, medidas, y objetivos de un Plan de Prevención o Descontaminación (c); entregar información falsa u ocultado cualquier antecedente relevante con el fin de encubrir u ocultar una infracción gravísima $(d)$; impedir deliberadamente la fiscalización, encubierto una infracción o evitado el ejercicio de las atribuciones de la Superintendencia (e); y ejecutar proyectos o actividades del Art. 10 de la ley No 19.300 al margen del Sistema de Evaluación de Impacto Ambiental, y se constate en ellos alguno de los efectos, características o circunstancias previstas en el Art. 11 de dicha ley $(f)$. Adicionalmente, el inciso final del Art. 28 de la Ley Orgánica de la Superintendencia del Medio Ambiente considera también como infracción gravísima "la negativa a dar cumplimiento a los requerimientos durante las acciones de fiscalización".

${ }^{68}$ Sobre la materia, ver TRIBUNAL AMBIENTAL DE SANTIAGO, Anuarios del Tribunal Ambiental de Santiago, Santiago: s/ed, años 2013 a 2015.
} 
Polít. crim. Vol. 13, No 26 (Diciembre 2018) Art. 4, pp. 771-835.

[http://www.politicacriminal.cl/Vol_13/n_26/Vol13N26A4.pdf]

fiscalizadora, los estándares de convicción y la proporcionalidad de la potestad sancionatoria de la Superintendencia de Medio Ambiente ${ }^{69}$.

Y el segundo, el alto cumplimiento de las normas administrativas de protección del medio ambiente que se ha revelado al estudiar la eficacia de las sanciones administrativas de la Superintendencia del Medio Ambiente. Así, según López, entre 2013 y 2015, se han realizado un total de 33.360 fiscalizaciones, señalando que "de éstas, sólo han derivado en procedimientos sancionatorios 325, por ende, a criterio de la Superintendencia, 33.035 fiscalizaciones, que representan un 99,03\%, han cumplido satisfactoriamente las disposiciones ambientales"; a lo que agrega que, "además, las cifras de cumplimiento son aún mayores, ya que no todos los procedimientos sancionatorios derivan en sanciones administrativas, por la existencia de los programas de cumplimiento, o porque la aplicación de una sanción no fue pertinente", pues "del total de procedimientos sancionatorios iniciados (325), sólo un $21 \%$ termina con una sanción administrativa" $" 70$.

Sin embargo, parecen todavía existir ámbitos en que la actividad sancionatoria de la administración no es aplicable (o su aplicación no parece suficiente) y respecto de los cuales podría justificarse la intervención del Derecho Penal.

Así lo ha expresado el Presidente del Tribunal Ambiental de Santiago, Ministro don Rafael Asenjo Zegers. Según Asenjo,

\begin{abstract}
"se observa que, en la práctica, estas sanciones generalmente recaen en el titular de un proyecto - el que por regla general será una persona jurídica - pero no alcanzan al directamente responsable de la estrategia, o a quien autorizó un determinado modelo de negocios, que omitió tomar los debidos resguardos o efectuar las debidas capacitaciones, entre otras causas de la afectación ambiental. Es decir, en general, las consecuencias, aunque representen importantísimos costos para las empresas, no suelen traducirse finalmente en cambios estructurales que aseguren buenas prácticas en el futuro para prevenir estos graves efectos sobre alguno de los componentes del medio ambiente ¿por qué? Porque los altos directivos generalmente no sufren en forma directa las consecuencias derivadas de su acción"71.
\end{abstract}

En consecuencia, según el Ministro Asenjo, no existiría, en la generalidad de los casos, una sanción para las personas naturales que, con sus actos individuales, sean responsables, por ejemplo, de infracciones gravísimas, que produzcan un daño "no susceptible de reparación"

\footnotetext{
${ }^{69}$ Sobre la materia, ver la Causa Rol R-6-2013, seguida en el segundo Tribunal Ambiental de Santiago, sobre "Reclamación de Rubén Cruz Pérez y otros contra la Superintendencia del Medio Ambiente. Proyecto "Pascua Lama", Región de Atacama, en Tribunal Ambiental de Santiago, Anuario del Tribunal Ambiental de Santiago 2014, Santiago, 2015, p. 65ss.

${ }^{70}$ LÓPEZ, Carlos, La eficacia de las sanciones administrativas de la Superintendencia del Medio Ambiente, Santiago: Tesis UChile, 2016, p. 69.

${ }^{71}$ Intervención del Presidente del Tribunal Ambiental de Santiago, Ministro Rafael Asenjo Zegers, en el seminario "El Derecho Penal y la protección del Medio Ambiente”, 25 de junio de 2015. La nota que recoge su iontervención está en http://www.tribunalambiental.cl/pdte-del-tribunal-ambiental-debemos-plantearnos-lainterrogante-acerca-de-la-responsabilidad-penal-de-las-personas-juridicas/ [visitado el 20.10.2017].
} 
MATUS, Jean Pierre; RAMIREZ, María Cecilia; CASTILLO, Marcelo.

"Acerca de la necesidad de una reforma urgente de los delitos de contaminación en Chile, a la luz de la evolución legislativa del siglo XXI”.

(Art. $36 \mathrm{~N}^{\circ} 1$ letra a), Ley $\left.\mathrm{N}^{\circ} 20.417\right)^{72}$. La sanción por estas infracciones recaerá, como se dijo, en las personas jurídicas titulares de los proyectos sujetos al sistema de gestión ambiental.

Por otra parte, para las personas naturales seguiría también siendo cierto que, tratándose de la burla al Sistema de Evaluación Ambiental, sólo podría ser aplicable la modesta pena de falta prevista en el Art. $495 \mathrm{~N}^{\circ} .9$ para el que "abriere establecimientos sin licencia de la autoridad, cuando sea necesaria"; mientras que para las personas jurídicas titulares de los proyectos infractores se les aplicaría una sanción administrativa, todo lo cual contrasta con la regla general en Chile respecto de las actividades requeridas de autorización previa, donde el emprendimiento de ellas sin autorización es sancionado penalmente ${ }^{73}$.

Asimismo, quien presenta — como persona natural — ante el Sistema de Evaluación de Impacto Ambiental una declaración jurada falsa sobre el impacto ambiental de su actividad o proyecto no está sujeto a ninguna sanción específica, como tampoco lo está quien presenta antecedentes falsos u omite los verdaderos a los organismos del sistema encargados de otorgar autorizaciones y supervigilar su cumplimiento. En cambio, en otros ámbitos de la vida económica conductas similares sí se encuentran sancionadas penalmente, sea como formas de delito de perjurio o de presentación de documentos falsos ${ }^{74}$. Tampoco existen aún sanciones penales dirigidas a las personas naturales que castiguen a quienes -como lo hace el Art. 327 del Código Penal respecto de los peritos judiciales y otros funcionarios auxiliares de la justicia que emiten informes falsos-, en el proceso de Evaluación de Impacto Ambiental, emitan, a favor de terceros interesados, informes falsos o incompletos que influyan en la decisiones de los organismos del Sistema, o que, interviniendo de cualquier manera en el proceso oculten o adulteren información que deba tomar en cuenta el órgano resolutivo competente. Indirectamente, la Ley Orgánica de la Superintendencia de Medio Ambiente sólo contempla, para casos similares, por una parte, la calificación de una infracción base como gravísima, cuando va acompañada de la entrega de información falsa

72 Según GUZMÁN, Rodrigo, Derecho Ambiental Chileno. Principios, instituciones, instrumentos de gestión, Santiago: Planeta Sostenible, 2012, p. 217, por “daño no susceptible de reparación” ha de entenderse "el caso en que la pérdida, detrimento, disminución o menoscabo significativo inferido al medio ambiente, a uno o más de sus componentes, o a sus interacciones, no sea susceptible de ser reparado, es decir, reponerlo a una calidad similar o restablecer sus propiedades básicas".

${ }^{73}$ Ver al respecto: Art. $3^{\circ}$ DL 3.631, de 1981, Fija Normas sobre Universidades; Art. 25 del D.L. 3.500, de 1980, establece Sistema de Pensiones; Arts. 60 letras a), b) y c) y 63 de la Ley $\mathrm{N}^{\circ} 18.045$, sobre Mercado de Valores; Arts. 46, 48 y 51 del DFL 251, de 1931, sobre Compañías de Seguros, Sociedades Anónimas y Bolsas de Comercio; Art. 39 del DFL 3, de 1997 (Hacienda), Ley General de Bancos; Art. 174 del DFL 1, de 2005 (Salud) fija texto refundido, coordinado y sistematizado del Decreto Ley $\mathrm{N}^{\circ} 2.763$, de 1979 y de las Leyes $\mathrm{N}^{\circ}$ 18.933 y $\mathrm{N}^{\circ}$ 18.469; Art. 38 de la Ley 19.220, que Regula Establecimientos de Bolsas de Productos Agropecuarios; Art. 8. ${ }^{\circ}$ inc. $1^{\circ}$ de la Ley 19.491 que regula el Funcionamiento de Administradoras de Recursos Financieros de Terceros Destinados a la Adquisición de Bienes; Art. 76 de la Ley 19.518, que fija Nuevo Estatuto de Capacitación y Empleo; Art. 30, incs. 5. a 7. ${ }^{\circ}$ de la Ley 19.728, que establece un Seguro de Desempleo; Art. 36 B, letra a), de la Ley No 18.168 General de Telecomunicaciones; Art. 23, incs..$^{\circ}$ y 2. ${ }^{\circ}$ de la Ley 18.118, que legisla sobre el Ejercicio de la Actividad de Martillero Público; Art. $4^{\circ}$ de la Ley N 20.345 sobre Sistema de Compensación y Liquidación de Instrumentos Financieros; y Art. 495 No 9 Cp.

${ }^{74}$ Véase nota al pie $\mathrm{N}^{\mathbf{0}} 29$. 
Polít. crim. Vol. 13, No 26 (Diciembre 2018) Art. 4, pp. 771-835.

[http://www.politicacriminal.cl/Vol_13/n_26/Vol13N26A4.pdf]

o el ocultamiento de cualquier antecedente relevante con el fin de encubrirla u ocultarla (Art. 36, $\mathrm{N}^{\mathrm{o}}$ 1, letra c)); y la infracción autónoma consistente del incumplimiento por parte de entidades técnicas certificadoras acreditadas por la Superintendencia, de los términos y condiciones bajo las cuales se les haya otorgado la autorización, o de las obligaciones que la misma ley les impone (Art. 35 letra d)). Pero, como se dijo, estas sanciones, en los hechos, se imponen sólo a las personas jurídicas titulares de los proyectos infractores o registradas como entidades técnicas certificadoras.

Queda, finalmente, la pregunta acerca de si las sanciones impuestas a las personas jurídicas, destinarias de facto de las normas administrativas que las imponen, son suficientes para el cumplimiento del fin constitucionalmente legítimo de proteger el medio ambiente.

Al respecto, es necesario insistir en que la Ley Orgánica de la Superintendencia del Medio Ambiente sí contempla como infracciones, calificables incluso de gravísimas, los hechos atribuibles a personas jurídicas consistentes en la burla del sistema administrativo de protección del medio ambiente y en la grave contaminación y daño ambiental y, por tanto, no existe el vacío que se detecta con relación a los hechos potencialmente sancionables respecto de personas naturales, salvo para el caso de la presentación de informaciones o declaraciones falsas a la autoridad, que sólo califica las infracciones como gravísimas pero no constituye una infracción independiente.

Por otra parte, las sanciones pecuniarias establecidas para los casos en que las infracciones administrativas sean calificables de gravísimas son muy superiores a las que podrían imponerse en el más grave de los casos a una persona jurídica responsable de un delito de cohecho a funcionarios públicos nacionales y extranjeros, lavado de activos, financiamiento del terrorismo y receptación, según dispone la Ley $\mathrm{N}^{\mathrm{o}} 20.393^{75}$. En efecto, mientras la letra a) del Art. 39 de la Ley Orgánica de la Superintendencia de Medio Ambiente dispone para tales casos la posibilidad de imponer una multa de hasta diez mil unidades tributarias anuales, el grado máximo de la multa aplicable a personas jurídicas responsables de delitos de cohecho a funcionarios públicos nacionales o extranjeros, lavado de activos, financiamiento del terrorismo o receptación, sólo puede alcanzar la suma de veinte mil unidades tributarias mensuales (Art. 12 Ley $\mathrm{N}^{\mathrm{o}}$ 20.393), esto es, prácticamente un sexto de la sanción administrativa disponible.

Sólo en relación con el resto de las sanciones disponibles en el sistema de la Ley № 20.393 podrían encontrarse diferencias que hagan pensar en una eventual mayor severidad del

\footnotetext{
${ }^{75}$ Para mayor profundidad respecto del sistema de responsabilidad penal de las personas jurídicas en Chile, véase: HERNÁNDEZ, Héctor, "La introducción de la responsabilidad penal de las personas jurídicas en Chile", en Política Criminal, No 9 (2010), en http://www.politicacriminal.cl/Vol_05/n_09/Vol5N9A5.pdf [visitado el 20.10.2017], pp. 208-239. Con respecto a modelos de prevención de delitos en los que pueden tener responsabilidad penal las personas jurídicas, véase: PIÑA, Juan Ignacio, Modelos de prevención de delitos en la empresa, Santiago: Thomson Reuters, 2012. Crítico a su establecimiento, WEEZEL, Alex v., "Contra la responsabilidad penal de las personas jurídicas", en Política Criminal, N $^{\circ} 9$ (2010), en http://www.politicacriminal.cl/Vol_05/n_09/Vol5N9A3.pdf [visitado el 20.10.2017], pp.114-142.
} 
MATUS, Jean Pierre; RAMIREZ, María Cecilia; CASTILLO, Marcelo.

"Acerca de la necesidad de una reforma urgente de los delitos de contaminación en Chile, a la luz de la evolución legislativa del siglo XXI".

régimen penal común frente al administrativo sancionador de las personas jurídicas, aunque con ciertos matices. En efecto, si bien es cierto la Ley $\mathrm{N}^{\circ} 20.393$ contempla en su Art. $8^{\circ}, \mathrm{N}^{\circ}$ 1, la disolución o cancelación de la personalidad jurídica de la persona jurídica responsable de delitos de cohecho a funcionarios públicos nacionales o extranjeros, lavado de activos, financiamiento del terrorismo o receptación; no lo es menos que dicha pena se encuentra sometida a importantes limitaciones: a) sólo se impone en casos de reincidencia o reiteración de crímenes y receptación; y b) no se impone a las empresas que presten un servicio de utilidad pública cuya interrupción pudiere causar graves consecuencias sociales y económicas o daños serios a la comunidad. Estas limitaciones, en casos de infracciones gravísimas, no se encuentran presentes respecto de las sanciones administrativas de revocación de la resolución de calificación ambiental o clausura del establecimiento, previstas en la letra a) del Art. 39 de la Ley Orgánica de la Superintendencia del Medio Ambiente.

Sin embargo, no se debe dejar de lado el hecho de que esa sanción de disolución o pérdida de la personalidad jurídica, así como las de prohibición temporal o perpetua de celebrar actos y contratos con los organismos del Estado y pérdida parcial o total de beneficios fiscales o prohibición absoluta de recepción de los mismos por un período determinado, también previstas en los números 2) y 3) del Art. $8^{\circ}$ de la Ley $\mathrm{N}^{\circ} 20.393$, pueden ser "esquivadas" mediante una distribución de riesgos en una estructura social compleja, lo que no necesariamente puede hacerse cuando se trata de actividades determinadas cuya resolución de calificación ambiental se revoca o las instalaciones donde se llevan a cabo son materialmente clausuradas.

Además, el sistema administrativo sancionador de la Ley Orgánica de la Superintendencia del Medio Ambiente no contempla la posibilidad de establecer planes de prevención de delitos ambientales que eventualmente pudieran cometer los empleados de las personas jurídicas como defensa de cumplimiento, quedando ésta restringida a la presentación de programas de cumplimiento ex post, para evitar la sanción administrativa, poniendo término al procedimiento correspondiente, según los términos de los Arts. 42 y siguientes de la Ley $\mathrm{N}^{\mathrm{o}} 20.417^{76}$, y al cumplimiento de las resoluciones de calificación ambiental y de los planes

\footnotetext{
${ }^{76}$ Según la definición de la normativa ambiental, un programa de cumplimiento, que puede poner término de manera anormal al procedimiento sancionatorio es "el conjunto de acciones y metas presentado por el infractor, para que dentro de un plazo fijado por la Superintendencia, los reponsables cumplan satisfactoriamente con la normativa ambiental que se indique”. Su presentación, inmediatamente después de la autodenuncia refuerza el carácter ex post, del mismo (para un detalle de la historia de la ley y la reglamentación aplicable a estos programas de cumplimiento ex post, en materia ambiental, véase OSSANDÓN, Jorge, Incentivos al cumplimiento ambiental, Santiago: Libromar, 2015, pp. 201-261, con explicación de los diversos casos presentados hasta 2015, en las páginas 265 a 359). En cambio, la defensa de cumplimiento que establece el Art. $3^{\circ}$ de la Ley $N^{\circ} 20.393$ consiste en que "se considerará que los deberes de dirección y supervisión se han cumplido cuando, con anterioridad a la comisión del delito, la persona jurídica hubiere adoptado e implementado modelos de organización, administración y supervisión para prevenir delitos como el cometido, conforme a lo dispuesto en el artículo siguiente", lo que destaca su carácter preventivo (con todo, sobre la limitación de los efectos de la defensa de cumplimiento preventivo, véase, por todos: MATUS, Jean Pierre, "La certificación de los programas de cumplimiento", en: ARROYO, Luis y NIETO, Adán (Dir.), El Derecho Penal Económico en la Era Compliance, Valencia: Tirant lo Blanch, 2013, pp.145-154).
} 
de contingencia dispuestos o aprobados por la autoridad ${ }^{77}$. De este modo, el efecto preventivo esperado de la necesidad de contar con tales planes ${ }^{78}$ no se produce en este ámbito. Tampoco se produce el efecto disuasivo de la existencia misma de los procesos penales, ni el criticado efecto simbólico de la calificación de ciertas infracciones como penales versus la supuesta menor entidad que tendría el considerarlas como administrativas ${ }^{79}$.

Todo lo anterior parece explicar que la OCDE, en su Evaluación del Desempeño Ambiental sobre Chile, del año 2016, haya recomendado "considerar la posibilidad de adoptar sanciones penales por delitos ambientales graves", por cuanto

"La legislación penal chilena no establece disposiciones específicas para las infracciones ambientales, situación que ha sido objeto de debates durante los últimos diez años. Chile debería materializar su intención de imponer una responsabilidad penal a varias categorías de delitos ambientales graves y establecer diferencias claras entre las infracciones pasibles de sanciones administrativas y aquellas punibles mediante sanciones penales" ${ }^{\prime \prime}$.

\section{El problema del cómo: la disputa por el modelo de regulación de los delitos de contaminación. Reseña y análisis crítico de los proyectos actualmente en tramitación}

A las discusiones en torno al si de la sanción penal de los hechos de grave contaminación y de burla del sistema de gestión administrativa del ambiente, le siguen, entre quienes están de acuerdo con adicionar la herramienta penal al actual sistema administrativo, las disputas en torno al cómo materializar esta pretensión.

En efecto, si se analizan los proyectos de ley actualmente en tramitación que pretenden e regulación sistemática de la materia, estableciendo delitos de carácter ambiental respecto a

\footnotetext{
77 Así, según el inciso primero del Art. 44 de la Ley $N^{\circ}$ 19.300, los planes de prevención o descontaminación se establecerán mediante decreto supremo del Ministerio del Medio Ambiente, el que deberá llevar ademas, la firma del ministro sectorial que corresponda. El inciso segundo de la norma citada, establece que la elaboración de estos planes y su propocisión a la autoridad competente, corresponde al Ministerio del Medio Ambiente, previo informe de la Secretaría Regional Ministerial Respectiva.

78 THEILE, Hans, “Die verfahrensrechtliche Relevanz der Einrichtung einzelner Compliance-Maßnahmen”, en ROTSCH, Thomas (Hrsg.), Criminal Compliance, Baden-Baden (Alemania): Nomos, 2015, pp.1205-1373, p. 1223. Con todo, como allí se afirma, no está completamente comprobado, desde el punto de vista empírico, un significativo efecto preventivo en la adopción de planes o modelos de prevención de delitos, aunque es esperable que ello pueda demostrarse en el futuro, atendidos los efectos en el comportamiento de los individuos de las instrucciones gerenciales y las ya existentes evidencias — no categóricas aún- en ese sentido, como la diferencia en la disminución de la victimización de las empresas con modelos de cumplimiento respecto de las que no lo tienen, según una encuesta realizada en Alemania el año 2007. Entre nosotros, sobre el aspecto preventivo de la compliance en el amplio marco de la autoregulación empresarial, véase NIETO, Adán, "Responsabilidad social, gobierno corporativo y autorregulación: sus influencias en el derecho penal de la empresa", en Política Criminal , № 5 (2008), A3-5, pp.1-18, especialmente, p. 16.

${ }^{79}$ Sobre el efecto simbólico de la calificación de ciertas infracciones como penales, véase: SILVA SÁNCHEZ, La expansión, cit. nota al pie $\mathrm{N}^{\mathrm{o}} 55$, p. 178, especialmente cita 383.

${ }^{80}$ OCDE, Evaluaciones del Desempeño Ambiental Chile 2016, Santiago, OCDE/CEPAL, 2016, p. 122, en http://portal.mma.gob.cl/wp-content/uploads/2016/07/Evaluacion-desempeno-Chile-WEBV2.pdf [visitado el 20.10.2017].
} 
MATUS, Jean Pierre; RAMIREZ, María Cecilia; CASTILLO, Marcelo. "Acerca de la necesidad de una reforma urgente de los delitos de contaminación en Chile, a la luz de la evolución legislativa del siglo XXI”.

la grave contaminación o daño del medio ambiente ${ }^{81}$, presentados con posterioridad a la entrada en vigencia del nuevo sistema de gestión ambiental (Ley $\mathrm{N}^{\circ} 20.417$, de 12 de enero de 2010) ${ }^{82}$, podemos apreciar en ellos claramente dos modelos diferentes de regulación ${ }^{83}$ :

${ }^{81}$ Además, existen tres otros proyectos de ley en actual tramitación en relación a aspectos especiales de la protección del medio ambiente, a saber, el contenido en el Boletín $\mathrm{N}^{\circ} 11168-12$, de 23 de marzo de 2017, que modifica la Ley $\mathrm{N}^{\circ} 20.283$, sobre recuperación del bosque nativo y fomento forestal, para tipificar como delito la extracción no autorizada de tierra de hojas, tipificando un delito de daño al medio ambiente; el contenido en el Boletín 10444-21 que modifica la Ley General de Pesca y Acuicultura en el sentido de tipificar el delito de pesca ilegal, sancionando como delito una conducta atentatoria contra la biodiversidad; y el contenido en el Boletín 7551-12, del 22 de marzo de 2011, que tipifica el delito de cohecho en gestiones ante la autoridad ambiental, sancionando penalmente un aspecto que podemos clasificar, dentro de lo que hemos denominado "burla del sistema administrativo".

${ }^{82}$ De los proyectos presentados con anterioridad a esta reforma estructural del sistema de protección del medio ambiente, no se han archivado aún los siguientes:

i) Boletín 4256-12, que sanciona los delitos contra el medio ambiente cometidos por personas jurídicas, de 21 de junio de 2006, Moción de las H. Diputadas Denise Pascal y Clemira Pacheco, basado en el Anteproyecto de Código Penal del Foro Penal, de 2005, en primer trámite constitucional, sin informe de la Comisión respectiva;

ii) Boletín 5654-12, sobre delitos contra el medio ambiente, Moción del H. Senador Guido Girardi, de 19 de diciembre de 2007, “diseñado y estructurado teniendo como base el trabajo investigativo de un equipo de juristas encabezado por el profesor Jean Pierre Matus, e integrado por los abogados Maria Cecilia Ramirez Guzmán, Marcos Orellana Cruz y Marcelo Castillo Sanchez, y que fuera publicado por la Editorial Jurídica de Chile el año 2004", archivado en marzo de 2010 y desarchivado, por acuerdo de Sala, el 28 de enero de 2014, a propósito de la discusión de la Moción contenida en el Boletín № 8920-07, en primer trámite constitucional, sin informe de la Comisión respectiva;

iii) Boletin 6048-07, que tipifica delitos que ofenden el medio ambiente, de 2 de septiembre de 2008, Moción de los H. Diputados Srs. Enríquez-Ominami, Escobar, Farías, Girardi, Jaramillo y Jiménez, que "sin pretender una reforma sistemática en la materia", "pretende enfatizar, en el ámbito de los delitos que ofenden el medio ambiente, un tipo que recoge una especial modalidad de contaminación que dice relación con el grave daño ambiental producto de emisiones contaminantes de gases a nivel industrial y vehicular en situaciones de pre emergencia y emergencia ambiental" en primer trámite constitucional, sin informe de la Comisión respectiva; $\mathrm{y}$

iv) Boletin 6754-12, que modifica el artículo 136, de ley $\mathrm{N}^{\circ}$ 18.892, aumentando las penas de determinados delitos medioambientales, de 4 de noviembre de 2009, Moción enfocada en el perfeccionamiento de la Ley General de Pesca, presentada por los H. Diputados Enrique Accorsi, Gabriel Ascencio, Roberto León, Juan Lobos, Osvaldo Palma, Denise Pascal y Patricio Vallespín, en primer trámite constitucional, sin informe de la Comisión respectiva.

Sin embargo, salvo lo que más adelante se dirá respecto del Proyecto contenido en el Boletín No 6754-12, es difícil que alguno de estos proyectos puedan concluir satisfactoriamente su tramitación, habida cuenta del hecho de que no pudieron considerar en su formulación las reformas introducidas por la mencionada Ley $\mathrm{N}^{\mathrm{o}} 20.417$. En cuanto a los proyectos analizados en MATUS, Derecho Penal del Medio Ambiente, cit. nota al pie $\mathrm{N}^{\mathrm{o}} 33$, pp. 216 y ss., contenidos en las mociones parlamentarias de los Diputados Sres. Aníbal Pérez, Juan Bustos, Luksic, Elgueta, Sánchez, Encina, Ojeda, José Pérez, Mora y Rincón sobre un proyecto de ley que tipifica el delito medioambiental (Boletín 2177-12); y de los Diputados Sres. Alessandri, don Gustavo; Delmastro, don Roberto; Arratia, don Rafael; Navarro, don Alejandro; Acuña, don Mario, y Sánchez, don Leopoldo sobre el proyecto de ley que establece penalidades a los vertederos clandestinos (Boletín 2401-12), se encuentran actualmente archivados.

${ }^{83}$ Aparte de los mencionados en el texto, cabe hacer presente que durante el segundo gobierno de la Presidenta Bachelet, el Ministerio del Medio Ambiente estableció una mesa de trabajo para elaborar un proyecto de ley que, en los términos coloquiales de los encargados, denominan de "delitos penales ambientales". El trabajo de 
a) El modelo basado en la codificación alemana, contemplado tanto en el Proyecto de Ley iniciado por Moción de la H. Senadora Isabel Allende, que incorpora en el Título III del Libro Segundo del Código Penal un párrafo que tipifica y sanciona delitos contra el medio ambiente y adecua la legislación vigente en la materia (Boletín $\mathrm{N}^{\circ}$ 8920-07, de 6 de mayo de 2013); como en el Proyecto de Ley iniciado por Mensaje del Sr. Presidente de la República, Sebastián Piñera, que establece un nuevo Código Penal (Boletín N 9274-07, de 10 de marzo de 2014); y

b) El modelo del Anteproyecto del Foro Penal, de $2005^{84}$, contemplado en el Proyecto de Ley iniciado por Moción de los H. Senadores Girardi, De Urresti, Horvath, Navarro y Walker, que sanciona delitos contra el medio ambiente (Boletín $\mathrm{N}^{\circ}$ 9367-12, de 3 de junio de 2014).

Analizaremos a continuación el detalle de los proyectos en actual tramitación que dicen relación con la regulación sistemática de los delitos de contaminación, para, sin entrar en una disputa acerca de la conveniencia o no de seguir los modelos que adoptan, profundizar en los aspectos técnicos que pueden permitir o no su éxito, en el evento que exista real consenso político para sancionar penalmente la grave contaminación ambiental.

\subsection{Proyectos basados en el modelo alemán}

En resumen, el modelo alemán separa la protección penal de los distintos medios del ambiente (agua, suelo, aire), e incluso las diferentes formas en que a través de ella se protege la salud y vida humana, animal y vegetal; y contempla algunos delitos donde también las funciones de control de la administración aparecen como objeto jurídico de protección penal en primer lugar, sobre todo en las figuras donde la sola conducta no autorizada es punible, como sucede respecto a las instalaciones de energía nuclear ( $\$ 329$ StGB). Pero, por regla general, se prefiere establecer al menos delitos de lesión o daño. En todos los casos, además, se recurre a la técnica de la ley penal en blanco, mediante la utilización de remisiones al actuar "indebido", o "contrario a los deberes impuestos por el derecho administrativo" ( $\$ 324$ y $324 S t G B)$, y se acepta que la ley penal se encuentre relativamente subordinada o sea accesoria a las disposiciones administrativas, en el sentido no sólo de las remisiones a

la "mesa" se hizo público en el Seminario organizado el 25 de junio del año 2015 en la Facultad de Derecho de la Universidad de Chile (véase la nota de prensa http://www.sma.gob.cl/index.php/noticias/notas/559-serealiza-primer-seminario-de-derecho-penal-y-proteccion-del-medio-ambiente [visitado el 20.10.2017]. Sin embargo, sus conclusiones, al igual que la propuesta del Anteproyecto de Código Penal de 2015, no se encuentran disponibles al público para su discusión científica. Atendido el rol que jugó en ese período Jorge Cash como Director Jurídico del Ministerio del Medio Ambiente, es posible que dicho trabajo siguiera la propuesta de su Memoria de Grado, basado en la idea de distinguir, siguiendo estrictamente los conceptos de la Ley N ${ }^{0} 19.300$, entre delitos de "grave contaminación ambiental", "cuando el ilícito sea consecuencia de la infracción a una norma reglamentaria; y de "grave daño ambiental", "cuando el perjuicio no tenga como antecedente la infracción normativa, sino, que provenga de un hecho cuya hipótesis se encuentra descrita en la norma punitiva" (CASH, Jorge, Propuesta de régimen Sancionatorio Penal Ambiental en base a un Sistema Mixto de Responsabilidad, como Instrumento de Prevención de Daños al Medio Ambiente, Santiago: Tesis UChile, 2011, pp. 183ss).

${ }^{84}$ Este modelo, como se explica en los antecedentes legislativos, recoge explícitamente la propuesta contenida en MATUS, Derecho Penal del Medio Ambiente, cit., nota al pie No 33, pp. 229 y ss. 
MATUS, Jean Pierre; RAMIREZ, María Cecilia; CASTILLO, Marcelo.

"Acerca de la necesidad de una reforma urgente de los delitos de contaminación en Chile, a la luz de la evolución legislativa del siglo XXI”.

las normas administrativas, sino también cuando se trata de tomar "prestados" conceptos propios del derecho administrativo, tales como "residuos" o "establecimientos de energía nuclear”. Y no se establece la responsabilidad penal de las personas jurídicas ${ }^{85}$.

Como veremos a continuación, la mayor parte de estas características son compartidas por los proyectos de 2013 de la H. Senadora Allende (Boletín $N^{\circ}$ 8920-07) y la regulación contamplada en el Proyecto de Código Penal de 2014 (Boletín $\mathrm{N}^{\circ}$ 9.274-07).

4.1.1. Proyecto de ley contenido que incorpora en el Título III del Libro Segundo del Código Penal, párrafo que tipifica y sanciona delitos contra el medio ambiente (Boletín $\mathrm{N}^{\circ}$ 8920-07)

Este proyecto de ley fue iniciado por Moción de la Honorable senadora señora Isabel Allende Bussi, con fecha 7 de marzo de 2013. Actualmente, se encuentra en su primer trámite constitucional, en la Comisión de Medio Ambiente y Bienes Nacionales del Senado, sin que hasta el momento se haya dado cuenta del Informe de dicha Comisión ante la Sala.

Según su autora, la protección penal del medio ambiente se fundamenta en el deber del Estado de velar por la no afectación del derecho a vivir en un ambiente libre de contaminación y de tutelar la preservación de la naturaleza, contenido en el Art. $19 \mathrm{~N}^{\circ} 8$ de nuestra Carta Fundamental. Agrega que, en la actualidad, el sistema de persecución criminal está siendo utilizado cada vez con mayor fuerza para dar protección al medio ambiente, lo cual se explicaría en una decisión adoptada por el Ministerio Público en orden a intentar otorgar tutela al medio ambiente, a través de los tipos penales hoy vigentes. Sin embargo, sostiene que existe un problema debido a que esos tipos penales son de antigua data, y, si bien se vinculan con los elementos que integran el medio ambiente, no lo reconocen como bien jurídico tutelado y parecen insuficientes para que el Ministerio Público pueda resolver de manera adecuada y proporcional las denuncias que se someten a su conocimiento, siendo "habitual que en estas materias apreciemos la imposición de sanciones por situaciones de bagatela o de poca monta y que hipótesis de mayor gravedad carezcan de tipos penales que les sean aplicables". Señala la Senadora Allende que, a este complejo escenario, debemos sumar el hecho de que la Ley $\mathrm{N}^{\circ} 20.417$ no contempló ninguna medida de coordinación con la persecución penal de situaciones de afectación del medio ambiente, todo lo cual genera, en este ámbito, fuertes niveles de inseguridad (desde la perspectiva de quien sufre la persecución) y relevantes lagunas de impunidad (desde la perspectiva del persecutor y la ciudadanía).

El proyecto propuesto dice tomar como punto de partida un concepto más restrictivo de medio ambiente que el establecido en la Ley No 19.300 , entendido como el conjunto de "los intereses de las generaciones presentes en mantener para sí, y para las generaciones

${ }^{85}$ Véase MATUS, Derecho Penal del Medio Ambiente, cit., nota al pie № 33, pp. 54-86, con notas y referencias bibliográficas. Para una visión general, con literatura más actualizada, puede consultarse , HEINE, Günter; HECKER, Bernd, Comentarios a los Arts. 324ss del Código penal, en SCHÖNKE/SCHRÖDER, Strafgestzbuch Kommentar, 29. Ed., München: Ch. Beck, 2014, pp. 2991-3090. 
venideras, determinados elementos indispensables para el desarrollo de la existencia de condiciones tales que aseguren una adecuada relación de uso-preservación de los recursos naturales", "de naturaleza colectiva, residiendo su titularidad en la sociedad toda, en cuanto a su respecto nadie puede ser excluido en el uso de estos recursos y su consumo se a todas las personas, en la medida de que se efectúe de conformidad al ordenamiento jurídico nacional". La finalidad de la Moción es establecer un completo reordenamiento del Derecho Penal del Medio Ambiente, no sólo sancionando la grave contaminación y el daño ambiental, reforzando de paso el sistema de prohibiciones contemplado en la regulación administrativa, sino modificando toda la regulación en la materia, incluyendo la protección de las especies animales y vegetales, los recursos hidrobiológicos, la masa forestal y el tráfico de residuos peligrosos. Es por ello que propone agregar 16 nuevos artículos al Código Penal, contenidos en el que sería el Párrafo $5^{\circ}$ del Título III del Libro Segundo, titulado "De los Delitos contra el Medio Ambiente", lo que, según se reconoce "implicará derogar o modificar buena parte del catálogo de tipos penales que hoy se usa en la materia", con la finalidad de "evitar problemas de aplicación e interpretación"86.

En detalle, los delitos de contaminación y daño ambiental propuestos son los siguientes:

a) Contaminación del agua, suelo y atmósfera con grave afectación del ambiente (Arts. 161-C, 161-D y 161-E del Código penal). Se castiga el vertimiento, la introducción y la emisión de contaminantes en el agua, el suelo y el aire, siempre que se haya verificado una infracción de las obligaciones establecidas en alguno de los instrumentos de gestión ambiental de la Ley $N^{\circ} 19.300$ y se produzca una grave afectación del ambiente. Se sanciona, además, en los mismos artículos, la hipótesis negligente y, separadamente la comisión por omisión (Art. 161-I);

b) Daño ambiental con grave afectación de zonas protegidas y glaciares (Art. 161-F). Se castiga el daño ambiental que produce una grave afectación del medio ambiente, efectuada

\footnotetext{
${ }^{86}$ En efecto, aparte de los delitos de contaminación y daño ambiental que analizaremos, la Moción propone una modificación sustancial del régimen de protección de las especies animales y los recursos hidrobiológicos, a través de la sanción de la caza, pesca, captura y afectación de especies de la fauna que cuenten con protección oficial o recursos hidrobiológicos que se encuentren en veda, incumpliendo una prohibición legal o reglamentaria, hipótesis respecto de la cual se castiga su comisión por omisión (Art. 161-I) y cuya pena se agrava si se realiza a través de elementos tóxicos, explosivos, redes prohibidas u otros capaces de generar estragos. Se castiga también el tráfico de flora y fauna que cuente con protección oficial (Art. 161-J), y la tala, corte o destrucción de árboles protegidos (Art. 161-K) que se realice con infracción de ley, de reglamento o de su autorización, o sin contar con las autorizaciones pertinentes; y al que introduzca, libere o disemine especies de flora o fauna no autóctona, u otros organismos, agentes químicos, bacteriológicos, virales o de cualquier otro orden, aptos para poner en riesgo la supervivencia de la flora y fauna que cuenta con protección oficial (Art. 161-L). Finalmente, en el Art. 161-LL, se castiga el tráfico de residuos peligrosos, además de la explotación de instalaciones en las que se realice una actividad peligrosa, todo ello, con infracción de ley, de reglamento o de su autorización o sin contar con ella, previéndose un agravamiento de pena en caso que, a consecuencia de dichas conductas, se produzca una grave afectación del medio ambiente o sus componentes. Todo lo anterior es complementado por seis artículos que introducen diversas modificaciones y derogaciones a las figuras que actualmente protegen el medio ambiente, tanto en el Código Penal como en las leyes especiales.
} 
MATUS, Jean Pierre; RAMIREZ, María Cecilia; CASTILLO, Marcelo.

"Acerca de la necesidad de una reforma urgente de los delitos de contaminación en Chile, a la luz de la evolución legislativa del siglo XXI".

por cualquier medio, en zonas protegidas y glaciares. Se sanciona, además, la hipótesis negligente y, en artículo separado, su comisión por omisión (Art. 161-I);

Puesto que la Moción señala expresamente que "se excluyen de la sanción penal las meras contravenciones de la regulación medio ambiental", para aplicar estas disposiciones propone en el Art. 161-G los siguientes "criterios que deberán tomarse en cuenta" para calificar como grave afectación el vertimiento, la introducción o la emisión de contaminantes o el daño ambiental: "1.- La magnitud de los efectos: se deberán considerar aspectos relativos a su extensión espacial, la cantidad de personas o comunidades afectadas, su duración y/o la particular peligrosidad de las acciones realizadas o de las sustancias liberadas"; "2.Reversibilidad de los efectos: se deberá tener en cuenta si los efectos producidos pueden ser reparados. La reversibilidad deberá considerar la factibilidad de la reparación desde una perspectiva temporal, técnica y económica"; y "3.- Valor ecológico: se tendrá en consideración aspectos relativos a la rareza y sensibilidad de las especies, comunidades y ecosistemas afectados".

Además, la Moción contempla penas y reglas especiales de determinación de la pena en sus Arts. $161 \mathrm{M}$ a O, a saber: agravante especial para el caso en que, producto de las conductas punibles se ocasionen lesiones o muertes (Art. 161-M); agravante por incumplimiento instrucciones otorgadas por alguna autoridad con competencia ambiental (Art. 161-N); y atenuantes especiales de auto denuncia, reparación y mitigación del daño ambiental (Art. 161-N). Entre las penas especiales, en el Art.161-ÑN, se establece como penas accesorias aplicables a estos delitos el comiso de los efectos y medios utilizados para cometer el delito, la inhabilitación absoluta para desarrollar la actividad, profesión u oficio que haya dado lugar a la comisión del delito sancionado por el tiempo que dure la condena, y la prohibición de que el autor del delito vuelva a requerir autorizaciones a las autoridades ambientales o sectoriales por el tiempo que dure la condena. Por último, el proyecto contiene una regla concursal especial, para el caso en que una misma conducta ejecutada por el mismo autor, dé lugar a dos o más delitos establecidos en el párrafo $5^{\circ}$, caso en el cual se aplicará la pena asignada al delito más grave, aumentada en uno o dos grados (Art. 161-O).

En cuanto a los delitos de contaminación y daño ambiental, el Proyecto viene a llenar el vacío denunciado en la legislación actual y que, por lo mismo, ha de valorarse positivamente. También ha de valorarse en este sentido la pretensión de que "se excluyan de la sanción penal las meras contravenciones de la regulación medio ambiental” (Punto V.6 de la Moción), que se logra con la introducción del concepto de grave afectación, y la propuesta de establecer un régimen concursal y de atenuantes y agravantes adecuado a la naturaleza de los delitos que se tratan.

Sin embargo, en su formulación, el Proyecto adolece de importantes problemas técnicos. En efecto, en primer lugar, en su fundamentación, la Moción que lo contiene plantea que "se consagra expresamente un régimen de accesoriedad conceptual con la regulación medio ambiental" (punto V.5), en circunstancia que ello no es así, al menos no plenamente. Desde luego, a pesar de la expresa mención a la infracción los instrumentos de gestión ambiental (resoluciones de calificación, planes prevención y descontaminación, etc.) y de la referencia 
del proyectado Art. 161-P acerca de entender las expresiones de los tipos penales conforme a su definición legal, lo cierto es que el proyectado Art. 161-G ofrece conceptos diferentes de los que ha de entenderse por grave afectación al ambiente, en relación con las definiciones de lo que el Art. $36 \mathrm{~N}^{\circ} 1$ de la Ley N²0.417 entiende como infracciones gravísimas ("daño ambiental, no susceptible de reparación" o haber "afectado gravemente la salud de la población", por ejemplo), de donde podría ser el caso que un fiscal del Ministerio Público calificase de delito un hecho que la Superintendencia del Medio Ambiente entienda como infracción que no alcanza a ser gravísima y, viceversa, que lo que la administración entienda como gravísimo no sea considerado como delito por el sistema de justicia criminal.

Este problema se agrava por el hecho de que la Moción no contempla reglas de coordinación entre la actividad sancionatoria de la Superintendencia del Medio Ambiente y la del Ministerio Público.

Además, al vincular los delitos de contaminación y daño ambiental con toda la regulación existente en materia ambiental, incluyendo las resoluciones de calificación ambiental, por una parte, se considera como elementos normativos de los delitos en cuestión disposiciones de carácter particular, que no tienen el rango de Decreto Supremo de aplicación general y, por lo mismo, difícilmente pueden superar el test de densidad normativa impuesto por el Tribunal Constitucional ${ }^{87}$; y, por otra, limita la aplicación de la ley a la existencia de tales normas que, tratándose de las normas de emisión chilenas, no necesariamente tienen carácter general ni abarcan todas las clases de emisiones posibles ${ }^{88}$. Además, se debe tener presente

${ }^{87}$ Según STC Rol N ${ }^{\circ} 781-07$ (Considerando $17^{\circ}$ ), el test de densidad normativa importa tanto un requisito material, esto es, que la norma remitida no complemente la disposición con expresiones vagas e imprecisas; como uno formal, en el sentido que dicha norma debe ser producto del ejercicio de la potestad reglamentaria del Poder Ejecutivo, debiendo por tanto emitirse en la forma de un Decreto Supremo y no bajo otros mecanismos como son los decretos exentos u otros actos de la administración”.

${ }^{88}$ Actualmente se han dictado sólo las siguientes normas de emisión, de aplicación general:

a) Respecto de contaminantes en el aire, por fuentes móviles: D.S. $\mathrm{N}^{\circ}$ 211, de 1991 (Transportes y Telecomunicaciones), que establece normas sobre emisiones de vehículos motorizados livianos; D.S. $\mathrm{N}^{\circ} 185$, de 1992 (Minería), que reglamenta funcionamiento de establecimientos emisores de anhídrido sulfuroso material particulado y arsénico en todo el territorio de la República; D.S. N 82, de 1993 (Transportes y Telecomunicaciones), que establece normas de emisión a vehículos y motores que indica; D.S. N 55 , de 1994 (Transportes y Telecomunicaciones), que establece normas de emisión aplicables a vehículos motorizados pesados que indica; D.S. N 54, de 1994 (Transportes y Telecomunicaciones), que establece normas de emisión aplicables a vehículos motorizados medianos que indica; D.S. No 104, de 2000 (Transportes y Telecomunicaciones), norma de emisión para motocicletas; D.S. $\mathrm{N}^{\mathrm{o}}$ 130, de 2002 (Transportes y Telecomunicaciones Subsecretaria de Transportes), normas de emisión de Co, Hct, Hcnm, Ch4, Nox y material particulado para motores de buses de locomoción colectiva de la ciudad de Santiago; D.S. N ${ }^{\circ} 103$, de 2000 (Transportes y Telecomunicaciones y Comisión Nacional del Medio Ambiente), norma la emisión de hidrocarburos no metánicos para vehículos livianos y medianos; D.S. No 4, de 1994 (Transportes y Telecomunicaciones), normas de emisión de contaminantes aplicables a los vehículos motorizados; D.S. $\mathrm{N}^{\circ}$ 149, de 2007 (Transportes y Telecomunicaciones, Subsecretaria de Transportes), que establece norma de emisión de NOHC y CO para el control del NOX en vehículos en uso de encendido por chispa (ciclo otto) que cumplen con las normas de emisión establecidas en el D.S. No 211, de 1991 y D.S. No 54 de 1994;

b) Respecto de la contaminación del aire por otras fuentes: D.S. $\mathrm{N}^{\circ} 32$, de 1990 (Salud), que establece el reglamento de funcionamiento de fuentes emisoras de contaminantes atmosféricos que indica en situaciones de 
MATUS, Jean Pierre; RAMIREZ, María Cecilia; CASTILLO, Marcelo.

"Acerca de la necesidad de una reforma urgente de los delitos de contaminación en Chile, a la luz de la evolución legislativa del siglo XXI".

que la infracción a estas normas no necesariamente representa un caso de gravedad suficiente, pues actualmente ellas se emplean como instrumentos de gestión ambiental, que permiten el gradual acercamiento de las fuentes a los límites que se fijan para cada una de ellas, en relación con los objetivos fijados en las Normas de Calidad Ambiental, lo que supone considerar el efecto acumulativo de ciertas emisiones en determinados ámbitos territoriales que, por lo mismo, no permite tomarlas en general como indicadores de la gravedad intrínseca de la emisión de contaminantes en cada fuente, individualmente considerada.

Adicionalmente, aún de aceptarse la posibilidad de configurar estos delitos basados en la infracción de las normas de gestión ambiental, su aplicación podría dirigirse tendencialmente a castigar a los titulares de proyectos que se encuentran dentro del sistema de gestión, favoreciendo indirectamente las actividades ilegales, fuera del sistema de protección del medio ambiente. Sobre ello, cabe recordar que la Ley $N^{\circ} 19.300$ sobre Bases Generales del Medio Ambiente entró plenamente en vigencia el 3 de abril de 1997, por lo que sólo a partir de dicha fecha los proyectos o actividades debieron ingresar obligatoriamente al Sistema de Evaluación de Impacto Ambiental.

Por otro lado, es muy criticable la deliberada decisión de que "no se consagra la responsabilidad penal de la persona jurídica en cuanto se estima que esta materia se encuentra

emergencia de contaminación atmosférica; D.S. N 185, de 1992 (Minería), que reglamenta funcionamiento de establecimientos emisores de anhídrido sulfuroso, material particulado y arsénico en todo el territorio de la República; D.S. $\mathrm{N}^{\circ}$ 4, de 1992 (Salud), que establece norma de emisión de material particulado a fuentes estacionarias puntuales y grupales; D.S. N 1583, de 1993 (Salud), que establece norma de emisión de material particulado a fuentes estacionarias puntuales que indica; D.S. No 167, de 1999 (Secretaría General de la Presidencia), norma de emisión para olores molestos; D.S. No . 165, de 1999 (Secretaría General de la Presidencia), Norma de emisión para la regulación del contaminante arsénico emitido al aire; D.S. N¹3, de 2011 (Medio Ambiente), que establece norma de emisión para centrales termoeléctricas; D.S. N 39, de 2012 (Medio Ambiente), que Establece norma de emisión de material particulado para los artefactos que combustionen o puedan combustionar leña y pellet de madera; D.S. $\mathrm{N}^{\circ}$ 37, de 2013 (Medio Ambiente), que Establece norma de emisión de compuestos TRS generadores de olor asociados a la fabricación de pulpa kraft o al sulfato; D.S. $\mathrm{N}^{\circ}$ 29, de 2013 (Medio Ambiente), que establece norma de emisión para incineración, coincineración y coprocesamiento; D.S. N ${ }^{\circ}$ 28, de 2013 (Medio Ambiente), que establece norma de emisión para fundiciones de cobre y fuentes emisoras de arsénico;

c) Respecto de la emisión de contaminantes en las aguas: D.S. N 609, de 1998 (Obras Públicas), que establece norma de emisión para la regulación de contaminantes asociados a las descargas de residuos industriales líquidos a sistemas de alcantarillado; D.S. No 90, de 2001 (Secretaría General de la Presidencia), norma de emisión para la regulación de contaminantes asociados a las descargas de residuos líquidos a aguas marinas y continentales superficiales; y D.S. 46, de 2002 (Secretaría General de la Presidencia), norma de emisión de residuos líquidos a aguas subterráneas;

d)Respecto de la emisión de contaminación lumínica en las II, III y IV Regiones: D.S. No 686 de 1999 (Ministerio de Economía Fomento y Reconstrucción), Norma de emisión para la regulación de la contaminación lumínica; Decreto N43, de 3 de mayo de 2013 (Ministerio del Medio Ambiente), que Establece norma de emisión para la regulación de la contaminación lumínica;

e) Respecto de la contaminación por ruidos molestos: D.S. No 146, de 1998 (Secretaría General de la Presidencia), norma de emisión de ruidos molestos generados por fuentes fijas; D.S. $\mathrm{N}^{\circ} 129$, de 2003 (Transportes y Telecomunicaciones), que establece norma de emisión de ruidos para buses de locomoción colectiva urbana y rural; D.S. N³8, de 2012 (Medio Ambiente), que Establece norma de emisión de ruidos generados por fuentes que indica. 
Polít. crim. Vol. 13, No 26 (Diciembre 2018) Art. 4, pp. 771-835.

[http://www.politicacriminal.cl/Vol_13/n_26/Vol13N26A4.pdf]

suficientemente abordada a través de los mecanismos establecidos en la ley 20.417 y a efectos de evitar infracciones al principio de non bis in idem" (Punto V.9. de la Moción).

En efecto, como ha resuelto nuestro Tribunal Constitucional, la existencia de sanciones administrativas en paralelo a las de carácter penal no es, per se, indicativa de un bis in idem, dado que "las posibilidades sancionatorias son amplias y muchas veces el legislador podrá concurrir, legítimamente, a fijar penas principales, penas accesorias, penas penales junto a sanciones administrativas o consecuencias no penales derivadas o anudadas a una pena penal", con la única limitación de que "en todas las situaciones, habrá que estar al caso concreto de cautela de los bienes jurídicos protegidos, su proporcionalidad y su respeto a la interdicción de la doble incriminación por el triple fundamento de identidad en la persona, la conducta y sus fundamentos" 89 . En consecuencia, la cuestión a determinar es si el conjunto de sanciones a imponer es o no proporcional a la infracción y si, en el caso concreto, existen diferentes fundamentos para su imposición conjunta. $Y$, en este caso concreto, la comparación de las sanciones penales y administrativas por hechos de grave contaminación, especialmente en caso de reiteración, no resulta a primera vista desproporcionada ni una simple acumulación de sanciones de la misma naturaleza, considerando que en el ámbito de la Ley No 20.393 se puede aplicar la disolución para tales graves y extremos casos, medida inexistente en el ámbito meramente administrativo. Por otra parte, en cuanto a sus fundamentos, como se expresó en los apartados anteriores, el sistema de compliance previsto en la Ley $\mathrm{N}^{\circ} 20.393$ es principalmente de carácter preventivo, mientras que el de la Ley № 20.417 es de carácter reactivo a la fiscalización, por lo que no se superpondrían sino que, al contrario, se complementarían.

\subsubsection{Proyecto de Código Penal del año 2014 (Boletín N 9.274-07)}

Este Proyecto de nuevo Código Penal inició su tramitación el día lunes 10 de marzo de 2014, por Mensaje Presidencial remitido en su último día de mandato por el entonces Presidente S. Piñera al Senado, y contiene un título completo dedicado a los delitos contra el Medio Ambiente (Título XIII del Libro Segundo). Sin embargo, salvo su ingreso y la cuenta en Sala que ordenó pasar su discusión a la Comisión de Constitución, Legislación y Reglamento del Senado, del día 12 de marzo de ese año, el Proyecto no ha tenido movimiento alguno, atendido el cambio político en la Presidencia de la República, del día 11 de ese mes, pasando a desempeñar el cargo la Presidenta M. Bachelet.

En el Mensaje Presidencial, se establece que el proyecto incluye la regulación sistematizada y ordenada de estos delitos, cuya justificación se encontraría en "la presencia de nuevos riesgos" que "ha traído como consecuencia la necesidad de tipificación en ámbitos de criminalidad con un sustrato técnico que resulta ajeno a los métodos de comisión del clásico Derecho Penal", lo que tendría como consecuencia "la acogida a recientes formas de delincuencia y la agravación general de las penas imponibles a delitos ya existentes". "De esta manera — añade el Mensaje — se busca recoger la preocupación nacional e internacional

${ }^{89}$ STC 26.11.2013, Rol No 20402-2013. 
MATUS, Jean Pierre; RAMIREZ, María Cecilia; CASTILLO, Marcelo.

"Acerca de la necesidad de una reforma urgente de los delitos de contaminación en Chile, a la luz de la evolución legislativa del siglo XXI”.

por los peligros que, para la vida y la salud, entrañan la contaminación producida en los distintos elementos que nos rodean, fruto de la degradación ambiental". Además, junto con la tipificación de estos delitos, se establecen ciertas reglas generales de importancia en este contexto: a) la que da competencia a los tribunales nacionales para la aplicación de la ley penal chilena a los hechos "que pongan en peligro la salud de los habitantes del territorio chileno o el medio ambiente en el territorio chileno" (Art. $4^{\circ}, \mathrm{N}^{\circ} 5^{\circ}$ ); b) las que establecen penas accesorias de prohibición de permisos de caza y pesca, así como la prohibición de celebrar actos y contratos con el Estado para los responsables de los delitos contra el medio ambiente (Art. 145, Nos 4 y 5); c) la que impone a dichas personas la prohibición de ingresar a áreas protegidas por el Estado, como condición para conceder la libertad vigilada (Art. 170); y d) la que considera asociación ilícita la que tiene dentro de su actividad permanente la comisión de esta clase de delitos (Art. 584). Sin embargo, a pesar de que el Proyecto amplía el ámbito actual de la responsabilidad de las personas jurídicas, más allá del reducido alcance de la actual Ley $\mathrm{N}^{\circ} 20.393$, lo cierto es que no se contempla la imposición de esta clase de sanciones para las personas jurídicas cuyos directivos o empleados sean responsables de esta clase de delitos.

En cuanto a los delitos en particular contra el medio ambiente, el Título XIII del Libro Segundo del proyecto de Código Penal de 2014 contempla como primera figura punible un delito de grave afectación al ambiente por contaminación o daño, tanto doloso como imprudente, castigando en el Art. 504 al que,

“con infracción de sus deberes y ocasionando con ello la afectación grave de uno o de varios de varios de los componentes del medio ambiente:

$1^{\circ}$ vertiere contaminantes en aguas marítimas o continentales;

$2^{\circ}$ extrajere aguas continentales, superficiales o subterráneas;

$3^{\circ}$ introdujere contaminantes en el suelo o en el subsuelo, continental o marítimo;

$4^{\circ}$ extrajere tierras del suelo o del subsuelo;

$5^{\circ}$ emitiere contaminantes al aire."

El Art. 505 define qué ha de entenderse con infracción de deberes, estableciendo, en primer lugar, que se trata de los casos en que se incumpliere un instrumento de gestión ambiental (normas de emisión o de calidad ambiental, planes de prevención, descontaminación o manejo, y también resoluciones de calificación ambiental u otro permiso). Sin embargo, ello no se aplica, en el caso de la emisión de contaminantes en el aire respecto de aplicable "respecto de las emisiones provenientes de vehículos sujetos a inscripción en el Registro Nacional de Vehículos Motorizados y de sistemas de calefacción o refrigeración domésticos", según dispone el inciso final del Art. 504.

El Art. 505 estima, además, como infracción de deberes, el haberse prescindido de someter la actividad al Sistema de Evaluación Ambiental, debiendo haberse hecho, o no se hubieren obtenido los permisos de carácter ambiental que hubieren sido exigibles. De este modo, la burla del sistema de protección del medio ambiente es castigada penalmente sólo en caso que ella preceda a una grave afectación o daño al medio ambiente. 
Por grave afectación al medio ambiente, el Art. 507 establece que se produce cuando, respecto de alguno de los componentes del medio ambiente, "existe un cambio adverso mensurable" y se presenta alguna de las siguientes condiciones: " $1{ }^{\circ}$. que tenga una extensión espacial de relevancia, teniendo en cuenta las particularidades ecológicas o geográficas de la zona afectada; $2^{\circ}$. que sus efectos tengan una duración prolongada en el tiempo; $3^{\circ}$. que sea irreparable o difícilmente reparable; $4^{\circ}$. que alcance a un número significativo de especies, según las características de la zona en que se produce; $5^{\circ}$. que afecte especies categorizadas como extintas, extintas en grado silvestre, en peligro crítico o en peligro o vulnerable; $6^{\circ}$. que ponga en peligro la salud de las personas."

Además, el Proyecto contempla, en el Art. 506, un caso especial de daño al medio ambiente, castigando al que, dolosa o imprudentemente, afectare gravemente un área protegida y al que, con infracción de una resolución de calificación ambiental o sin haberse sometido a ella, afectaren un glaciar.

A dicha figura especial, el Proyecto añade un delito de tráfico de residuos peligrosos (Art. 508), una reformulación de los delitos de caza y pesca ilegales (Art. 509 a 511), un delito de atentado contra la salud animal o vegetal (Art. 51) y otro respecto del bosque nativo (Art. 513).

Por último, siguiendo el sistema general del Proyecto ${ }^{90}$, los Arts. 514 y siguientes contemplan una serie de reglas comunes, aplicables a los delitos consagrados en el título, como son: agravantes especiales (Art. 514) ${ }^{91}$, la consideración de agravante muy calificada para los delitos de lesiones graves u homicidio, en el caso de que la "grave afectación" al medio ambiente haya causado dichos resultados (Art. 515) ${ }^{92}$; atenuantes especiales de auto denuncia y reparación ambiental (Art. 516) ${ }^{93}$, normas de determinación de las penas de día-multa (Art.

${ }^{90}$ Cuyo "catálogo de atenuantes y agravantes genéricas es bastante restringido, privilegiando atenuantes y agravantes especiales de acuerdo a la naturaleza de los delitos de la parte especial", según reza el Mensaje.

${ }^{91}$ Art. 514. Agravantes. Serán circunstancias agravantes para los efectos de este título las siguientes:

1. desobedecer órdenes o resoluciones de la autoridad;

2. ocultar información ante procesos de control o fiscalización ambiental, siempre que el hecho no constituyere delito por sí mismo;

3. afectar el suministro de un servicio público.

92 Art. 515. Muerte o lesiones graves. Si con ocasión de la comisión de los delitos previstos en el Párrafo 1 de este título el responsable matare a una persona o le irrogare alguna de las lesiones previstas en el inciso primero del artículo 222, el tribunal estimará el hecho como una agravante muy calificada para determinar la pena correspondiente a los delitos de homicidio o lesiones.

La pena a que se refiere y ordena agravar el inciso anterior se impondrá también si con motivo u ocasión de la comisión del delito el responsable causare la muerte o lesiones graves a una persona y ello fuere imputable a imprudencia temeraria. Si la muerte o las lesiones graves fueren imputables a simple imprudencia del responsable, el tribunal estimará el hecho como una agravante muy calificada de la pena que corresponda imponer conforme a las reglas generales.

En lo demás, para la aplicación de las penas antedichas junto con la pena establecida en los artículos de este título se estará a lo dispuesto en el artículo 82 ”.

${ }^{93}$ Art. 516. Atenuantes. Serán circunstancias atenuantes para los efectos de este título las siguientes:

1. la autodenuncia del responsable; 
MATUS, Jean Pierre; RAMIREZ, María Cecilia; CASTILLO, Marcelo.

"Acerca de la necesidad de una reforma urgente de los delitos de contaminación en Chile, a la luz de la evolución legislativa del siglo XXI”.

517), de prohibición de caza y pesca y de la medida de seguridad de prohibición de ingreso a áreas protegidas (Art. 518); y la regla que declara dependencia conceptual de estas normas con la legislación ambiental (Art. 519).

Las similitudes técnicas de este Proyecto - presentado por un Presidente representante de una coalición de partidos de centro derecha - con el contenido en la Moción suscrita por la Senadora del Partido Socialista I. Allende, antes analizado, nos permiten, por una parte, destacar un aspecto central de lo que hasta aquí se ha dicho: que existe una aparente transversalidad o consenso amplio en el mundo político en orden a sancionar penalmente los graves atentados contra el medio ambiente. Y, por otra, resumir las críticas posibles al texto presentado, como pasamos a explicar a continuación.

En primer lugar, en cuanto a los delitos de contaminación y daño ambiental, el Proyecto también viene a llenar el vacío denunciado en la legislación actual, por lo que ha de valorarse positivamente, lo mismo que la limitación al castigo exclusivo de la grave contaminación o daño ambiental. Sin embargo, al igual que la Moción de la Senadora Allende, en su formulación, el Proyecto adolece de algunos problemas técnicos relevantes: a pesar de consagrar una regla de accesoriedad conceptual en el Art. 519, los conceptos relevantes, esto es, la determinación de la grave afectación, contaminación o daño ambiental se expresan de espaldas a la regulación de la Ley $\mathrm{N}^{\circ} 20.417$, sin tomar en cuenta lo que allí se define como infracciones gravísimas. Además, al remitir el concepto de infracción de deberes a normativa contingente y particularizada, como son las resoluciones de calificación y los planes prevención y descontaminación, se aparta de las exigencias que para la adecuada formulación de tipos penales con leyes penales en blanco ha establecido nuestro Tribunal Constitucional (Decreto Supremo del Presidente de la República). Tampoco contempla reglas de coordinación entre la actividad sancionatoria de la Superintendencia del Medio Ambiente y la del Ministerio Público, lo que podría llevar al absurdo que situaciones que el Ministerio Público entendiese como delitos, fuesen calificadas como infracciones leves o simplemente graves por la Superintendencia.

En cuanto a la sanción a la burla del sistema de protección, el Proyecto de Código Penal avanza respecto de la Moción, al considerar que la burla directa es un antecedente para sancionar la grave contaminación. Sin embargo, tendencialmente, al no castigar la burla de manera autónoma (o, al menos, no considerarla agravante), favorece a quienes realizan sus actividades fuera del sistema de control frente a quienes están sometidos al mismo y, por tanto, a un mayor riesgo de sanción. No obstante, la agravante prevista en el $\mathrm{N}^{\mathrm{o}} 2$ del Art. 514 (omitir información a la autoridad), sumadas al sistema general de castigo de

2. el desarrollo de actividades inmediatas tras la consumación del delito cuya finalidad sea la evitación de ulteriores consecuencias que sean lesivas respecto de los componentes del medio ambiente o la salud de las personas;

3. el aviso inmediato y por medios efectivos de la ocurrencia del delito y de todas sus consecuencias a las autoridades con competencia ambiental y sanitaria, y a las comunidades o personas que puedan verse afectadas por éstas. 
Polít. crim. Vol. 13, № 26 (Diciembre 2018) Art. 4, pp. 771-835.

[http://www.politicacriminal.cl/Vol_13/n_26/Vol13N26A4.pdf]

presentaciones falsas ante las autoridades (Art. 405), son también aspectos positivos que deben valorarse.

Finalmente, también es criticable que un Proyecto de Código Penal del siglo XXI, en cuyo Mensaje se señala expresamente que "con este Proyecto de Código Penal, Chile busca dar un paso más, tanto en lo que respecta a la penalización de conductas adicionales a las que hoy incorpora la Ley $\mathrm{N}^{\circ} 20.393$ - en esta ampliación del catálogo figura, entre otros, los delitos contra la vida que se produzcan en un contexto de seguridad del trabajo, trata de personas, delitos contra el medio ambiente y fabricación y tráfico ilegal de armas", al establecerse en el inc. $3^{\circ}$ del Art. 181 del Proyecto los casos en que efectivamente ha de imponerse sanciones penales a las personas jurídicas no se incluyan los delitos contra el medio ambiente de los Arts. 504 a 514.

\subsection{Proyecto basado en el Anteproyecto de la Comisión Foro Penal de 2005 (Boletín $\mathbf{N}^{\circ}$ 9367-12)}

Este Proyecto, originado en la Moción de los Honorables Senadores señores Girardi, De Urresti, Horvath, Navarro y Walker, de fecha 3 de junio de 2014, se fundamenta, según allí se señala, en la ausencia de delitos para sancionar los atentados contra el medio ambiente en nuestro ordenamiento jurídico, lo que habría hecho posible la ocurrencia de grandes desastres ecológicos y la dilución de las responsabilidades que en ellos le ha cabido a empresas y autoridades.

Allí se señala que el "proyecto de ley se ha diseñado y estructurado teniendo como base el trabajo investigativo de un equipo de juristas encabezado por el profesor Jean Pierre Matus, y que fuera publicado por la Editorial Jurídica de Chile el año 2004 bajo el título 'Derecho Penal del Medio Ambiente. Estudios y propuesta para un nuevo Derecho Penal Ambiental chileno"'. Pero, dado que esta propuesta en realidad había sido antes recogida en el Anteproyecto de Código Penal para la Nación de 2005, de la Comisión Foro Penal, este es el modelo oficial al que nos parece oportuno remitirnos ${ }^{94}$.

Este proyecto propone proteger penalmente al medio ambiente, entendido según lo ha definido la Ley $\mathrm{N}^{\circ}$ 19.300, es decir, en un sentido amplio, que incluye no sólo elementos naturales, sino también aquellos artificiales de naturaleza física, química, biológica y sociocultural y consta de tres títulos: en el primero de ellos se establecen los delitos de grave contaminación o daño ambiental y tráfico de sustancias peligrosas; en el segundo, se consagran las disposiciones relativas a conductas que afectan el correcto funcionamiento del

\footnotetext{
${ }^{94}$ En el Congreso Nacional, la propuesta del Foro Penal había sido recogida antes en el Proyecto contenido en el el Boletín 5654-12, archivado en marzo de 2010 y desarchivado, por acuerdo de Sala, el 28 de enero de 2014 , a propósito de la discusión de la Moción contenida en el Boletín No 8920-07, suscrita por la Senadora I. Allende, comentado antes arriba en el texto. Para mayores antecedentes, véase MATUS, Jean Pierre, "Fundamentos y propuesta legislativa para una nueva protección penal del medio ambiente en Chile, elaborada por la Comisión Foro Penal", en Zeitschrift für Internationale Strafrechtsdogmatik, No 7 (2008), pp. 304-324.
} 
MATUS, Jean Pierre; RAMIREZ, María Cecilia; CASTILLO, Marcelo.

"Acerca de la necesidad de una reforma urgente de los delitos de contaminación en Chile, a la luz de la evolución legislativa del siglo XXI”.

Sistema de Evaluación de Impacto Ambiental; y en el tercero, se consagran disposiciones varias.

En el detalle, el Art. $1^{\circ}$ del Proyecto sanciona al responsable de una fuente emisora que produzca una grave pérdida, disminución, detrimento o menoscabo al medio ambiente o a uno o más de sus componentes, agravándose la pena en caso de que, con ello se pusiere en serio peligro la vida o salud de las personas; y, agravándose aún más, en caso que el delito causare efectivamente la muerte o lesiones graves a una persona. El Art. $2^{\circ}$ contiene la hipótesis culposa o cometida con infracción de ley, reglamento o instrumento de gestión ambiental de este delito. El Art. $3^{\circ}$, castiga el tráfico de sustancias peligrosas sin autorización, agravándose la pena en caso de que ello implicase un serio riesgo para la salud o la vida de las personas.

En el Título II se tipifica los delitos consistentes en ejecutar, o mandar ejecutar, modificar o mandar a modificar un proyecto o actividad que, según la ley debe ser sometido al Sistema de Evaluación de Impacto Ambiental, sin previamente haberlo hecho, a sabiendas, lo que se castiga con pena de multa. Se impone pena privativa de libertad si, además, se actuase en contra de instrucciones o resoluciones de la autoridad ambiental (Arts. 4 y 5).

Se castiga además al funcionario público encargado de conceder los permisos o pronunciarse acerca de los proyectos o actividades sometidos al Sistema de Evaluación Ambiental y a los miembros de la Comisión de Evaluación Ambiental, que concedieren dichos permisos o emitiere dictamen favorable, en los casos en que, conforme a la ley o los reglamente, ello no estuviese permitido (Art. 6)

El Art. 7, impone las penas de perjurio al que presentare datos falsos u omitiere información relevante a la autoridad ambiental en los procesos e instrumentos del Sistema de Gestión Ambiental.

En el Título III, se contienen disposiciones varias, relativas, en primer lugar, a la remisión de esta regulación a un reglamento que determine las sustancias y cantidades o proporciones de contaminantes provenientes de una misma fuente emisora cuya emisión al medio ambiente sea capaz de producir un grave daño ambiental y, en su caso, de poner en serio peligro la vida y salud de las personas (Art. 8). En segundo lugar, regula ciertos aspectos probatorios, sobre todo en relación con el valor de la prueba pericial (Arts. 10 y 11). En tercer lugar, establece una regla de autoría, según la cual se considerarán autores de los delitos contemplados en esta ley, los que aparezcan ante la autoridad ambiental como titulares de los proyectos o actividades en que incida el delito $\mathrm{y}$, respecto de personas jurídicas, sus representantes, gerentes, directores, $\mathrm{y}$, en general, todos quienes tengan o compartan de hecho o jurídicamente facultades de administración, salvo prueba en contrario (Art. 12). Por último, se establecen sanciones a las personas jurídicas cuyos representantes, gerentes, directores y administradores de hecho o de derecho, fueren condenados por los delitos de esa ley, que consisten en la clausura del proyecto o actividad u una multa de entre 5000 y 15000 UTA, sin perjuicio de las acciones civiles y administrativas correspondientes (Art. 13). 
Polít. crim. Vol. 13, No 26 (Diciembre 2018) Art. 4, pp. 771-835.

[http://www.politicacriminal.cl/Vol_13/n_26/Vol13N26A4.pdf]

En su primer trámite constitucional, la sala del Senado dio cuenta del proyecto con fecha 30 de junio de 2014 y pasó a la Comisión de Medio Ambiente y Bienes Nacionales del Senado, sin que hasta el momento se haya dado cuenta del Informe de dicha Comisión ante el Senado.

Como es posible apreciar de lo expuesto, este proyecto sanciona la grave contaminación y daño ambiental como hipótesis general, incluyendo su comisión con negligencia, el tráfico de residuos, y los casos de burla al sistema, sea por los particulares como por los funcionarios parte de la Administración.

Sin embargo, por su expresa referencia a las propuestas realizadas antes de la reforma al sistema de protección del medio ambiente, consagradas en la Ley $\mathrm{N}^{\circ} 20.417$, de 2010, su contenido normativo se encuentra en parte desactualizado y debe ser objeto de revisión crítica.

En efecto, respecto de los delitos de contaminación propiamente tales, aunque su intención es llenar los vacíos existentes, castigando penalmente sólo la grave contaminación —al igual que los proyectos antes analizados-, sus disposiciones se basan en algunos supuestos normativos y fácticos antes y hoy inexistentes: primero, que no existiría un sistema administrativo sancionador centralizado, como la actual Superintendencia del Medio Ambiente; y, segundo, que la autoridad administrativa estaría en condiciones de elaborar, además de las normas de emisión y calidad ambiental pertinentes, especiales reglamentaciones para determinar el límite de lo penalmente relevante, esto es, el grave daño ambiental. Sin embargo, por una parte, hoy el sistema sancionador administrativo existe; y, por otra, parece muy difícil que la administración esté en condiciones de elaborar la reglamentación especial propuesta, atendidas las dificultades que existen para la dictación de las normas básicas de emisión y calidad en las distintas zonas del país y para los diferentes elementos contaminantes. Tampoco contempla el proyecto una regla de coordinación entre la Superintendencia del Medio Ambiente y el Ministerio Público ${ }^{95}$.

En cambio, respecto de las sanciones por la burla del sistema de protección del medio ambiente, el proyecto es el más avanzado de los tres que se han presentado con posterioridad a la entrada en vigencia de la Ley $\mathrm{N}^{\mathrm{o}} 20.417$, de 2010, en el sentido de llenar efectivamente los vacíos existentes en la legislación, estableciendo el castigo autónomo de la burla directa e indirecta del sistema y los delitos funcionarios correspondientes, aunque debe ser ajustado en sus referencias a la realidad normativa e institucional actual, particularmente en cuanto a la necesaria coordinación con el sistema sancionador entregado a la Superintendencia del Medio Ambiente.

Por otra parte, la forma como el Proyecto plantea el establecimiento de la responsabilidad penal de las personas jurídicas aparece también desfasada respecto de las actuales disposiciones vigentes, tras la promulgación de la Ley $\mathrm{N}^{\mathbf{0}} 20.393$.

\footnotetext{
${ }^{95}$ Desde otra perspectiva, más críticas a este Proyecto pueden verse en BASCUÑÁN, cit. nota al pie No 42.
} 
MATUS, Jean Pierre; RAMIREZ, María Cecilia; CASTILLO, Marcelo.

"Acerca de la necesidad de una reforma urgente de los delitos de contaminación en Chile, a la luz de la evolución legislativa del siglo XXI”.

Con todo, cabe destacar positivamente un par de aspectos especiales del Proyecto que los anteriormente analizados no consideran: la idea de establecer en la literalidad del texto de los tipos penales un sistema top-dawn, haciendo directamente responsables a los titulares de los proyectos que se traten; la regla sobre causalidad general ${ }^{96}$; y la forma cómo atribuye penas a los directivos de las empresas responsables, imponiéndoles la que les corresponde al autor, en un símil de la responsabilidad por el mando que ahora existe en el Art. 35 de la Ley N $^{\circ}$ 20.357, que tipifica crímenes de lesa humanidad y genocidio y crímenes y delitos de guerra ${ }^{97}$.

\section{Conclusiones}

En primer lugar, a la hora de analizar las reformas legales efectivamente producidas en materia penal ambiental en esta última década, es posible constatar que tanto los procesos de internacionalización como de intensificación local de nuestro sistema punitivo han conducido a una más detallada protección de la biodiversidad y al establecimiento del castigo del tráfico ilícito de residuos peligrosos.

En efecto, por una parte, la legislación nacional se ha ido adaptando a las exigencias de los tratados internacionales, particularmente en lo que respecta a la protección aislada de ciertos componentes del ambiente y de ciertas formas particulares de su puesta en peligro y daño: la protección penal de las especies CITES, en la Ley de Caza y en la Ley N ${ }^{\circ}$ 20.962, de 2016; la protección del medio frente al tráfico de residuos peligrosos, en la Ley $\mathrm{N}^{\circ} 20.920$, de 2016; el castigo del transporte, traslado o depósito de residuos tóxicos, peligrosos o infecciosos, en cualquier clase de vehículos, en la Ley No 20.879, que introdujo el Art. 192 bis en la Ley N ${ }^{\circ}$ 18.290 del Tránsito; la protección del medio ambiente frente a los peligros de las armas nucleares y de destrucción masiva, leyes $\mathrm{N}^{\circ} 18.302$, de 1984; $\mathrm{N}^{\circ} 17.798$, modificada por la $\mathrm{N}^{\mathrm{o}} 20.813$, de 2015; y la $\mathrm{N}^{\mathrm{o}} 18.314$, de 1984, modificada por la $\mathrm{N}^{\mathrm{o}} 20.467$, de 2010.

Por otra parte, el proceso intensificación del Derecho Penal local también ha impactado en la de la protección de ciertos componentes del medio ambiente. Significativa es al respecto la decidida protección de las especies hidrobiológicas, a través de sucesivas modificaciones de la Ley General de Pesca, la última de las cuales tuvo lugar el año 2008 (Ley No 20.293 que castiga la caza o captura de cualquier cetáceo); del Bosque Nativo, a través de la Ley $\mathrm{N}^{\circ}$ 20.283, de 2008; del suelo ante los peligros que se enfrentan al momento de cerrar faenas mineras (Ley $\mathrm{N}^{\circ}$ 20.511, de 2011); de los espacios naturales y la masa forestal, a través de la modificación de las leyes que castigan su incendio (Ley $\mathrm{N}^{\circ} 20.653$, de 2013, que modificó el

\footnotetext{
${ }^{96}$ Regla que fue muy criticada en su oportunidad por HERNÁNDEZ, Héctor, "El problema de la "causalidad general" en el Derecho Penal chileno (con ocasión del art. 232 del Anteproyecto de Nuevo Código Penal)", en Política Criminal, $\mathrm{N}^{\circ} 1$ (2006), A7, en http://www.politicacriminal.cl/n_01/pdf_01/a 7.pdf [visitado el 20.10.2017], pp. 1-33.

${ }^{97}$ Sobre las dificultades que producen esta clase de disposiciones que se alejan de las categorías tradicionales de responsabilidad penal, véase el intento, entre nosotros, de asimilar su contenido con el de las categorías dogmáticas tradicionales, véase WINTER, Jaime, La responsabilidad por el mando en el Derecho Penal Internacional, Santiago: Tesis UChile, 2009.
} 
Polít. crim. Vol. 13, No 26 (Diciembre 2018) Art. 4, pp. 771-835.

[http://www.politicacriminal.cl/Vol_13/n_26/Vol13N26A4.pdf]

Código Penal y la Ley de Bosques, incorporando el incendio negligente y de las Áreas Silvestres Protegidas).

Sin embargo, la experiencia ha demostrado que la legislación existente, a pesar de los avances señalados, es insuficiente para dar respuesta penal a los fenómenos de grave contaminación y daño ambiental, así como a la burla del sistema administrativo de protección del ambiente. En efecto, la contaminación del aire sigue regulada por faltas de insignificante aplicación práctica y el único tipo penal que contempla sanciones más o menos significativas, el Art. 291 del Código Penal, presenta ciertas limitaciones estructurales que hacen difícil su aplicación, siendo las principales su expresión como un delito que castiga la conducta activa de propagar contaminantes, sin sancionar las figuras culposas y sin una clara referencia a los normas de rango inferior que delimitarían el ámbito de lo punible. Similares limitaciones enfrentan las disposiciones que enfrentan la contaminación de las aguas: a pesar de los aspectos modernos del Art. 136 de la Ley General de Pesca y Acuicultura, que ordena castigar tanto al que contamina como al que lo ordena, dicha disposición no contempla la sanción expresa del delito culposo.

No obstante, ni la constatación de esas limitaciones ni el reconocimiento de la existencia de un interés legítimo, constitucional e internacionalmente reconocido, en orden a asegurar el derecho a vivir en un medio ambiente libre de contaminación, parecen suficientes, entre nosotros, para afirmar la existencia de un verdadero consenso político y académico en orden a establecer verdaderos delitos de contaminación y de protección del sistema de gestión ambiental que vengan a llenar el vacío existente. Aquí se discuten el "si" y el "cómo" de la criminalización en la materia. En efecto, respecto de "si", se cuestiona que sea necesario establecer esta clase de delitos tanto por la inexistencia de una obligación precisa en ese sentido, ya sea en la Constitución o en los instrumentos internacionales suscritos por Chile, como por consideraciones en orden a la supuesta ilegitimidad de una expansión del Derecho penal a estas materias, que se consideran propias del derecho administrativo. Además, frente a las insuficiencias de la legislación existente (particularmente los delitos de los Arts. 291 del Código Penal y 136 de la Ley General de Pesca y Acuicultura), se opone la reciente introducción de una nueva institucionalidad ambiental (Ley No 20.417, de 2010), que crea la Superintendencia del Medio Ambiente con amplias facultades fiscalizadores y sancionatorias, tanto respecto de hechos que puedan considerarse de grave contaminación como de burla del sistema administrativo de gestión del ambiente.

Sin embargo, un análisis de las facultades sancionatorias de la Superintendencia del Medio Ambiente permite afirmar que, a pesar de las importantes reformas introducidas por la ley, sobre todo el reemplazo del sistema de coordinación por uno centralizado de fiscalización y sanción, todavía existen ámbitos que requieren protección penal: desde luego, por regla general, este nuevo sistema no sanciona a las personas naturales responsables de ejecutar un proyecto burlando el sistema de gestión del ambiente o, derechamente, ordenando contaminar o destruir alguno de sus componentes o, sin ordenarlo, provocar la negligente contaminación de los mismos, puesto que el nuevo sistema administrativo impone sanciones solo a los titulares de los proyectos, generalmente personas jurídicas. Tampoco se sanciona especialmente la presentación de declaraciones falsas ante la autoridad ambiental, salvo el 
MATUS, Jean Pierre; RAMIREZ, María Cecilia; CASTILLO, Marcelo.

"Acerca de la necesidad de una reforma urgente de los delitos de contaminación en Chile, a la luz de la evolución legislativa del siglo XXI".

caso especial de certificación falsa por parte de entidades autorizadas al efecto. Además, a pesar de que el sistema administrativo se dirige principalmente a la sanción de las personas jurídicas, con sanciones pecuniarias que pueden ser significativamente mayores a las establecidas en la Ley $\mathrm{N}^{\mathrm{0}} 20.393$, sobre responsabilidad penal de las personas jurídicas, lo cierto es que no se establece la obligación de contar con planes de prevención que sirvan de defensa de cumplimiento, ni sanciones tales como la disolución de la persona jurídica.

Todo lo anterior permite entender las recomendaciones de la OCDE sobre la necesidad de establecer sanciones penales en materia ambiental y la persistencia de parte de nuestros legisladores, sin distinción de color político, en presentar a la discusión nuevos proyectos de ley que contemplen sanciones penales para los más graves hechos de contaminación y daño ambiental, así como para una eficaz protección del sistema administrativo de gestión del ambiente.

Sin embargo, estos proyectos reflejan también una discrepancia no menor en el "cómo" proteger penalmente el ambiente de los fenómenos de grave contaminación y burla del sistema administrativo de gestión del ambiente. A ello se suma el hecho de que ninguno de los proyectos presentados hasta ahora está libre de críticas relevantes, tanto técnicas como políticas. Los que siguen el modelo alemán, por ejemplo, incomprensiblemente dejan fuera del ámbito de sus disposiciones a las personas jurídicas, a pesar de existir ya una ley que establece los presupuestos para su sanción y las penas aplicables. Por su parte, el proyecto que sigue un modelo más criollo, descansa en exceso en la creencia de que el Ministerio del Medio Ambiente tendrá capacidad normativa suficiente para delimitar el ámbito de lo punible de aquello que es parte de lo administrativamente sancionable.

Como consecuencia de lo anterior, y a la vista de las dificultades planteadas al momento de pretender establecer nuevos delitos de contaminación y de sanción de la burla del sistema de gestión ambiental, hemos llegado a la conclusión de que tal vez en este momento político las diferencias existentes se puedan resolver abandonando la pretensión de una nueva regulación comprensiva de la materia y, en cambio, adoptar un enfoque que apunte al perfeccionamiento de la legislación ya existente, particularmente en lo que dice relación con las deficiencias ya detectadas en los dos principales delitos de contaminación actualmente vigentes: el Art. 291 del Código Penal, respecto de la contaminación del suelo y el aire; y el Art. 136 de la Ley General de Pesca y Acuicultura, respecto de la contaminación de las aguas. La propuesta que se basa en estas ideas ha sido presentada al H. Senador Guido Girardi para su tramitación ante el Congreso Nacional, transformándose en el Proyecto de Ley ingresado con el patrocinio de los Senadores De Urresti, Navarro, Ossandón y Quinteros con fecha 25 de octubre de 2017 (Boletín No 11.482-07), el que se transcribe a continuación.

ANEXO. Proyecto de ley, iniciado en moción de los Honorables Senadores señores Girardi, De Urresti, Navarro, Ossandón y Quinteros, que modifica el Código Penal y otros cuerpos legales, en lo relativo a los delitos contra el medio ambiente (Boletín $\mathbf{N}^{\circ}$ 11.482-07)

\section{I.- Introducción}


La protección penal del medio ambiente, atendido el extenso y cada vez más creciente deterioro del medio ambiente y de los recursos naturales, así como la aparición de nuevas formas de contaminación, de origen antrópico, y la creación en nuestro derecho de "delitos contra el medio ambiente" es un antiguo anhelo y una necesidad aún no satisfecha en la comunidad jurídica, científica y ambiental nacional, ya que nuestro Código Penal, de factura decimonónica, no fue capaz de prever ni menos imaginar este tipo de agresiones en contra de la Naturaleza.

En ese contexto, desde hace más de diez años, Senadores y Diputados de diferentes pensamientos y corrientes políticas y filosóficas, con un indiscutible espíritu cívico y compromiso ético, hemos presentado diversas mociones, las que han tenido escaso grado de avance legislativo, con el objetivo de crear "delitos contra el medio ambiente", los que, desafortunadamente, no se han convertido en leyes, pese a ser una necesidad políticocriminal evidente por su enorme dañosidad social y ambiental.

Sin embargo, a pesar de que hoy, como hace diez años, no existen en nuestro ordenamiento jurídico normas que, como las previstas en el derecho comparado, castiguen directamente la grave contaminación (tanto dolosa como negligente) del aire, las aguas y el suelo-, se han realizado avances significativos en la protección del medio ambiente y sus elementos, principalmente frente a los peligros de extinción de las especies, el trafico ilícito de desechos y la destrucción causada por el uso indebido del fuego, mediante reformas parciales a diversos cuerpos legales específicos, aunque sin una mirada global o ecosistémica.

Además, la experiencia práctica ha terminado por destacar las verdaderas deficiencias de los que serían nuestros embrionarios delitos de contaminación (Art. 291 del Código Penal y 136 de la Ley General de Pesca), cuyo perfeccionamiento vendría a llenar las lagunas de punibilidad que dejan su defectuosa redacción, sin necesidad de hacerse cargo de la creación de una reglamentación especial que fije los límites de la "grave contaminación", como la que proponíamos hace una década.

Por otra parte, el estudio de la nueva institucionalidad ambiental, que ha venido a reforzar significativamente sus potestades sancionatorias de carácter administrativo, nos permite delimitar el ámbito de lo perseguible administrativamente de aquello que sería objeto de sanción penal. En efecto, la creación de la Superintendencia del Medio Ambiente creo severos instrumentos de sanción y represión administrativa bastante eficaces, con multas muy altas, pero limitados en principio sólo a los proyectos que han sido sometidos al Sistema de Evaluación de Impacto Ambiental (SEIA), vía Declaración o Estudio de Impacto Ambiental, o a los otros instrumentos de gestión ambiental que creó la Ley 19.300 sobre Bases Generales del Medio Ambiente, tales como Normas de Calidad Ambiental Primarias y Secundarias, Normas de Emisión, Planes de Manejo, Prevención o Descontaminación, entre otros.

Sin embargo, el sistema administrativo-sancionador que creó la Ley 20.417, al estar estrechamente ligado a los citados instrumentos de gestión ambiental, dejo una enorme brecha de conductas susceptibles de ser sancionadas, tanto administrativa como penalmente, 
MATUS, Jean Pierre; RAMIREZ, María Cecilia; CASTILLO, Marcelo.

"Acerca de la necesidad de una reforma urgente de los delitos de contaminación en Chile, a la luz de la evolución legislativa del siglo XXI”.

"en tierra de nadie", cuando, por ejemplo, los titulares no ingresan sus proyectos al SEIA; o cuando no existen normas de calidad o de emisión que regulen determinados contaminantes, o simplemente, cuando se dañan ex profeso recursos naturales o bienes ambientales de titularidad común, como el agua o la biodiversidad; o cuando ciertos sujetos deciden "sustraerse", en forma dolosa, al cumplimiento de la legislación ambiental, en lo que podríamos encuadrar al verdadero "delincuente ecológico", cuya peligrosidad quedó de manifiesto en los incendios más grandes de la historia de nuestro país ocurridos en el verano pasado.

Por lo anterior, la OCDE, en su Evaluación del Desempeño Ambiental sobre Chile, del año 2016, señaló que: "La legislación penal chilena no establece disposiciones específicas para las infracciones ambientales, situación que ha sido objeto de debates durante los últimos diez años. Chile debería materializar su intención de imponer una responsabilidad penal a varias categorías de delitos ambientales graves y establecer diferencias claras entre las infracciones pasibles de sanciones administrativas y aquellas punibles mediante sanciones penales", agregando la recomendación a Chile de "considerar la posibilidad de adoptar sanciones penales por delitos ambientales graves" $" 98$.

\section{II.- Fundamentos para refundir los proyectos que establecen un sistema de protección penal y delitos en contra del medio ambiente}

Concordante con lo anterior, los que suscribimos este Proyecto de Ley y de conformidad con lo dispuesto en el Art. 17 A de la Ley Orgánica Constitucional del Congreso Nacional, proponemos a la Sala del Senado un Proyecto de Ley para refundir las materias comprendidas en los proyectos contenidos en los Boletines $\mathrm{N}^{\circ}$ 8920-07, $\mathrm{N}^{\circ}$ 9367-12, $\mathrm{N}^{\circ}$ 5654-12, todos en primer trámite constitucional, cuyas ideas matrices tienen entre sí relación directa, al proponer todos figuras penales que sancionan la grave contaminación y el daño del medio ambiente.

En efecto, los proyectos contenidos en el Boletín $\mathrm{N}^{\circ}$ 9367-12, Moción de los H Senadores Sres. Girardi, De Urresti, Horvath, Navarro y Walker, y Boletín N 5654-12, Moción del H. Senador Guido Girardi, se han diseñado y estructurado teniendo como base el trabajo investigativo de un equipo de juristas encabezado por el profesor Jean Pierre Matus, e integrado por los abogados Maria Cecilia Ramírez Guzmán, Marcos Orellana Cruz y Marcelo Castillo Sánchez.

En resumen, allí se propone castigar la grave contaminación y la burla del sistema de protección del medio ambiente, así como establecer sanciones adecuadas a las personas

98 OCDE, Evaluaciones del Desempeño Ambiental Chile 2016, Santiago, OCDE/CEPAL, 2016, p.122, disponible también en línea <http://portal.mma.gob.cl/wp-content/uploads/2016/07/Evaluaciondesempeno-Chile-WEBV2.pdf>, fecha de consulta: 04.07.2017. 
Polít. crim. Vol. 13, No 26 (Diciembre 2018) Art. 4, pp. 771-835.

[http://www.politicacriminal.cl/Vol_13/n_26/Vol13N26A4.pdf]

jurídicas y otras disposiciones complementarias respecto a la responsabilidad de los directivos principales de éstas.

Por su parte, el proyecto contemplado en el Boletín $\mathrm{N}^{\circ}$ 920-07, si bien no tiene como base el trabajo investigativo antes mencionado, propone también el castigo de los hechos de grave contaminación y daño del medio ambiente, así como otros delitos relativos a la protección de componentes del medio ambiente.

Todos los proyectos aceptan el principio de accesoriedad conceptual a las disposiciones de la Ley $\mathrm{N}^{\circ} 19.300$ y de la normativa ambiental aplicable, en cuanto a la interpretación y aplicación de los conceptos y normas ambientales. Y, al mismo tiempo, admiten que no puede sancionarse penalmente los casos de infracciones menores, especialmente en lo que respecta a la contaminación causada por chimeneas y otras fuentes fijas domiciliarias así como la que provocan los vehículos sujetos a inscripción en el Registro Nacional de Vehículos Motorizados.

En el convencimiento de que -tal como se explica en los fundamentos de las Mociones contenidas en los Boletines citados- la protección del medio ambiente a nivel penal es necesaria, por la insuficiencia de la legislación actual para enfrentar los graves casos de contaminación culposa de aguas y suelos de que se ha sido testigo en los últimos años; y por las limitaciones del sistema administrativo de gestión del medio ambiente, que principalmente apunta a la sanción de las personas jurídicas titulares de los proyectos, dejando impunes a las personas naturales que deciden o no evitan los graves hechos de contaminación, tal como lo ha manifestado la OCDE en las Evaluaciones sobre Desempeño Ambiental sobre Chile, del año 2016, que recomienda "considerar la posibilidad de adoptar sanciones penales por delitos ambientales graves", y el propio Presidente del Segundo Tribunal Ambiental de Santiago, Ministro Rafael Asenjo Zegers, en el seminario "El Derecho Penal y la Protección del Medio Ambiente", proponemos refundir los proyectos respectivos, para facilitar su discusión y despacho.

Los que suscribimos este proyecto estamos convencidos que, aunque sin duda produciría un efecto simbólico mayor el establecimiento de un título especial en el Código Penal que sancione estas figuras o, al menos, una ley especial que regulase completamente la materia, lo cierto es que actualmente existen en nuestro Código Penal y en la Ley General de Pesca dos disposiciones que, por defectos principalmente técnicos en su formulación legal, no han podido tener la aplicación práctica que la ciudadanía y los fiscales del Ministerio Público han pretendido darle respecto de los últimos hechos de grave contaminación y connotación social, como los derrames en el Río Cruces, de Valdivia (2004), y en las Bahías de San Vicente (2007), Poza Pureo en Calbuco (2011), y Quinteros (2014, 2015 y 2016). Por tanto, sin entrar en la discusión sistemática, se propone la adopción de las reformas técnicas que hagan operativas estas normas, para sancionar los hechos de grave contaminación y daño ambiental, con estricta sujeción a los conceptos de gravedad en el daño ambiental introducidos por la ley $\mathrm{N}^{\circ} 20.417$ En el mismo sentido, se propone una reforma a la Ley sobre Monumentos Nacionales, para una mejor protección del grave daño ambiental causado a los mismos o a sus componentes. La principal reforma en todos ellos es, aparte de la adecuación de las penas, 
MATUS, Jean Pierre; RAMIREZ, María Cecilia; CASTILLO, Marcelo.

"Acerca de la necesidad de una reforma urgente de los delitos de contaminación en Chile, a la luz de la evolución legislativa del siglo XXI”.

la expresa sanción de los hechos negligentes o imprudentes, que son la mayor parte de los casos reales de contaminación y daño ambiental.

Además, se propone establecer los delitos relativos a la protección del Sistema de Evaluación Ambiental estrictamente necesarios para llenar los vacíos hoy existentes en la legislación administrativa, considerando la burla directa del sistema de protección del medio ambiente una agravante que se incorpora a cada uno de los delitos de contaminación reformados y manteniendo la técnica tradicional en esta clase de delitos vinculados a la protección de la administración. Así, se propone sancionar tanto la presentación de documentos falsos, etc., como la aprobación o concesión indebida de permisos ambientales.

Finalmente, se propone hacer expresa mención a la responsabilidad de los administradores de las empresas en cuyo ámbito se cometen los delitos que se trata, así como la extensión de la responsabilidad penal de las personas jurídicas a los delitos reformados.

El Proyecto de Ley así resultante, refundiría los propuestos en las Mociones de los Boletines $\mathrm{N}^{\circ}$ 8920-07, $\mathrm{N}^{\circ}$ 9367-12, $\mathrm{N}^{\circ}$ 5654-12, en actual tramitación legislativa, y, sobre este trabajo y análisis, queremos dejar constancia que en su redacción, nuevamente, contamos con la valiosa colaboración, de los profesores Jean Pierre Matus, María Cecilia Ramírez Guzmán y Marcelo Castillo Sánchez.

Por estas consideraciones es que proponemos el siguiente,

\section{"PROYECTO DE LEY SOBRE DELITOS CONTRA EL MEDIO AMBIENTE"}

Artículo 1 .- Modifíquese el Art. 291 del Código Penal, en los siguientes términos:

$\left.1^{\circ}\right)$ Agréguese, antes de la expresión "propagaren indebidamente", la frase "emitieren, vertieren, introdujeren o";

$2^{\circ}$ ) Introdúzcase, antes de la expresión "que por su naturaleza", la frase "causen una grave contaminación o daño ambiental no susceptible de reparación, haya afectado gravemente la salud de la población o constituyan reiteración o reincidencia de dos o más infracciones calificadas como graves por la Superintendencia del Medio Ambiente, dentro de un mismo año calendario, o";

$3^{\circ}$ ) Añádase, antes del punto aparte, la expresión "y multa de 50 a 3.000 unidades tributarias mensuales, sin perjuicio de las sanciones administrativas correspondientes";

$4^{\circ}$ ) Agréguense los siguientes incisos segundo a quinto:

"Si la emisión, vertimiento, introducción o propagación de que habla el inciso anterior se causa por mera negligencia o imprudencia, la pena será de presidio menor en su grado máximo y multa de 50 a 2.000 unidades tributarias mensuales, sin perjuicio de las sanciones administrativas correspondientes. 
Polít. crim. Vol. 13, No 26 (Diciembre 2018) Art. 4, pp. 771-835.

[http://www.politicacriminal.cl/Vol_13/n_26/Vol13N26A4.pdf]

Se entenderá que emiten, vierten, introducen o propagan indebidamente las sustancias a que se refiere el inciso anterior quienes realicen dichas conductas sin contar con la debida autorización o sobrepasando las normas de emisión aplicables.

Se impondrá el grado superior de las penas previstas en este artículo si la emisión, vertimiento, introducción o propagación se causan por quienes ejecuten un proyecto o actividad que, debiéndose someter al sistema de evaluación ambiental, no ha obtenido la correspondiente resolución de calificación ambiental o la ha obtenido mediante cohecho, falsedad o engaño.

Las disposiciones de este artículo no serán aplicables a las emisiones provenientes de vehículos sujetos a inscripción en el Registro Nacional de Vehículos Motorizados, chimeneas $\mathrm{y}$

demás sistemas de calefacción o refrigeración domésticos, las que, en caso de exceder las normas de emisión correspondientes, se regirán por las disposiciones generales aplicables en la materia."

Artículo $2^{\circ}$. Modifíquese el artículo 136 de la Ley General de Pesca y Acuicultura, cuyo texto refundido se ha establecido por Decreto Supremo $N^{\circ} 430$, de 1992, en el siguiente sentido:

$\left.1^{\circ}\right)$ Sustitúyase la expresión "recursos hidrobiológicos", por "recursos hidrobiológicos o medio ambiente marino";

$2^{\circ}$ ) Sustitúyase la expresión "multa de 50 a 3.000 unidades tributarias mensuales" por la frase "con presidio menor en su grado máximo y multa de 50 a 3.000 unidades tributarias mensuales, sin perjuicio de las sanciones administrativas correspondientes";

$\left.3^{\circ}\right)$ Sustitúyase la frase "Si procediere con dolo, además de la multa, la pena a aplicar será la de presidio menor en su grado mínimo", por "Si procediere con mera imprudencia o negligencia, la pena a aplicar será la de presidio menor en su grado medio y multa de 50 a 2.000 unidades tributarias mensuales, sin perjuicio de las sanciones administrativas correspondientes",

$\left.4^{\circ}\right)$ Agréguese el siguiente inciso tercero:

"Se impondrá el grado superior de las penas previstas en este artículo si el daño a los recursos hidrobiológicos o al medio ambiente marino se causa por quienes ejecuten un proyecto o actividad que, debiéndose someter al sistema de evaluación ambiental, no ha obtenido la correspondiente resolución de calificación ambiental o la ha obtenido mediante cohecho, falsedad o engaño." 
MATUS, Jean Pierre; RAMIREZ, María Cecilia; CASTILLO, Marcelo.

"Acerca de la necesidad de una reforma urgente de los delitos de contaminación en Chile, a la luz de la evolución legislativa del siglo XXI”.

Artículo $3^{\circ}$. Agréguense el artículo 38 de la Ley $\mathrm{N}^{\circ}$ 17.288, sobre Monumentos Nacionales, los siguientes incisos segundo a cuarto:

"Si el daño al monumento nacional consistiere en uno de carácter ambiental no susceptible de reparación, hubiere afectado gravemente la salud de la población o fuere producto de la reiteración o reincidencia de dos o más infracciones calificadas como graves por la Superintendencia del Medio Ambiente, dentro de un mismo año calendario, la pena a imponer será de presidio menor en su grado máximo y multa de 50 a 3.000 unidades tributarias mensuales, sin perjuicio de las sanciones administrativas correspondientes.

Si el daño a que se refiere el inciso anterior se causare por mera negligencia o imprudencia, se impondrá la pena de presidio menor en su grado medio y multa de 50 a 2.000 unidades tributarias mensuales, sin perjuicio de las sanciones administrativas correspondientes.

Se impondrá el grado superior de las penas previstas en los dos incisos anteriores si el daño se causa por quienes ejecuten un proyecto o actividad que, debiéndose someter al sistema de evaluación ambiental, no ha obtenido la correspondiente resolución de calificación ambiental o la ha obtenido mediante cohecho, falsedad o engaño."

Artículo $4^{\circ}$. Sin perjuicio de las reglas generales, se considerarán también autores por los delitos establecidos en los artículos 291 del Código Penal, 136 de la Ley General, de Pesca y Acuicultura, y 38 de la Ley de Monumentos Nacionales, los que aparezcan ante la autoridad ambiental como titulares de los proyectos o actividades en que incida el delito y, tratándose de personas jurídicas, sus representantes legales, gerentes o directores, y en general, todos quienes tengan o compartan de hecho o jurídicamente facultades de administración de la misma, salvo prueba en contrario.

Se estimará suficiente prueba para eximir de la responsabilidad penal a las personas señaladas en el inciso anterior, la de haberse opuesto al acto u omisión que constituye el delito, intentando seriamente evitar su realización; o mediante el establecimiento previo de medidas de control administrativo que sus subordinados hubiesen infringido, sin su conocimiento o sin que les fuese posible evitarlo, por provenir de acciones de sabotaje $u$ otras intervenciones de terceros de similares características.

En el caso de los directores o gerentes de una persona jurídica, su oposición al acto que constituye el delito, podrá acreditarse con la exhibición de las actas correspondientes a la sesión del Directorio en que se decidió su realización.

Artículo $5^{\circ}$.- Será castigado con las penas del artículo 210 del Código Penal, el que presentare una declaración de impacto ambiental, un estudio de impacto ambiental, una adenda, un plan de reparación, un plan de cumplimiento o sus aclaraciones, rectificaciones o ampliaciones, en los términos previstos en las Leyes $\mathrm{N}^{\circ} 19.300$ y $\mathrm{N}^{\circ} 20.417$ y sus reglamentos, conteniendo datos falsos u omitiendo información relevante acerca de la predicción y evaluación del impacto ambiental del proyecto o actividad, incluidas las eventuales situaciones de riesgo, las medidas que se adoptaran para eliminar o minimizar los 
Polít. crim. Vol. 13, No 26 (Diciembre 2018) Art. 4, pp. 771-835.

[http://www.politicacriminal.cl/Vol_13/n_26/Vol13N26A4.pdf]

efectos adversos del proyecto o actividad y las acciones de reparación que se realizarán, cuando ello sea procedente.

Se considerará también autor del delito previsto en el artículo 210 del Código Penal, al que, estando obligado por ley, reglamento o resolución de calificación ambiental a efectuar mediciones de los contaminantes que emitan, o monitoreos del impacto de dichos contaminantes sobre el medio ambiente y sus componentes, emitiere o mandare emitir informes falsos, adulterados o incompletos acerca de dichas emisiones o del impacto de las mismas.

Artículo $6^{\circ}$.- Será castigado como autor del delito del artículo 228 del Código Penal, el funcionario público que debiendo o pudiendo conceder un permiso o pronunciarse respecto de proyectos o actividades sometidos al sistema de evaluación de impacto ambiental, concediere dicho permiso, aprobare o tomare parte en la aprobación de una resolución de calificación ambiental en los casos que la ley o los reglamentos respectivos no lo permitieren, o emitiere favorablemente un pronunciamiento solicitado, cuando ello no fuere legal o reglamentariamente procedente.

Artículo $7^{\circ}$.- Reemplácese, en el inciso primero del artículo $1^{\circ}$ de la Ley $\mathrm{N}^{\circ} 20.393$, la expresión "y en los artículos 250, 251 bis y 456 bis A del Código Penal" por ", en el artículo 136 de la Ley General de Pesca y Acuicultura, en el artículo 38 de la Ley de Monumentos Nacionales, en los artículos $5^{\circ}$ y $6^{\circ}$ de la Ley sobre Delitos Contra el Medio Ambiente y en los artículos 250, 251 bis, 291 y 456 bis A del Código Penal"

Artículo $8^{\circ}$.- La aprobación de un estudio o declaración de impacto ambiental en las circunstancias descritas en el artículo $6^{\circ}$ de esta ley, no producirá otro efecto que el de ser circunstancia atenuante en la comisión de los delitos contemplados en sus artículos $1^{\circ}$ a $5^{\circ}$, a menos de probarse que el responsable de los mismos se hubiere concertado con los funcionarios que indebidamente aprobaron el proyecto o actividad que se trate, caso en el cual esta última circunstancia se considerará como agravante, sin perjuicio de las penas que pudieran corresponder por los delitos de cohecho, negociación incompatible, tráfico de influencias y demás que pudieran haberse cometido.

Artículo 9 ${ }^{\circ}$.- En los delitos contemplados en el artículo 291 del Código Penal, 136 de la Ley General de Pesca y Acuicultura, 38 de la Ley de Monumentos Nacionales, y en los artículos $5^{\circ}$ y $6^{\circ}$ de esta ley, se considerará como circunstancia agravante el hecho de que el delito se cometa con incumplimiento de las precisas instrucciones otorgadas por alguna autoridad de competencia ambiental, las cuales hayan sido conocidas por el imputado.

Respecto de estos mismos delitos se considerarán como circunstancias atenuantes, las siguientes:

$1^{\text {a }}$. La auto denuncia del imputado en los términos del artículo 41, del Artículo Segundo de la Ley N²0.417; 
MATUS, Jean Pierre; RAMIREZ, María Cecilia; CASTILLO, Marcelo.

"Acerca de la necesidad de una reforma urgente de los delitos de contaminación en Chile, a la luz de la evolución legislativa del siglo XXI”.

$2^{\text {a }}$. El desarrollo de actividades inmediatas tras la consumación del delito cuya finalidad sea la evitación de ulteriores perniciosas consecuencias, lesivas para el medio ambiente, sus componentes, la salud pública y la salud animal o vegetal; y

$3^{\text {a }}$. En caso de no poder desarrollar las actividades mencionadas en el número anterior, el aviso inmediato de la ocurrencia del delito y de todas sus consecuencias a las autoridades con competencia ambiental y sanitaria, y a las comunidades aledañas que puedan verse afectadas, siempre que dicho aviso permita evitar sus perniciosas consecuencias, lesivas para el medio ambiente, sus componentes, la salud pública y la salud animal o vegetal." 
Polít. crim. Vol. 13, No 26 (Diciembre 2018) Art. 4, pp. 771-835.

[http://www.politicacriminal.cl/Vol_13/n_26/Vol13N26A4.pdf]

\section{Bibliografía}

ABOSO, Gustavo, Derecho Penal Ambiental. Estudio sobre los principales problemas en la regulación de los delitos contra el ambiente en la sociedad del riesgo, Montevideo: BdeF, 2015.

ABUMOHOR, José, Incendio Forestal Parque Nacional Torres del Paine, Santiago, ONEMI, 2012 , http://repositoriodigitalonemi.cl/web/bitstream/handle/2012/1613/ConsolidadoIncen dioForestalTdelPaine2011_2012.pdf?sequence=1, [visitado el 20.10.2017].

AGUILAR, Gonzalo, "Las deficiencias de la fórmula "derecho a vivir en un medio ambiente libre de contaminación en la Constitución chilena y algunas propuestas para su revisión”, en Estudios Constitucionales, Vol. 14, № 2 (2016), pp. 365-416.

ANWANDTER V., Sofía; SOLÍS S., Pía, ¿Debe intervenir el Derecho Penal respecto de la introducción y producción de Organismos Genéticamente Modificados, en Chile, para una adecuada tutela del medio ambiente? Análisis a la luz de los elementos que conforman el principio de precaución, Valparaíso, Tesis Universidad de Valparaíso, 2017.

BASCUÑÁN R., Antonio, “Comentario crítico a la regulación de los delitos contra el medio ambiente en el Anteproyecto de Código Penal de 2005", Revista de Estudios Públicos, $\mathrm{N}^{\mathrm{o}} 110$ (2008), pp. 241-322.

BERMÚDEZ, Jorge, Fundamentos de Derecho Ambiental, Valparaíso: Ediciones Universitarias de Valparaíso, 2016.

BIBLIOTECA DEL CONGRESO NACIONAL, Historia de la Ley $N^{o}$ 20.116, Valparaíso, s/ed., en http://www.bcn.cl/historiadelaley/nc/lista-de-resultado-de-busqueda/20116/ [visitado el 20.10.2017].

BIBLIOTECA DEL CONGRESO NACIONAL, Historia de la Ley $N^{o}$ 20.293, en: http://www.bcn.cl/historiadelaley/nc/historia-de-la-ley/5161/ [visitado el 20.10.2017].

BIBLIOTECA DEL CONGRESO NACIONAL, Historia de la Ley $N^{o}$ 20.653, Valparaíso, s/ed., en http://www.bcn.cl/historiadelaley/nc/historia-de-la-ley/4449/ [visitado el 20.10.2017].

BIBLIOTECA DEL CONGRESO NACIONAL, Historia de la Ley $N^{o}$ 20.879, Valparaíso: s/ed, en http://www.bcn.cl/historiadelaley/nc/historia-de-la-ley/4659/ [visitado el 20.10.2017]. 
MATUS, Jean Pierre; RAMIREZ, María Cecilia; CASTILLO, Marcelo.

"Acerca de la necesidad de una reforma urgente de los delitos de contaminación en Chile, a la luz de la evolución legislativa del siglo XXI".

BIBLIOTECA DEL CONGRESO NACIONAL, Historia de la Ley $N^{o}$ 20.920, Valparaíso: s/ed., en http://www.bcn.cl/historiadelaley/nc/historia-de-la-ley/5030/ [visitado el 20.10.2017].

BIBLIOTECA DEL CONGRESO NACIONAL, Historia de la Ley $N^{o}$ 20.962, Valparaíso: s/ed., en http://www.bcn.cl/historiadelaley/nc/historia-de-la-ley/5855/ [visitado el 20.10.2017].

BIBLIOTECA DEL CONGRESO NACIONAL, Historia de la Ley $N^{o} 21.020$, Valparaíso, s/ed., en http://www.bcn.cl/historiadelaley/nc/lista-de-resultado-de-busqueda/21020/ [visitado el 20.10.2017].

BOETTIGER, Camila, "Nueva Institucionalidad Ambiental”, en Actualidad Jurídica, No 22 (2010), pp. 429-454, p. 433.

BUJÁN, Fernando, Delitos ambientales y accesoriedad administrativa, aspectos problemáticos, Buenos Aires: Lajouane, 2009.

BUllemORE, V., Curso de Derecho Penal, Vol. 3, Santiago: Legal Publishing, 2007.

CÁRDENAS, Claudia, "La implementación de los crímenes de competencia de la Corte Penal Internacional en la Ley N 20.357”, en Revista de Derecho (Valdivia), Vol. XXIII, No 2 (2010), pp. 23-44.

CÁRDENAS, Claudia, "Los crímenes del Estatuto de la Corte Penal Internacional en el derecho chileno, necesidad de una implementación", en Política Criminal, $\mathrm{N}^{\mathrm{o}} 2$ (2006), A1, pp. 1-17, en: http://www.politicacriminal.cl/n_02/a_1_2.pdf [visitado el 20.10.2017].

CARNEVALI, Raúl, Problemas de política criminal y otros estudios, Santiago: Legal Publishing, 2009.

CASH, Jorge, Propuesta de régimen Sancionatorio Penal Ambiental en base a un Sistema Mixto de Responsabilidad, como Instrumento de Prevención de Daños al Medio Ambiente, Santiago: Tesis UChile, 2011.

CASSESE, Antonio, "Fostering Increased Conformity with International Standards: Monitoring and Institutional Fact-Finding”, en CASSESE, Antonio (Ed.), Realizing Utopia: The Future of International Law, Oxford: Oxford U. Press, 2012, pp. 295303.

CASSOLA, Gustavo, Medio Ambiente y Derecho Penal. Un acercamiento, Montevideo: BdeF, 2005. 
Polít. crim. Vol. 13, № 26 (Diciembre 2018) Art. 4, pp. 771-835.

[http://www.politicacriminal.cl/Vol_13/n_26/Vol13N26A4.pdf]

CITES, Decisiones de la Conferencia de las Partes en la CITES en vigor después de su $16^{a}$ reunión, Bongkok: s/e, 2013, en https://cites.org/sites/default/files/esp/dec/valid16/S16-Dec.pdf [visitado el 20.10.2017].

ESTEVE, José, Derecho del medio ambiente, Madrid: Marcial Pons, 2014.

FERNÁNDEZ, Pedro, Manual de Derecho Ambiental Chileno, $3^{\circ}$ ed., Santiago: Thomson Reuters, 2013.

FERRÉ M., Ferran, Análisis, recopilación y comentario de la normativa aplicable al transporte marítimo, Barcelona: Tesis UPC, 2010.

FRANCISCO, Carta Encíclica Laudato si' del Santo Padre Francsico sobre el cuidado de la Casa Común, Ciudad del Vaticano: e/ed., 2015, en http://w2.vatican.va/content/francesco/es/encyclicals/documents/papafrancesco_20150524_enciclica-laudato-si.html [visitado el 20.10.2017], No 173).

FUENTES, Ximena y ARÍSTEGUI, Juan Pablo, “ ¿Nos basta con los convenios internacionales existentes para una adecuada regulación del uso sustentable de los recursos naturales?", en CENTRO DE ESTUDIOS DE DERECHO AMBIENTAL, FACULTAD DE DERECHO DE LA UNIVERSIDAD DE CHILE, Actas de las VII Jornadas de Derecho ambiental. Recursos naturales: ¿sustentatibildad o sobreexplotación?”, Santiago: Thomson Reuters, 2014, pp. 65-105.

GIGLIO V., Nicolo (Dir.), Informe País: Estado del medio ambiente en Chile. Comparación 1999-2015, Santiago: U. de Chile, 2015.

GRACIA MARTÍN, Luis, Modernización del Derecho Penal y Derecho Penal del enemigo, Lima: Idemsa, 2007.

GUILOFF, Matías, “El dilema del artículo $19 \mathrm{~N}^{\circ} 8$ inciso 2", en Revista de Derecho (Coquimbo), Vol. 18, No 1 (2011), pp. 147-169.

GUZMÁN, Rodrigo, Derecho Ambiental Chileno. Principios, instituciones, instrumentos de gestión, Santiago: Planeta Sostenible, 2012.

HEFENDEHL, Ronald, “Derecho Penal Medio Ambiental: ¿por qué o cómo?”, en Revista de Estudios Públicos, No 110 (2008), pp. 165-192.

HEINE, Günter; HECKER, Bernd, Comentarios a los Arts. 324ss del Código penal, en SCHÖNKE/SCHRÖDER, Strafgestzbuch Kommentar, 29. Ed., München: Ch. Beck, 2014, pp. 2991-3090. 
MATUS, Jean Pierre; RAMIREZ, María Cecilia; CASTILLO, Marcelo.

"Acerca de la necesidad de una reforma urgente de los delitos de contaminación en Chile, a la luz de la evolución legislativa del siglo XXI".

HERNÁNDEZ, Héctor, "El problema de la "causalidad general" en el Derecho Penal chileno (con ocasión del art. 232 del Anteproyecto de Nuevo Código Penal)", en Política Criminal, $\mathrm{N}^{\mathrm{o}} 1$ (2006), A7, en http://www.politicacriminal.cl/n_01/pdf_01/a_7.pdf [visitado el 20.10.2017], pp. 1-33.

HERNÁNDEZ, Héctor, "La introducción de la responsabilidad penal de las personas jurídicas en Chile", en Política Criminal, $\mathrm{N}^{\circ} 9$ (2010), en http://www.politicacriminal.cl/Vol_05/n_09/Vol5N9A5.pdf [visitado el 20.10.2017], pp. 208-239.

HUMPHREYS, Stephen; OTOMO, Yoriko, "Theorizing International Environmental Law", en OXFORD, Anne and HOFFMAN, Florian, The Oxford Handbook of the Theory of International Law, Oxford: Oxford Univ. Press, 2016, pp. 797-825.

LOIBL, Gerhard, "Dispute avoidance and dispute settlement in International Environmental Law. Some reflections on recent developments", en SECRETARÍA GENERAL OEA, XXIV Curso de Derecho Internacional del Comité Jurídico Interamericano (1997), Washington: OEA, 1998, pp. 101-126.

LÓPEZ, Carlos, La eficacia de las sanciones administrativas de la Superintendencia del Medio Ambiente, Santiago: Tesis UChile, 2016.

MATUS A., Jean Pierre; RAMÍREZ G., M Cecilia y CASTILLO S., Marcelo, "Informe sobre el derecho penal ambiental en el Derecho comparado de tradición continental", en Gaceta Jurídica, Nº 260 (2002), pp. 7ss.

MATUS, Jean Pierre (Ed.), Derecho Penal del Medio Ambiente. Estudios y propuesta para un nuevo Derecho Penal Ambiental chileno, Santiago: Ed. Jurídica de Chile, 2004.

MATUS, Jean Pierre y RÁMIREZ, María Cecilia, Fundamentos y Límites Constitucionales del Derecho Penal positivo, Santiago: Thomson Reuters, 2015.

MATUS, Jean Pierre y RAMÍREZ, María Cecilia, Manual de Derecho Penal chileno, Parte Especial, Valencia: Editorial Tirant lo Blanch, 2017.

MATUS, Jean Pierre, "Evolución del Derecho Penal chileno en el siglo XXI: Democratización, diversificación, intensificación e internacionalización de la respuesta penal", en Nova Criminis, Nº 7 (2014), pp. 149-174.

MATUS, Jean Pierre, "Fundamentos y propuesta legislativa para una nueva protección penal del medio ambiente en Chile, elaborada por la Comisión Foro Penal”, en Zeitschrift für Internationale Strafrechtsdogmatik, No 7 (2008), pp. 304-324. 
Polít. crim. Vol. 13, No 26 (Diciembre 2018) Art. 4, pp. 771-835.

[http://www.politicacriminal.cl/Vol_13/n_26/Vol13N26A4.pdf]

MATUS, Jean Pierre, "La certificación de los programas de cumplimiento", en: ARROLLO, Luis y NIETO, Adán (Dir.), El Derecho Penal Económico en la Era Compliance, Valencia: Tirant lo Blanch, 2013, pp. 145-154.

MATUS, Jean Pierre, "La Política Criminal de los Tratados Internacionales", en Ius et Praxis, Vol. 13, N¹ (2007), pp. $267-289$.

MATUS, Jean Pierre, "Sobre el sentido y alcance del artículo 291 del Código Penal”, en Revista de Derecho (Valdivia), Vol. XXVI, No 2 (2013), pp. 137-167.

MATUS, Jean Pierre; ORELLANA, Marcos, "Acerca de la existencia de obligaciones internacionales de establecer delitos medioambientales, contempladas en los tratados suscritos por la República de Chile”, en Revista de Derecho y Jurisprudencia, Vol. XCVIII, No 4 (2001), pp. 93-113.

MATUS, Jean Pierre; RAMÍREZ, M ${ }^{\mathrm{a}}$ Cecilia; CASTILLO, Marcelo; y ORELLANA, Marcos, "Análisis dogmático del Derecho Penal Ambiental chileno, a la luz del Derecho Comparado y las obligaciones contraídas por Chile en el ámbito del Derecho Internacional. Conclusiones y propuesta legislativa fundada para una nueva protección penal del medio ambiente en Chile”, en Ius et Praxis, Año 9, № 2 (2003), pp. 11-57.

MUÑOZ CONDE, Francisco; LÓPEZ PEREGRÍN, Carmen; GARCÍA ÁLVAREZ, Pastora, Manual de Derecho Penal Medioambiental, Valencia: Tirat Lo Blanch, 2013.

MUÑOZ LORENTE, José y FERNANDEZ CRUZ, José Ángel. "Estudio dogmático penal de los artículos 291 del Código penal y 136 de la Ley General de Pesca y Acuicultura: A propósito del caso del Santuario de la Naturaleza Carlos Anwandter”, en Política $\begin{array}{llllll}\text { criminal, } & \text { Vol. } & 5, & N^{\circ} & 10 & \text { (2010), }\end{array}$ http://www.politicacriminal.cl/Vol_05/n_10/Vol5N10A4.pdf [visitado el 20.10.2017], pp. 410-454.

NIETO, Adán, "Responsabilidad social, gobierno corporativo y autorregulación: sus influencias en el derecho penal de la empresa", en Política Criminal , No 5 (2008), A3-5, pp.1-18.

OCDE, Evaluaciones del Desempeño Ambiental Chile 2016, Santiago: OCDE/CEPAL, 2016, en http://portal.mma.gob.cl/wp-content/uploads/2016/07/Evaluaciondesempeno-Chile-WEBV2.pdf [visitado el 20.10.2017].

OSSANDÓN, Jorge, Incentivos al cumplimiento ambiental, Santiago: Libromar, 2015.

OSSANDÓN, María Magdalena, "Eficiencia del Derecho Penal. El caso de los Delitos contra el Medio Ambiente", en Revista de Derecho de la Pontificia Universidad Católica de Valparaíso, Vol. N XXIV (2003), pp. $379-394$. 
MATUS, Jean Pierre; RAMIREZ, María Cecilia; CASTILLO, Marcelo.

"Acerca de la necesidad de una reforma urgente de los delitos de contaminación en Chile, a la luz de la evolución legislativa del siglo XXI”.

PIÑA, Juan Ignacio, Modelos de prevención de delitos en la empresa, Santiago: Thomson Reuters, 2012.

QUEIROZ, Cláudia C.; GURGEL, Yaira P.; COSTA, Rafaela C., “A responsabilidade penal das pessoas jurídicas de direito público nos crimes ambientais: necessidade de adequação das sanções penais da lei de n. 9.605/98", en Veredas do Direito, Belo Horizonte, Vol. 10, № 19 (2013), pp. 301-324.

QUINTERO OLIVARES, Gonzalo, Derecho Penal Ambiental, Valencia: Tirant Lo Blanch, 2013.

QUIROGA, S.; TRONCOSO, R., Análisis de delitos de carácter ambiental contenidos en el código penal y las leyes especiales chilenas, Talca: Tesis UTAL, 2002.

SANTIBÁÑEZ Q., Fernando, El cambio climático y los recursos hídricos de Chile, Santiago: Ministerio de Agricultura, 2016, en http://www.odepa.cl/wpcontent/files_mf/1482956610RecursosHidricosCambioClimatico.pdf [visitado el 20.10.2017].

SILVA SÁNCHEZ, Jesús María, La expansión del Derecho Penal, aspectos de la Política criminal en las sociedades postindustriales, $3^{a}$ ed., Montevideo: BdeF, 2008.

SILVA SÁNCHEZ, Jesus María; MONTANER, Raquel, Los delitos contra el medio ambiente. Reforma legal y aplicación judicial, Barcelona: Atelier, 2012.

SILVA, Hernán, El Delito ambiental en el Derecho Chileno y Comparado, Santiago: Ed. Thomson Reuters, 2010.

SUSSKIND, Lawrence E.; H. ALI, Saleem, Environmental Diplomacy: Negotiating More Effective Global Agreements, $2^{a}$ Ed., Oxford: Oxford Univ. Press, 2014.

THEILE, Hans, "Die verfahrensrechtliche Relevanz der Einrichtung einzelner ComplianceMaßnahmen", en ROTSCH, Thomas (Hrsg.), Criminal Compliance, Baden-Baden (Alemania): Nomos, 2015, pp.1205-1373.

TOMASELLO, Leslie, Régimen jurídico de la contaminación marina, $2^{a}$ ed., Santiago: Librotecnia, 2011.

TRIBUNAL AMBIENTAL DE SANTIAGO, Anuarios del Tribunal Ambiental de Santiago, Santiago: s/ed, años 2013 a 2015.

VALENZUELA, Rafael, El Derecho Ambiental. Presente y pasado. $2^{a}$ ed., Santiago: Editorial Jurídica de Chile, 2012. 
Polít. crim. Vol. 13, № 26 (Diciembre 2018) Art. 4, pp. 771-835.

[http://www.politicacriminal.cl/Vol_13/n_26/Vol13N26A4.pdf]

VALLS, Mario F., Derecho Ambiental, $2^{a}$ Ed., Buenos Aires: Abeledo Perrot, 2012.

WEEZEL, Alex v., "Contra la responsabilidad penal de las personas jurídicas”, en Política $\begin{array}{lllll}\text { Criminal, } & \mathrm{N}^{\circ} & 9 & \text { (2010), }\end{array}$ http://www.politicacriminal.cl/Vol_05/n_09/Vol5N9A3.pdf [visitado el 20.10.2017], pp.114-142.

WINTER, Jaime, La responsabilidad por el mando en el Derecho Penal Internacional, Santiago: Tesis UChile, 2009. 